\title{
The Intermetallic Compound ZnPd and Its Role in Methanol Steam Reforming
}

\author{
M. Armbrüster ${ }^{1, *}$, M. Behrens ${ }^{2}$, K. Föttinger ${ }^{3}$, M. Friedrich ${ }^{1}$, É. Gaudry ${ }^{4}$, \\ S.K. Matam ${ }^{5}$, H.R. Sharma ${ }^{6}$
}

${ }^{1}$ Max-Planck-Institut für Chemische Physik fester Stoffe, Nöthnitzer Str. 40, 01187 Dresden, Germany

${ }^{2}$ Fritz Haber Institute of the Max Planck Society, Inorganic Chemistry Department, Faradayweg 4-6, 14195 Berlin, Germany

${ }^{3}$ Institute of Materials Chemistry, Vienna University of Technology, Getreidemarkt 9 BC, 1060 Vienna, Austria

${ }^{4}$ Institut Jean Lamour, UMR 7198, CNRS-Université de Lorraine, École des Mines, Parc de Saurupt, 54042 Nancy Cedex, France.

${ }^{5}$ Empa, Swiss Federal Laboratories for Materials Science and Technology, Laboratory for Solid State Chemistry and Catalysis, Ueberlandstrasse 129, CH-8600 Duebendorf, Switzerland.

${ }^{6}$ University of Liverpool, Department of Physics, Great Britain 


\section{Content}

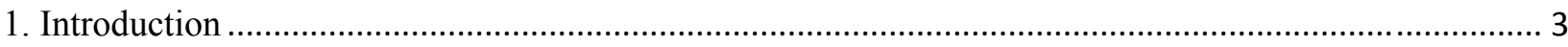

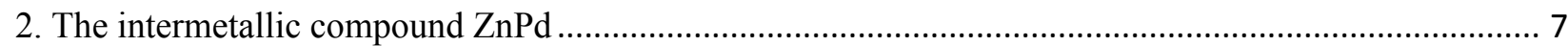

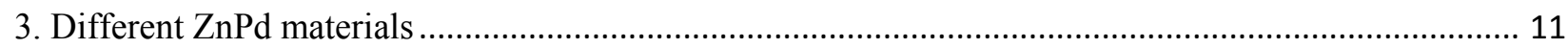

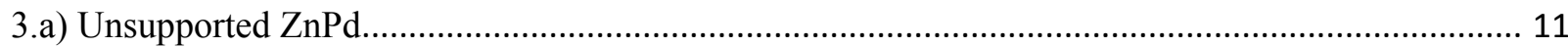

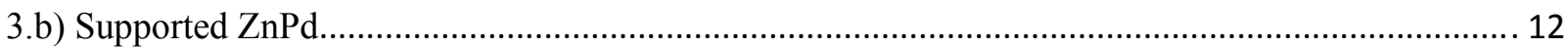

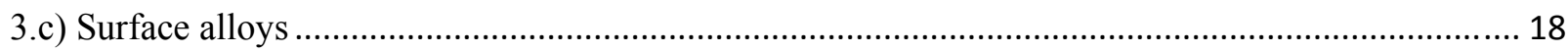

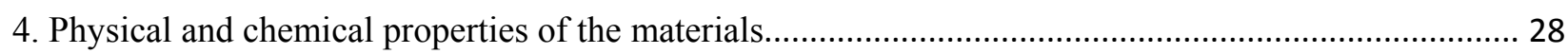

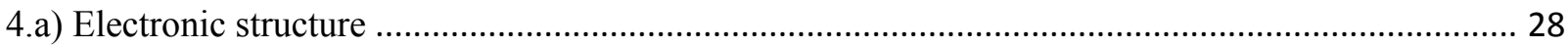

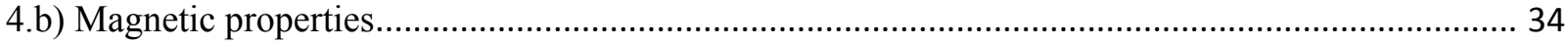

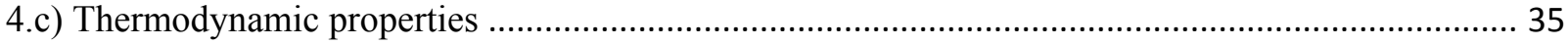

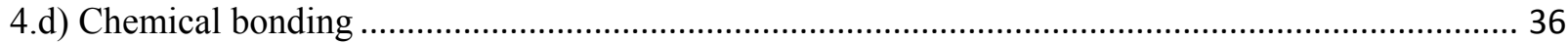

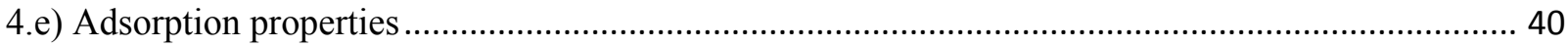

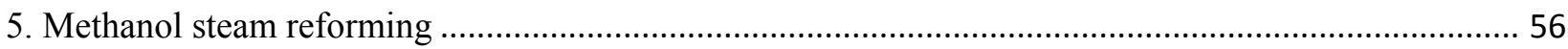

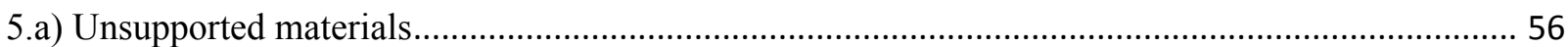

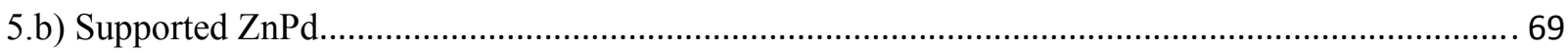

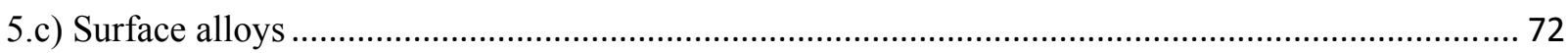

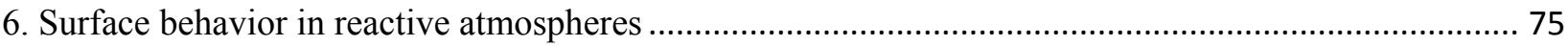

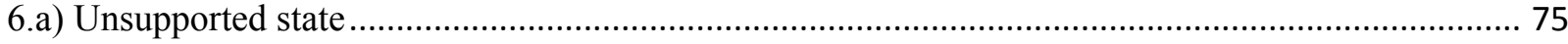

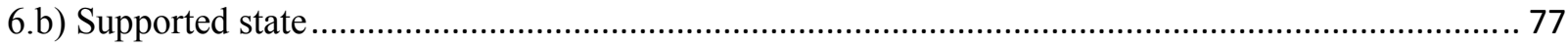

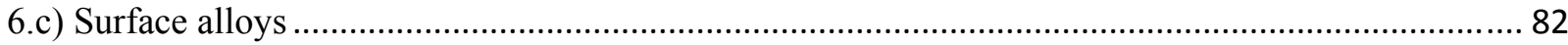

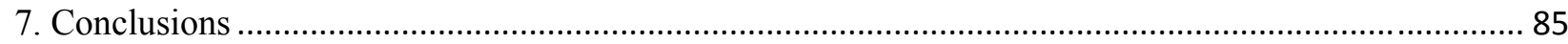

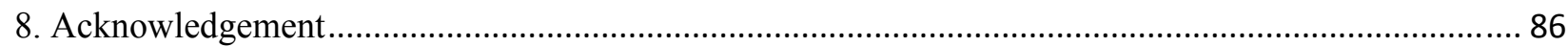

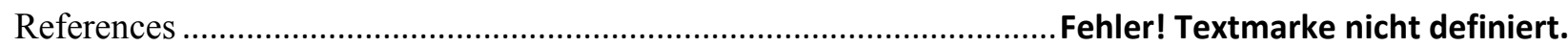




\section{Introduction}

Today's energy supply is still largely depending on fossil fuels. Because of the environmental problems and the scarcity of fossil fuel reserves, a change towards a sustainable and $\mathrm{CO}_{2}$ neutral energy supply and infrastructure has to take place. Final goal is to use mainly the energy of the sun reaching our planet and to transform it either into electricity (e.g. using wind- or water-power as well as photovoltaics), biofuels or hydrogen (e.g. by photo catalysis). The strongly varying electricity generation requires a storage possibility, which poses a huge and hitherto unsolved challenge to the existing infrastructure. One possibility under consideration is to use surplus electricity to generate hydrogen by electrolysis, thus storing the electricity in form of chemical energy.

Handling and storage of hydrogen in its elemental form and these huge quantities must be safe, sustainable and cheap. Storage in its elemental form - either under high pressure or as liquid - is missing public acceptance. Complex or metallic hydrides as storage media lack materials with high cyclability, appropriate release temperatures and low costs up to now ${ }^{[1]}$. This leaves chemical storage of hydrogen as the most likely scenario. Several small molecules are under consideration, of which methanol has a high potential due to its high hydrogen content, easy handling and storage. Synthesis procedures are highly optimized, making the production of methanol a cheap process which is already taking place in the megaton per year range. These reasons led to the suggestion of the so-called methanol economy by Olah et al. [2].

To release the hydrogen from methanol, the following reactions can be considered:
a) methanol decomposition:
$\mathrm{CH}_{3} \mathrm{OH} \rightarrow \mathrm{CO}+2 \mathrm{H}_{2}$
$\Delta \mathrm{H}^{0}=90 \mathrm{kJmol}^{-1}$
b) methanol steam reforming:
$\mathrm{CH}_{3} \mathrm{OH}+\mathrm{H}_{2} \mathrm{O} \rightarrow \mathrm{CO}_{2}+3 \mathrm{H}_{2}$
$\Delta \mathrm{H}^{0}=49 \mathrm{kJmol}^{-1}$
c) oxidative steam reforming:
$\mathrm{CH}_{3} \mathrm{OH}+\mathrm{H}_{2} \mathrm{O}+x \mathrm{O}_{2} \rightarrow \mathrm{CO}_{2}+3-2 x \mathrm{H}_{2}+2 x \mathrm{H}_{2} \mathrm{O}$

Out of these, steam reforming has the huge advantage of releasing very pure and nearly $\mathrm{CO}$-free hydrogen. Co-feeding oxygen allows to overcome the endothermicity of the reaction and to perform it autothermally. The presence of $\mathrm{CO}$ in traces of $>20 \mathrm{ppm}$ has to be avoided to enable long-time performance of the subsequently used proton exchange membrane (PEM) fuel cells to generate electricity without a further cleaning step ${ }^{[3 ; 4]}$. Up to now, most research has been devoted to $\mathrm{Cu} / \mathrm{ZnO} / \mathrm{Al}_{2} \mathrm{O}_{3}$ catalysts for the steam reforming of methanol - reference 
${ }^{[5]}$ provides a review of the different materials. The $\mathrm{Cu}$-catalysts are unfortunately not stable against sintering, are pyrophoric materials and generate $\mathrm{CO}$ levels of around $1500 \mathrm{ppm}$ in methanol steam reforming ${ }^{[6-8]}$.

In search for alternatives, avoiding the above drawbacks, Iwasa et al. tested a series of noble-metal-based systems, a compilation can be found in ${ }^{[9]}$. Amongst them $\mathrm{Pd} / \mathrm{ZnO}$ proved to be especially promising after high temperature reduction in hydrogen ${ }^{[10]}$. During this step, the palladium activates hydrogen which leads to reduction of the $\mathrm{ZnO}$ to the elemental state in the direct vicinity of the palladium particles ${ }^{[11 ; 12]}$. The zinc then reacts with the palladium to form the intermetallic compound $\mathrm{ZnPd}$ - the leading character of this review. Since this pioneering work, a huge number of investigations have been performed on a variety of $\mathrm{Pd}-\mathrm{Zn}$ materials to understand the formation mechanism and to explore the catalytically active species in this material. In defiance of the higher costs compared to the $\mathrm{Cu}$-based systems, $\mathrm{ZnPd}$ possess industrial potential as reflected by recent patent literature and publications showing the feasibility of methanol steam reforming (MSR) at millisecond contact time, high conversion and low temperature over $\mathrm{ZnPd}$ compared to other fuels ${ }^{[13 ; 14]}$. Besides being studied as catalyst in methanol steam reforming, the intermetallic compound $\mathrm{ZnPd}$ supported on $\mathrm{ZnO}$ is also a hydrogenation catalyst ${ }^{[15-27]}$, active in the reverse-water-gas-shift reaction ${ }^{[28-30]}$, the partial oxidation of methanol ${ }^{[31-33]}$, the steam reforming of ethanol ${ }^{[34]}$, the hydroformylation of ethylene ${ }^{[16]}$, the oxidative acetoxylation ${ }^{[35 ; 36]}$, the esterification ${ }^{[37]}$ and can be used as catalyst to grow $\mathrm{ZnO}$ nanorods ${ }^{[38]}$. General information about intermetallic compounds in catalysis can be found in a recent review ${ }^{[39]}$.

The lack of knowledge on the Pd-Zn material(s) and the role of the different phases present in the catalysts prompted this review. The intermetallic compound $\mathrm{ZnPd}$ possesses a rather simple bulk structure (Pearson symbol tP2, space group $P 4 / m m m, C u T i$ type of structure) which can be derived from the $\mathrm{CsCl}$ type of structure by a tetragonal distortion along one of the principle axes (Figure 1). Alternatively, the structure can be described in relation to the face centered cubic (fcc) structure of palladium, resulting in the $\mathrm{CuAu}$ type of structure. Staying with the first description, the experimental lattice parameters are $a=$ 2.8931(1) $\AA$ and $c=3.3426(2) \AA$ resulting in a $c / a$ ratio of 1.155 at equimolar composition ${ }^{[40]}$. For the fcc-related structure description, the resulting lattice parameters are $a_{\mathrm{fcc}}=\sqrt{ } 2 \times a=$ $4.0915 \AA$ and $c_{\mathrm{fcc}}=c=3.3426$. Each zinc (palladium) atom in the structure is surrounded by eight palladium (zinc) atoms at a distance of $2.6416 \AA$ forming a tetragonal prism. Next, the closest homoatomic contacts (4) follow at $2.8931 \AA$ lying within (001), thus forming 
homoatomic $4^{4}$ nets with the central atom. The coordination is completed by two homoatomic neighbors at $3.3426 \AA$, leading to a total coordination number of 14 .

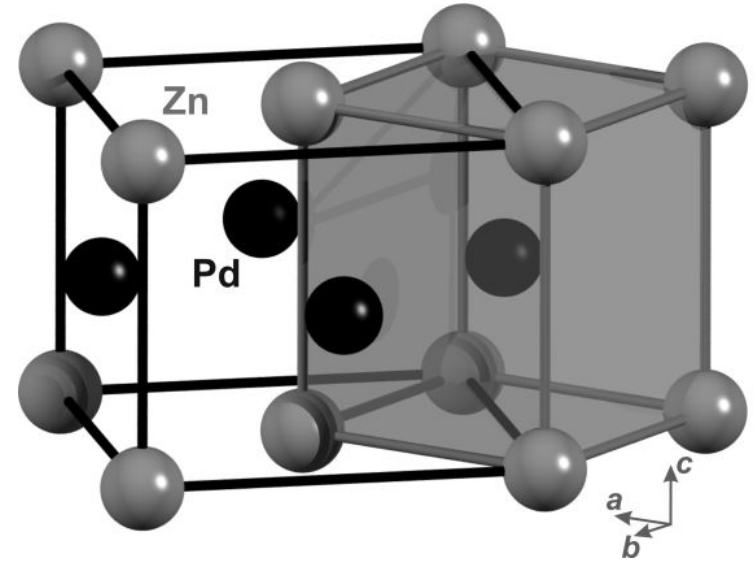

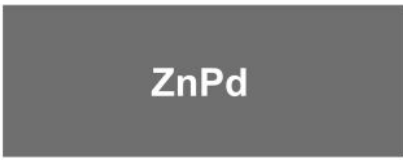

bulk ZnPd

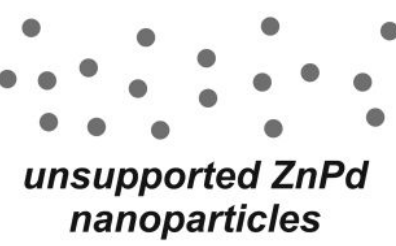

ZnPd

Pd

$\mathrm{ZnPd}$

surface alloy

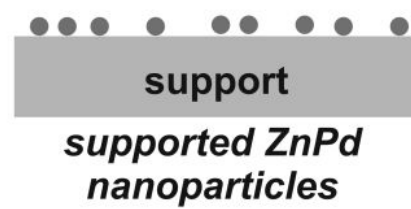

Figure 1: Crystal structure of the intermetallic compound ZnPd (black unit cell: СиАи type of structure, grey unit cell: CuTi type of structure) and the different forms of $Z n P d$ reported in the literature.

The simple crystal structure allows in depth studies as will be seen throughout this review. To enable a deep understanding, several materials have been employed in numerous studies (Fig. 1). Metallurgically prepared unsupported, single-phase and polycrystalline ZnPd powder represents the best characterized material. However, the very small specific surface area poses a severe drawback for catalytic applications. This can be overcome by using unsupported nanoparticles, which form the second type of materials investigated. The rather simple preparation makes the third class, i.e. supported nanoparticles, the most widely studied system. Here, things become more complicated since the $\mathrm{ZnPd} / \mathrm{ZnO}$ interface increases the complexity. The fourth class of materials which has been investigated are so-called surface alloys or near-surface intermetallic phases (NSIPs), which are especially suited for investigations in ultra-high vacuum. When dealing with these thermodynamically unstable materials, complexity for the surface alloys is partly reduced, since the $\mathrm{ZnPd} / \mathrm{ZnO}$ interface is no longer present. On the other hand, the complexity increases because several surface structures have been observed experimentally. Concerning the structure of the intermetallic compound, the description as CuTi type of structure is used for the bulk materials frequently. Since the surface alloys are grown on palladium single crystals, the $\mathrm{CuAu}$ type of structure notation is applied for these materials. Covering the whole range of materials, thus closing the materials gap ${ }^{[41]}$, a knowledge-based development becomes feasible as recently shown in the case of Ga-Pd intermetallic compounds as selective semi-hydrogenation catalysts leading finally to noble metal-free catalysts ${ }^{[42 ; 43]}$. 
This review provides an overview on the work performed with respect to the intermetallic compound $\mathrm{ZnPd}$ in the catalysis community. In addition, it also reviews the work on the intermetallic compound $\mathrm{ZnPd}$ in the solid state community. Here, a lot of effort has been devoted to determine the range of existence, crystal structure and physical properties, which provides a complementary understanding of the compound. This literature review deals with a large variety of materials (i. e. unsupported bulk compounds synthesized from the elements, nanoparticulate compounds in an unsupported and supported state, as well as surface alloys) and aims at providing an overview of the data published till February 2013. An attempt is made to work out differences between the materials studied for a better understanding of the catalytic reaction. 


\section{The intermetallic compound ZnPd}

This section deals with bulk samples of the intermetallic compound $\mathrm{ZnPd}$ in thermodynamic equilibrium. The tetragonal structure of the room temperature modification of $\mathrm{ZnPd}$ was first reported by Nowotny et al. in $1950^{[44]}$. The binary Pd-Zn phase diagram comprises several intermetallic compounds which have been investigated by several authors (Fig. 2 presents a worked-over phase diagram). Only little is known about the lowtemperature phase $\mathrm{ZnPd}_{2}(\mathrm{RT})$, its range of existence was mostly determined according to two-phase samples ${ }^{[45]}$. Due to the large amount of different (line) phases existing in the range of $\mathrm{Zn}=75-79$ at.- $\%$, a final picture of the temperature region above $1023 \mathrm{~K}$ including the liquidus line has not been concluded yet ${ }^{[46-49]}$. The phase borders of the tetragonal $\mathrm{ZnPd}$ phase reveal a large expansion towards Pd-richer compositions (max. 62.5 at.-\% Pd) and a minor expansion towards the Zn-rich region (max. 53 at.- $\% \mathrm{Zn}$ ) ${ }^{[50-53]}$. Up to now it is unknown, how non-equimolar compositions are realized by the crystal structure, i.e., if interstitial sites are occupied, if the majority component replaces the minority component or if the homogeneity range is realized by defects.

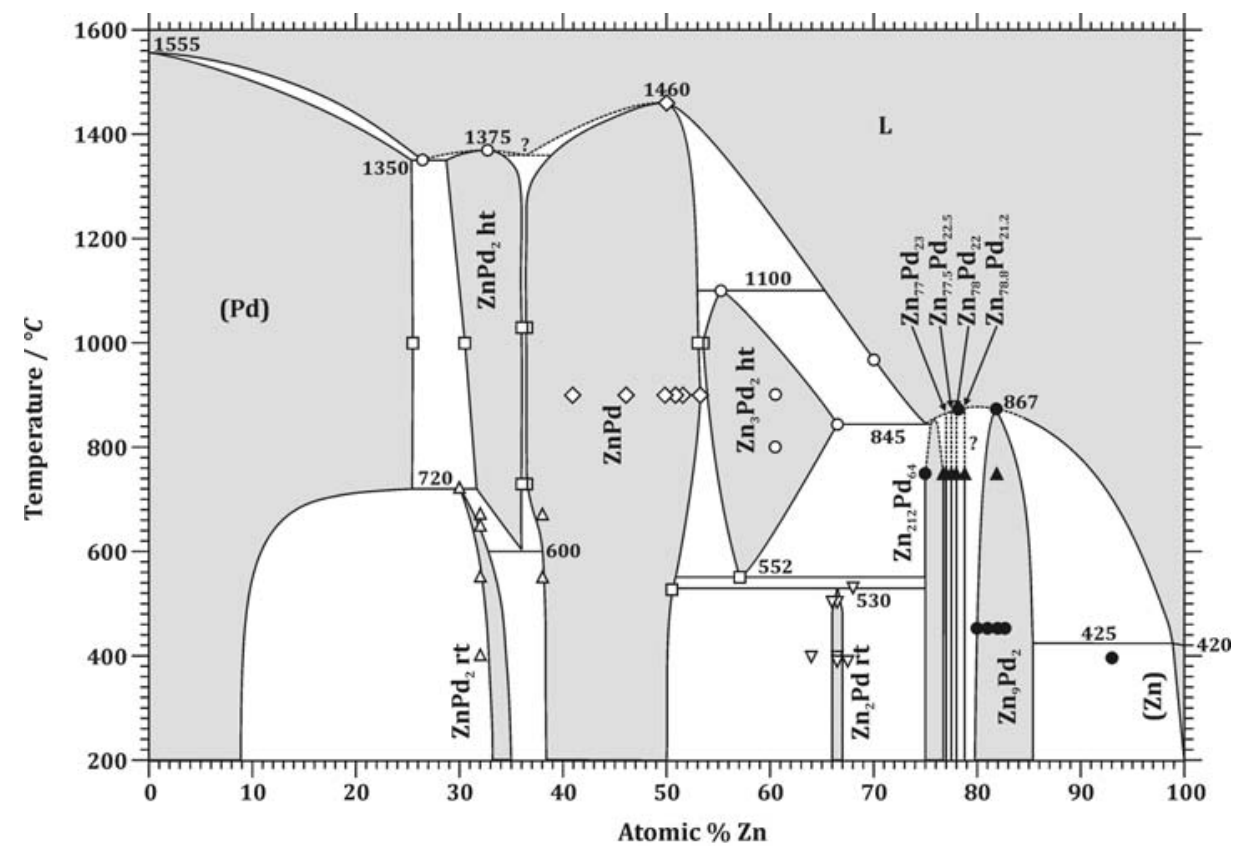

Figure 2: Phase diagram of the Pd-Zn system. Symbols depict important data from: $\forall$ ${ }^{[50 ; 51]},-{ }^{[54]}, 8^{[45]}, \mathrm{M}^{[40 ; 52]}, \mathrm{X}^{[55]},{ }^{[46]}$ and $7^{[47-49]}$.

Fig. 3 summarizes the influence of the composition and the annealing temperature on the lattice parameters ${ }^{[45 ; 52 ; 56-58]}$. While the annealing temperature has little effect, addition of zinc 
to the compound leads to a monotonic increase of the $c / a$ ratio, thus raising the tetragonal distortion of the structure.

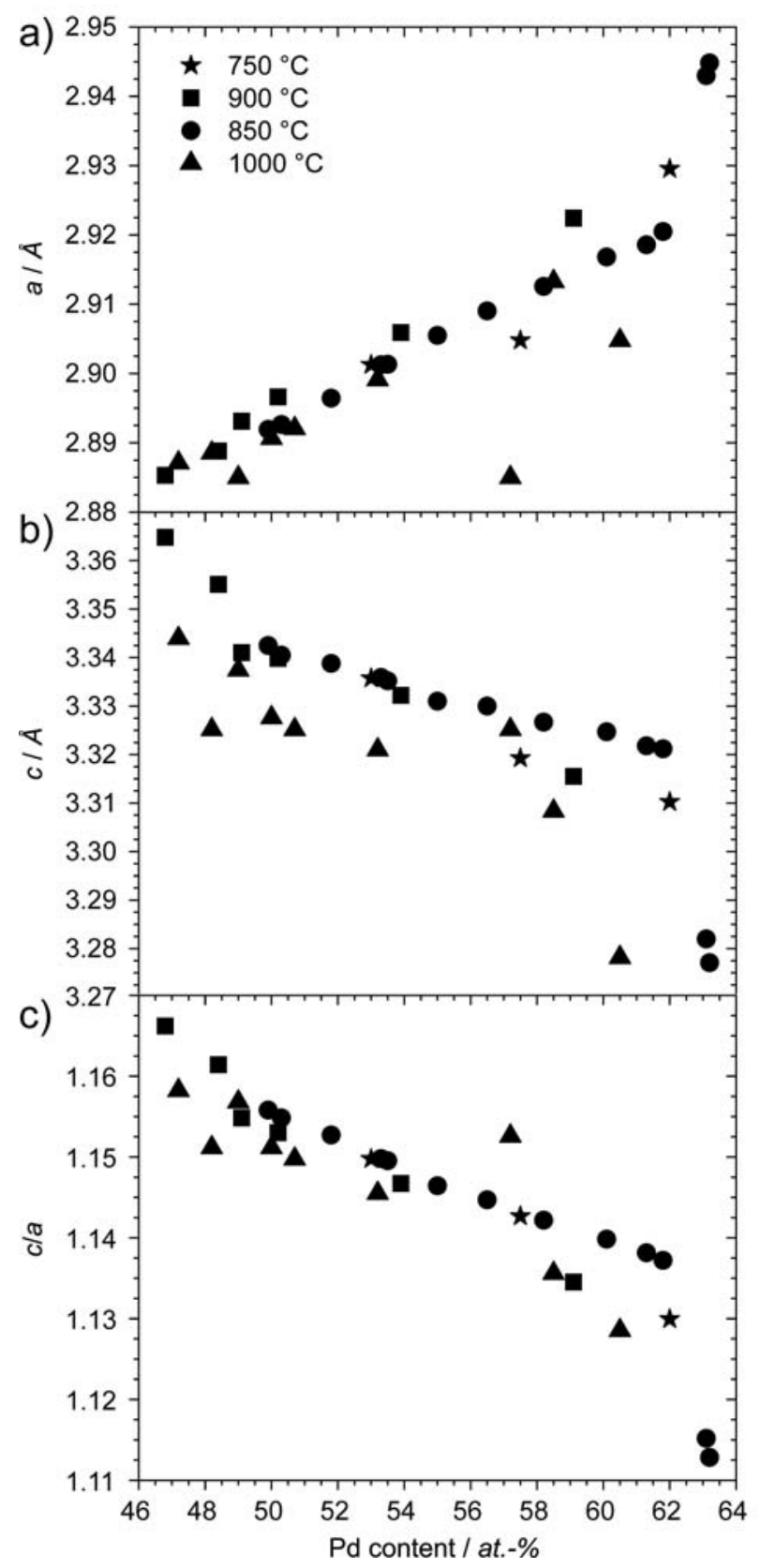

Figure 3: Dependence of a) the lattice parameter $a$ b) the lattice parameter $c$ and $c$ ) the c/a ratio on the composition and the annealing temperature. Data from $\xi^{[45]},,^{[58]}, !^{[52]}$ and $7^{[56 ; 57]}$.

Determination of the melting point in $\mathrm{Zn}$-based systems turns out to be difficult because of the high vapor pressure of zinc, leading to severe zinc loss even before reaching the liquid state. Hence, early thermal analysis data in the Pd-Zn system were only recorded until 1273 $\mathrm{K}$, hindering a proper melting point determination ${ }^{[54]}$. Consistently, the first complete phase diagram was drawn as tentative above that temperature region ${ }^{[59]}$. Therein, the high- 
temperature region of the tetragonal phase at the equimolar composition was interpolated and not proven experimentally. Recent advances in experimental techniques allowed the redetermination of the thermal behavior of $\mathrm{ZnPd}$ in closed quartz glass ampoules. Thermal analysis of a $\mathrm{ZnPd}$ sample revealed that partial melting of the tetragonal phase does not start until $1523 \mathrm{~K}$ before it melts completely at $1721 \mathrm{~K}$ (Fig. 4) ${ }^{[52]}$. Thus, no indication for the proposed cubic high-temperature modification could be found. The experimentally determined melting point of $\mathrm{ZnPd}$ exceeds the melting point suggested earlier for the equimolar composition by $150 \mathrm{~K}$.

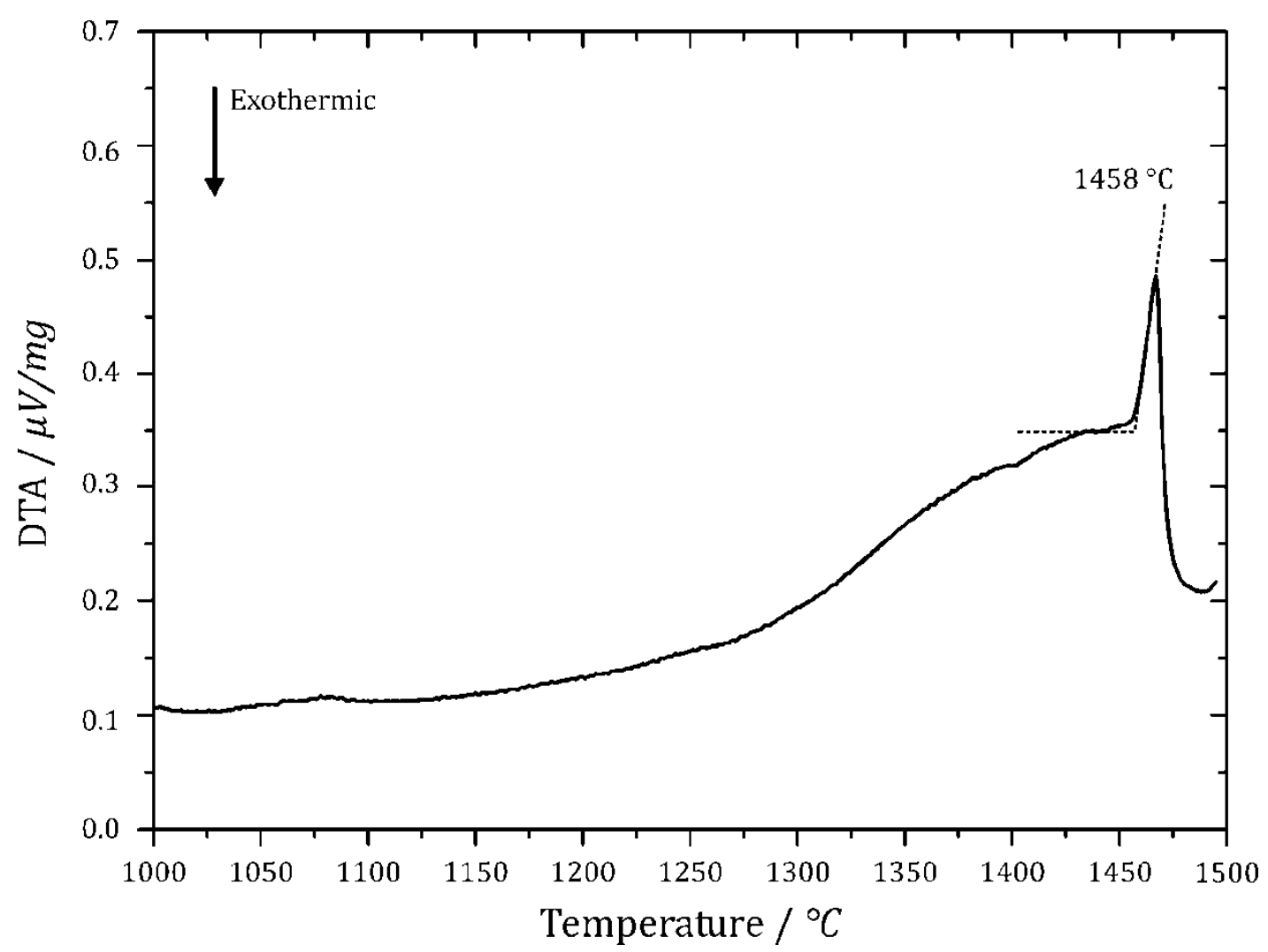

Figure 4: Differential thermal analysis (section of the heating curve) of single-phase ZnPd (CuAu-type of crystal structure) under argon $(20 \mathrm{~K} / \mathrm{min})$. The displayed value corresponds to the onset temperature of the endothermic peak ${ }^{[52]}$.

Earlier investigations of the high-temperature region of the Pd-Zn system at the compositions $\mathrm{ZnPd}_{2}$ and $\mathrm{Zn}_{3} \mathrm{Pd}_{2}$ were conducted by Nowotny et al. ${ }^{[45]}$ and Köster et al. ${ }^{[54]}$. Both compounds realize the cubic $\mathrm{CsCl}$ type of crystal structure and lead to the assumption that both phases merge at high temperatures to form a single phase region, including the equiatomic compound $\mathrm{ZnPd}$. This idea is supported by the chemically similar Ni-Zn system wherein a cubic high-temperature modification of $\mathrm{ZnNi}$ has been proven ${ }^{[60]}$. Nevertheless, no experimental proof for the cubic high temperature modification of $\mathrm{ZnPd}$ was given by the 
authors. Recent experimental efforts to synthesize the cubic modification, either by quenching from melt or by quenching the solid sample from $1503 \mathrm{~K}$, did not provide any hints for its existence $^{[40]}$. In addition, DFT-based quantum chemical calculations on both the tetragonal and the hypothetic cubic structure were performed ${ }^{[40]}$. Total energy calculations, considering the volume dependency of the unit cells, clearly contradict the existence of the cubic phase (Fig. 5), calculating a $c / a$ ratio of 1.155 for the relaxed structure ${ }^{[40]}$, thus corroborating earlier DFT studies stating the stability of the tetragonal crystal structure ${ }^{[61]}$. To conclude, up to now neither experimental nor theoretical studies gave evidence for the existence of the cubic hightemperature modification of $\mathrm{ZnPd}$ at the equiatomic composition.
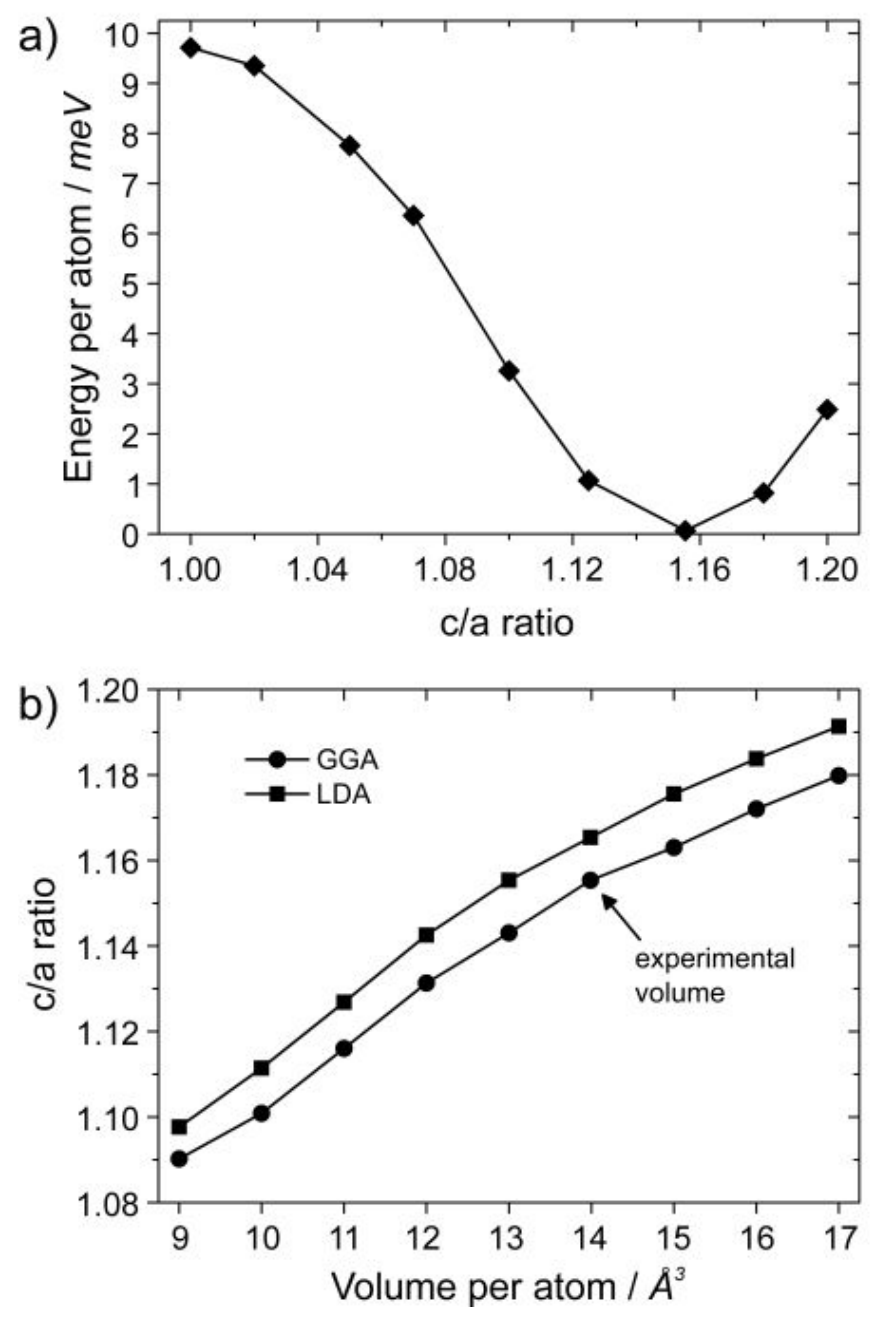

Figure 5: a) Total energy per atom vs. c/a ratio is obtained by DFT calculations within GGA for tetragonal ZnPd at the experimentally observed unit cell volume of 13.989 $A^{3}$. The minimum was observed at the experimental c/a value of $\sim 1.155$, the cubic structure with $c / a=1$ has a much higher energy. b) Axial ratio c/a vs. unit cell volume for GGA and LDA calculations. The arrow marks the experimentally determined c/a ratio and volume (image reproduced from ${ }^{[40]}$ ). 


\section{Different ZnPd materials}

\section{3.a) Unsupported ZnPd}

The synthesis from the elements in the system Pd-Zn poses the challenge of overcoming diffusion limitations by high temperatures on the one hand and zinc loss due to its relatively high vapor pressure at high temperatures on the other hand. Thus, a successful synthesis starts from fine palladium powder and rather course zinc granules as starting materials. Since both elements do not react with quartz glass in the relevant temperature regime, syntheses in evacuated quartz glass ampoules are appropriate. To control the exothermic reaction between the elements $\left(8 \mathrm{H}_{\mathrm{R}, 1273 \mathrm{~K}}=-100.4 \mathrm{kJmol}^{-1}{ }^{[56]}\right)$ the quartz glass ampoule is slowly heated to the melting point of zinc $(693 \mathrm{~K})$ with $5 \mathrm{Kh}^{-1}$. Subsequently, the diffusion barriers are overcome by heating to $1123 \mathrm{~K}$ with $1 \mathrm{Kmin}^{-1}$ and annealing for 6 days before the ampoule is quenched in water ${ }^{[40 ; 62]}$. Usually, this procedure results in single-phase samples - otherwise the product has to be ground and annealed in an evacuated quartz glass ampoule at $1173 \mathrm{~K}$ for another 7 days. $\mathrm{ZnPd}$ is rather hard and brittle with a silvery metallic luster. Contrary to previously reported synthesis routes ${ }^{[44 ; 45 ; 54]}$, which always had to deal with evaporating zinc, the method described here is capable of preparing the compound with the desired Pd:Zn ratio. The resulting material can be ground to result in a specific surface area of around $0.03 \mathrm{~m}^{2} \mathrm{~g}^{-1}$, which is sufficient to investigate its intrinsic catalytic properties.

Higher specific surface areas can be obtained using bottom-up strategies, i.e. nanoparticulate synthesis of the material. Several approaches have been described in literature. Cable et al. ${ }^{[63]}$ converted palladium nanoparticles into unsupported nanoparticulate $\mathrm{ZnPd}$ by introducing the zinc in form of zerovalent organometallic zinc precursors. Applying co-reduction of $\mathrm{Zn}^{2+}$ and $\mathrm{Pd}^{2+}$ by Superhydride ${ }^{\circledR}$ in block copolymer micelles, Bronstein et al. ${ }^{[64]}$ obtained $\mathrm{ZnPd}$ nanoparticles which were subsequently tested as a catalyst for the selective hydrogenation of dehydrolinalool. Synthesis of $\mathrm{ZnPd}$ can also be achieved by an aerosol method developed in the laboratory of Datye ${ }^{[65 ; 66]}$. The resulting particles have a mean diameter of around $130 \mathrm{~nm}$ corresponding in a specific surface area of $4.7 \mathrm{~m}^{2} \mathrm{~g}^{-1}$. Thermal decomposition of the double complex salt $\left[\mathrm{Pd}\left(\mathrm{NH}_{3}\right)_{4}\right]\left[\mathrm{Zn}(\mathrm{ox})_{2}\left(\mathrm{H}_{2} \mathrm{O}\right)_{2}\right] \times 2 \mathrm{H}_{2} \mathrm{O}$ in helium or hydrogen atmosphere between 473 to $673 \mathrm{~K}$ leads to the formation of the intermetallic compound in a nanoparticulate form ${ }^{[67]}$. To investigate a possible size-dependence of the intrinsic catalytic properties of $\mathrm{ZnPd}$ in methanol steam reforming ${ }^{[68 ; 69]}$, size-controlled synthesis of unsupported $\mathrm{ZnPd}$ nanoparticles is required. This has recently been achieved by a systematic exploration of different synthesis paths to nanoparticulate $\mathrm{ZnPd}{ }^{[70]}$. While co- 
reduction of $\mathrm{Pd}^{2+}$ and $\mathrm{Zn}^{2+}$ as well as the use of $\mathrm{ZnH}_{2}$ as reducing agent and simultaneous $\mathrm{Zn}$ source did not allow controlling the size, electroless plating of pre-synthesized zinc nanoparticles by $\mathrm{Pd}^{2+}$ resulted in controlling the crystallite size between 2 and $5 \mathrm{~nm}$.

Mesoporous $\mathrm{ZnPd}$ can be synthesized by first leaching of the intermetallic compound $\mathrm{Al}_{21} \mathrm{Pd}_{8}$ with $20 \% \mathrm{NaOH}$ aqueous solution and immersion of an aqueous $\mathrm{ZnCl}_{2}$ solution into the remaining porous palladium ${ }^{[71]}$. The intermetallic compound $\mathrm{ZnPd}$ is subsequently formed by reducing the palladium sponge at $773 \mathrm{~K}$ in hydrogen.

Since the heterogeneously catalyzed methanol steam reforming takes place at the surface of the catalyst, it would be highly desirable to know about the surface structures of the unsupported bulk- and nano-materials. Up to now, this question was not approached experimentally due to the lack of single-crystalline material sufficiently large for surface science studies. The single crystal growth of the intermetallic compound poses high experimental hurdles due to the combination of high temperatures needed as well as the high vapor pressure and reactivity of zinc at these temperatures.

\section{3.b) Supported $\mathrm{ZnPd}$}

Supported ZnPd particles with the tetragonal bulk structure can be prepared by two approaches: Pre-formed ZnPd nanoparticles can be deposited on an inert support in a similar way as shown e.g. for $\mathrm{GaPd} / \mathrm{Al}_{2} \mathrm{O}_{3}$ catalysts ${ }^{[72]}$, or $\mathrm{Pd} / \mathrm{ZnO}$ composites can be heated in hydrogen. The former approach makes use of the materials described in the forgoing section and is not considered further. The latter approach works due to the partial reducibility of the $\mathrm{ZnO}$ component under reductive conditions. For instance, Wang et al. studied a 15.9 wt.\% $\mathrm{Pd} / \mathrm{ZnO}$ prepared by co-precipitation by temperature programmed reduction (TPR) and desorption (TPD), electrical conductivity measurements and X-ray diffraction (XRD) ${ }^{[73 ; 74]}$. The strong interaction between metallic palladium or palladium hydride and the support leads to hydrogen spillover during reduction. This enables the reduction of the $\mathrm{ZnO}$ in the vicinity of the palladium particles and the formation of the intermetallic compound $\mathrm{ZnPd}$ at elevated reduction temperatures. For instance, the $\mathrm{Pd} / \mathrm{ZnO}$ material investigated in the abovementioned literature reports is transformed into $\mathrm{ZnPd} / \mathrm{ZnO}$ with a particle size of the intermetallic compound between 5 and $14 \mathrm{~nm}$ after treatment with $5 \% \mathrm{H}_{2}$ at $523-573 \mathrm{~K}^{[73]}$. Besides $\mathrm{Pd} / \mathrm{ZnO}$, also $\mathrm{CeO}_{2}$ has been investigated as support for the intermetallic compound $\mathrm{ZnPd}{ }^{[75]}$. The latter is formed during reduction after co-impregnation of $\mathrm{CeO}_{2}$ with palladium and zinc salts. 
It is noted that pure $\mathrm{ZnO}$ cannot be reduced by hydrogen at these low temperatures. Only the presence of metal particles that can activate dihydrogen and act as reactant for the formed reduced zinc species enables formation of intermetallic compounds from $\mathrm{ZnO}$ already at much milder conditions. Palladium is very effective in producing atomic hydrogen at room temperature as seen e.g. from its hydride formation capability even below room temperature [76]. These hydrides thermally decompose upon heating, but atomic hydrogen species will still be present on the palladium surface also at higher temperatures as dihydrogen is dissociatively adsorbed. Before the single steps of $\mathrm{ZnPd}$ formation by partial reduction of $\mathrm{Pd} / \mathrm{ZnO}$ and the chemistry of the interface will be covered in more detail, the preparation of suitable $\mathrm{Pd} / \mathrm{ZnO}$ catalysts as starting materials will be briefly addressed.

$\mathrm{Pd} / \mathrm{ZnO}$ can be prepared by various methods the most important being impregnation of a pre-formed $\mathrm{ZnO}$ support with a palladium precursor. Karim et al. studied the preparation of $\mathrm{ZnPd} / \mathrm{ZnO}$ using different deposition methods for $\mathrm{Pd}$ and reported an effect of the resulting $\mathrm{ZnO}$ morphology on the catalytic properties in methanol steam reforming ${ }^{[77]}$. No matter how the $\mathrm{Pd} / \mathrm{ZnO}$ precursor was prepared, it can be assumed that the formation of $\mathrm{ZnPd}$ proceeds at reactive interfaces between palladium metal and partially reduced $\mathrm{ZnO}_{x}$ species. Thus, to obtain a uniform material, it is important that these interfaces all show a similar reactivity, i.e. the microstructure of the $\mathrm{Pd} / \mathrm{ZnO}$ material should be relatively homogeneous. This is in particular important for academic studies aiming at structure-performance relationships, but may be equally crucial for the catalytic performance of the resulting catalyst. For instance, large palladium particles, which are less reactive at conditions which already lead to $\mathrm{ZnPd}$ formation of the smaller particles, might remain in the monometallic state and dominate the activity and selectivity of the resulting complex $\mathrm{Pd} / \mathrm{ZnPd} / \mathrm{ZnO}$ system ${ }^{[69]}$. To avoid such inhomogeneities and to achieve a uniform microstructure, i.e. uniform particle sizes of the metal and the support with similar metal-support interaction at all interfaces, typically requires a semi-empirical optimization of the impregnation process. The choice of the right palladium precursor, the appropriate $\mathrm{pH}$ of deposition as well as suitable drying and calcinations conditions has critical impact on the success of the impregnation and all these parameters have to be considered when synthesizing a $\mathrm{Pd} / \mathrm{ZnO}$ catalyst. It is well-known that in particular the $\mathrm{pH}$ value of the precursor solution as well as the nature and amount of additives that compete for the adsorption sites will determine the distribution and dispersion of the palladium particles in supported catalysts prepared by impregnation. Many literature reports cover these issues and for further information the reader may refer to, e.g., the contributions of Marceau et al. ${ }^{[78 ; 79]}$ and Regalbuto ${ }^{[80]}$. Intermetallic compound formation 
occurs even without pre-reduction under MSR conditions ${ }^{[81]}$. The dynamics of the in situ formation of $\mathrm{ZnPd}$ have been studied by Conant et al. on a catalyst prepared by coimpregnation of $\mathrm{Pd}$ and $\mathrm{Zn}$ nitrates on alumina ${ }^{[82]}$. An increase in conversion and $\mathrm{CO}_{2}$ selectivity in the methanol steam reforming reaction over the first approximately 2 hours on stream at $527 \mathrm{~K}$ was observed, which was ascribed to in situ formation of the ZnPd phase under reaction conditions. Further information was gathered applying time-resolved X-ray absorption spectroscopy (XAS) combined with simultaneous mass spectrometric activity measurements, both performed during catalytic methanol steam reforming, to study the structural changes of palladium nanoparticles supported on $\mathrm{ZnO}{ }^{[83]}$. The formation of the catalytically active and selective $\mathrm{ZnPd}$ in methanol/water atmosphere was monitored in real time. The features in the Pd K edge XANES spectra at around 24,390 and $24,430 \mathrm{eV}$ decreased in intensity and an additional feature at about $24,410 \mathrm{eV}$ appeared. These spectral changes attributed to $\mathrm{ZnPd}$ formation were paralleled by a pronounced switch in reactivity from methanol decomposition $\left(\mathrm{CO}+\mathrm{H}_{2}\right)$ to steam reforming $\left(\mathrm{CO}_{2}+\mathrm{H}_{2}\right)$, as clearly identified by a decrease of the $\mathrm{CO}$ content and an increase of the $\mathrm{CO}_{2}$ content with time-on-stream in the effluent gas. This confirms directly that the presence of $\mathrm{ZnPd}$ is necessary to reach high selectivity.

An alternative method of preparation is co-precipitation of Pd- and Zn-precursors, which is more common for the preparation of base metal catalysts. In such an experiment the active component is prepared simultaneously with the support material. If the co-precipitation is well-controlled, this method allows for homogeneous distribution of palladium and zinc in the precipitate. The resulting microstructure of the $\mathrm{Pd} / \mathrm{ZnO}$ composite after thermal treatment has a good chance to exhibit uniform particles and interfaces that result in complete conversion of the metallic palladium in a single phase intermetallic compound like $\mathrm{ZnPd}$, in particular if the co-precipitated precursors are well-defined compounds with a mixed $\mathrm{Pd}^{2+} / \mathrm{Zn}^{2+}$ cationic lattice ${ }^{[84]}$.

If the calcined $\mathrm{PdO} / \mathrm{ZnO}$ materials are brought into a hydrogen containing atmosphere, the first thing that will happen, usually already at or below room temperature, is the reduction of the $\mathrm{PdO}$ component to form $\mathrm{PdH}_{x}$. Under such conditions, bulk palladium forms the $\beta$ hydride phase with $x \approx 0.6$. Formation of $\mathrm{PdH}_{x}$ from palladium nanoparticles is known to be size-dependent and this intermediate will not always be observed on small palladium particles [85-87]. Upon further heating $\mathrm{PdH}_{x}$ will be thermally decomposed and metallic palladium particles supported on $\mathrm{ZnO}$ will be obtained. These events can be observed in temperature- 
programmed reduction (TPR) experiments as a hydrogen consumption peak at room temperature according to

$$
\mathrm{PdO}+(1+x / 2) \mathrm{H}_{2} \rightarrow \mathrm{PdH}_{x}+\mathrm{H}_{2} \mathrm{O}
$$

and a hydrogen release peak as the temperature is ramped caused by the decomposition of the palladium hydride

$$
\mathrm{PdH}_{x} \rightarrow \mathrm{Pd}+x / 2 \mathrm{H}_{2}
$$

It is noted that the hydrogen balance of the both reactions often yields larger values than can be expected for a stoichiometric reduction of PdO. This is related to a spill-over of hydrogen from the palladium particles, where it is initially adsorbed, onto the surface of the support ${ }^{[88]}$. These hydrogen species do not only diffuse onto the oxide, but at sufficiently high temperatures also partially reduce the $\mathrm{ZnO}$ support. The origin of this effect is thought to be the perimeter of the palladium particles and it is often discussed in terms of strong metalsupport interaction (SMSI). The SMSI effect is associated with three observations ${ }^{[89]}$ : i) when reduced at low temperature, the catalyst shows a conventional chemical behavior of the two individual components, ii) high-temperature reduction strongly alters the chemisorption properties ("SMSI state") and iii) the phenomenon is reversible by oxidation and mild reduction bringing the catalyst back to state i). While in the first publication by Tauster ${ }^{[90]}$ on the noble metal/titania system that described this phenomenon, the involvement of intermetallic compounds was suggested, the SMSI is today assigned to a covering of the metallic particles by a mobile and partly reduced support ${ }^{[91]}$, a view which was also taken by Tauster in a later publication ${ }^{[92]}$. A recent review of the topic can be found in ${ }^{[93]}$. Many different interpretations of the SMSI effect can be found in literature and this effect is often used as explanation for unusual catalytic behavior with varying pre-treatment conditions. Here, we take a perspective of a synthetic chemist and introduce the SMSI state as an intermediate stage in a proceeding solid state reaction. The latter results in the formation of the intermetallic compound, and, in consequence, the loss of reversibility of the SMSI. To distinguish this effect from the SMSI it has been named "reductive metal-support interaction (RMSI)" [9]. In case of $\mathrm{ZnPd}$, the thermodynamic driving force of this reaction is the high stability of the intermetallic compound reflected in its large enthalpy of formation ${ }^{[56]}$ as well as the formation of water. 
Before Iwasa et al. ${ }^{[94]}$ monitored the formation of the intermetallic compound $\mathrm{ZnPd}$ from $\mathrm{Pd} / \mathrm{ZnO}$ by $\mathrm{XRD}$, an earlier study already reported the formation of $\mathrm{ZnPd}$ in reducing atmospheres ${ }^{[11]}$. Iwasa et al. describe, that under similar conditions, no intermetallic compound was formed on less reducible supports like $\mathrm{Pd} / \mathrm{SiO}_{2}$ or $\mathrm{Pd} / \mathrm{ZrO}_{2}$. In addition to XRD, the compound formation was also detected by X-ray photoelectron spectroscopy ${ }^{[94 ; 95]}$. The $\mathrm{Pd} 3 d_{5 / 2}$ signal for elemental palladium is observed at $335.1 \mathrm{eV}$. The reductive treatment of $\mathrm{Pd} / \mathrm{ZnO}$ at $673 \mathrm{~K}$ with $4 \%$ hydrogen leads to a shift of $0.6 \mathrm{eV}$ of the $\mathrm{Pd} 3 d_{5 / 2}$ signal to higher binding energy. As mentioned above, the intermetallic compound ZnPd can also be readily formed from $\mathrm{Pd} / \mathrm{ZnO}$ under methanol steam reforming conditions without a dedicated pre-reduction, since the presence of elemental palladium causes decomposition of methanol resulting in a hydrogen-rich, thus strongly reducing atmosphere ${ }^{[96]}$.

More experimental insight into the formation mechanism of $\mathrm{ZnPd}$ was provided by Penner et al. ${ }^{[97]}$ by synthesizing well-defined thin film model systems by embedding epitaxially grown Pd-particles in an amorphous $\mathrm{ZnO}$ matrix which is mechanically stabilized by $\mathrm{SiO}_{2}$. The advantage of this approach is the possibility to perform in depth TEM characterization on these materials. The formation of well-ordered $\mathrm{ZnPd}$ in $100 \% \mathrm{H}_{2}$ was observed at temperatures as low as $473 \mathrm{~K}$ and it was stable up to $873 \mathrm{~K}$, where it partially decomposed into Pd-rich silicides (due to reaction with the stabilizing silica layer). The epitaxial growth of the palladium particles causes their alike crystallographic orientation. This enabled the observation that the $\mathrm{ZnPd}$ intermetallic compound is formed by a topochemical reaction starting at the surface of the palladium particles. In contrast, a similar $\mathrm{Pd} / \mathrm{SiO}_{2}$ thin film model revealed amorphisation of the palladium particles by reduction, most likely because of hydride formation. This clearly does not happen in the presence of $\mathrm{ZnO}$ as otherwise the crystallographic orientation between the different particles would be lost.

Most likely, hydrogen is activated on the palladium surface or a crystalline $\alpha$-Pdhydride with low hydrogen content is formed. Thus, the most likely sequence of the reaction of hydrogen with $\mathrm{Pd} / \mathrm{ZnO}$ under the removal of water is:

$$
\mathrm{Pd} / \mathrm{ZnO} \rightarrow{ }^{\prime} \mathrm{PdH}_{x} " / \mathrm{ZnO} \rightarrow{ }^{\prime} \mathrm{Pd}\left(\mathrm{H}_{x}\right) " / \mathrm{ZnO}_{1-y} / \mathrm{ZnO} \rightarrow \mathrm{ZnPd} / \mathrm{ZnO},
$$

where " $\mathrm{PdH}_{x}$ " and " $\mathrm{Pd}\left(\mathrm{H}_{x}\right)$ " can represent either a crystalline Pd-hydride or activated hydrogen on the surface and $y \leq 1 ; \mathrm{ZnO}_{1-y}$ corresponds to the oxidic component of the SMSI state. The " $\mathrm{PdH}_{x}$ " and SMSI states are not easily recovered as their range of stability strongly depends on the preparation conditions. 
Depending on the reduction conditions, $\mathrm{ZnPd}_{2}$ can be observed as an intermediate during reduction of $\mathrm{Pd} / \mathrm{ZnO}{ }^{[73]}$. This was recently also observed in $\mathrm{ZnPd} / \mathrm{ZnO} / \mathrm{ZnAl}_{2} \mathrm{O}_{4}$ samples prepared from a co-precipitated layered double hydroxide precursor ${ }^{[84]}$. Reduction of the precursor in hydrogen at $523 \mathrm{~K}$ did not lead to complete formation of the $\mathrm{ZnPd}$ phase, but the presence of $\mathrm{ZnPd}_{2}$ particles was identified by high resolution transmission electron microscopy (HRTEM) (Fig. 6). Interestingly, the particle was covered by a partially ordered shell of $\mathrm{ZnO}$ as one would expect as a result of SMSI. Such an arrangement can be seen as an indication that the inner metal particle is successively enriched in zinc via the reactive interface and that intermediate intermetallic phases are formed by a Zn-enrichment of elemental palladium according to the Pd-Zn phase diagram (compare Fig. 2) in course of the $\mathrm{ZnPd}$ formation.
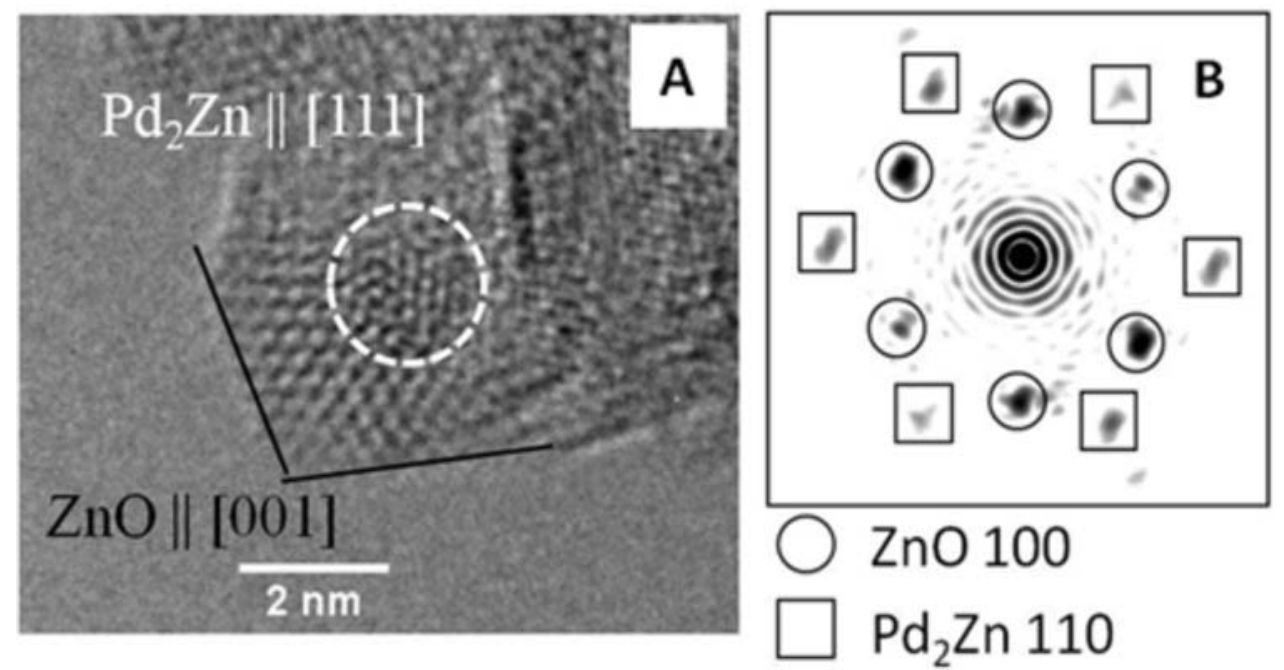

Figure 6: High-resolution TEM image of a $\mathrm{ZnO}$-shell/ZnPd2-core arrangement, which probably is an intermediate in the reduction reaction of $\mathrm{Pd} / \mathrm{ZnO}$ composites to ZnPd/ZnO in hydrogen and can be understood as an SMSI-state (from ${ }^{[84]}$ ).

$\mathrm{ZnPd}$ catalysts were also prepared on mesoporous alumina for oxidative steam reforming of methanol (OSR) ${ }^{[98]}$. After impregnation of the mesoporous support with palladium acetate, the noble metal was pre-reduced using $\mathrm{Zn}\left(\mathrm{BH}_{4}\right)_{2}$. The intimate mixing of zinc and palladium then allowed for formation of the intermetallic compound upon reduction in hydrogen at $773 \mathrm{~K}$. Leaving the powder catalyst behind, Fukuhara et al. synthesized

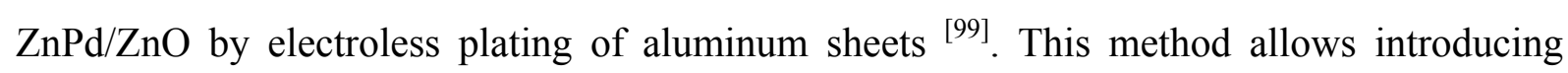
ZnPd-based catalysts in microstructured reactors with a high material efficiency, thus bringing the materials closer to application. The intermetallic compound was formed after the 
plating process when the as plated sheets were reduced in hydrogen at $623 \mathrm{~K}$, showing a $\mathrm{CO}_{2}$ selectivity of $97.3 \%$.

In summary, supported $\mathrm{ZnPd}$ can be prepared relatively easily by reduction of $\mathrm{Pd} / \mathrm{ZnO}$ in hydrogen or under reaction conditions. The exact reduction conditions depend on the used precursor material and its properties and synthesis conditions. If uniform and single-phase intermetallic particles are desired as in catalytic applications, care has to be taken the $\mathrm{Pd} / \mathrm{ZnO}$ precursor is synthesized in a homogeneous form and treated at sufficiently high temperatures and for extended time to ensure complete formation of $\mathrm{ZnPd}$ and avoid the presence elemental palladium or Zn-poorer intermetallic compounds or alloys. The mechanism of formation is relatively complex and the reaction proceeds through various intermediates, whose range of existence is a function of the $\mathrm{Pd} / \mathrm{ZnO}$ microstructure and the reduction conditions. One intermediate is probably an SMSI-state which is easily overlooked in the case of $\mathrm{ZnPd}$ as it is formed at much lower temperatures compared to many other combinations of noble metal and reducible oxide and easily results in the irreversible RMSIstate by the formation of the intermetallic compound $\mathrm{ZnPd}$. One question unresolved so far is the $\mathrm{Pd}: \mathrm{Zn}$ ratio of the supported $\mathrm{ZnPd}$ particles, which can vary significantly according to the phase diagram (Fig. 2). Besides being decisive to gather meaningful quantum chemical results, the composition also plays a decisive role in the catalytic behavior as shown in section 5.a).

\section{3.c) Surface alloys}

Leaving the thermodynamically stable unsupported and the supported materials behind, we approach the field of surface science and - due to the lack of large single crystals - the domain of the fourth class of materials (i.e. surface alloys). ZnPd surface alloys - lately termed near-surface intermetallic phases (NSIPs) ${ }^{[100]}$ - are generally formed upon deposition of zinc on a palladium single crystalline surface (or vice versa) in ultra-high vacuum, followed by thermal annealing ${ }^{[101]}$. Occasionally, the surface alloys are formed by depositing zinc on a polycrystalline palladium foil ${ }^{[102]}$ or co-evaporation of zinc and palladium on $\operatorname{Ru}(001)^{[103]}$, by depositing palladium on $\mathrm{Zn}(0001)^{[104]}$ or by decomposing diethyl zinc on $\operatorname{Pd}(100)^{[105]}$. A very recent approach is to model the supported catalysts by deposition of $\mathrm{Pd}$ on $\mathrm{ZnO}(10 \overline{1} 0)$ and $\mathrm{ZnO}(0001)$ surfaces and subsequent reduction in hydrogen ${ }^{[106]}$. Below we present the literature on the surface alloys prepared by zinc deposition on $\operatorname{Pd}(111)$ surface, which is the most studied surface system, followed by surface alloys grown on $\operatorname{Pd}(110)$. 
Depending on substrate temperature and coverage, different NSIPs are formed on $\operatorname{Pd}(111)$. Depositing several monolayers (ML) of zinc at low temperatures and subsequent annealing at $300-550 \mathrm{~K}$, a surface alloy is formed which exhibits a $\mathrm{p}(2 \times 1)$ buckled superstructure using low-energy electron diffraction (LEED) - in the following referred to as surface alloy 1 or, in short, SA-1 ${ }^{[101 ; 107]}$. Upon further heating to $550 \mathrm{~K}$ zinc diffuses into the Pd-bulk leading to formation of a rather flat monolayer surface alloy at $630 \mathrm{~K}(\mathrm{SA}-2)^{[102 ; 108]}$. In contrast to the deposition at low temperatures, the deposition of zinc at room temperature results directly in formation of SA-1, but with domains aligned along the three high symmetry directions of the substrate. Thus a $\mathrm{p}(2 \times 2)$ LEED pattern is observed, resulting from the three superimposed $\mathrm{p}(2 \times 1)$ patterns ${ }^{[109]}$. Due to the different domains present, we refer to this state as SA-3. After completion of the growth of the bilayer SA-1, zinc metal films grow with an almost layer-by-layer fashion, forming a $(1 \times 1)$ structure as revealed by STM and LEED ${ }^{[108]}$. Another well-ordered surface alloy with a rectangular $(6 \times 4 \sqrt{3} / 3)$ LEED structure is formed when depositing more than $3 \mathrm{ML}$ of zinc at $750 \mathrm{~K}$ (SA-4) - a phase not considered further in this review ${ }^{[110]}$. Heating the substrate to more than $800 \mathrm{~K}$ leads to decomposition of the NSIPs and desorption of the zinc.

A wide variety of surface science techniques has been used to characterize the NSIPs, which have been summarized in Table 1. Here, we focus on synthesis, surface structure and chemistry, growth mode, stability and electronic properties of the NSIPs, knowledge of which is the prerequisite for fundamental understanding of the catalytic reaction on the surface. The influence of surface properties on the catalytic reaction will be discussed in section 5 . 
Table 1: List of studies of ZnPd surface alloys by various techniques.

\begin{tabular}{|c|c|c|c|}
\hline System & Method & Information & References \\
\hline $\mathrm{Pd} / \mathrm{Zn}(001)$ & UPS & valence band & {$[104]$} \\
\hline $\mathrm{Pd}, \mathrm{Zn} / \mathrm{Ru}(001)$ & XPS, TDS & $\begin{array}{l}\text { stability, valence band, } \mathrm{CO} \\
\text { adsorption }\end{array}$ & [103] \\
\hline $\mathrm{Zn} / \mathrm{Pd}(111)$ & XPS, LEED, UPS & $\begin{array}{l}\text { growth mode, structure, } \\
\text { stability valence band }\end{array}$ & [101] \\
\hline $\mathrm{Zn} / \mathrm{Pd}(111)$ & TPD, LEED & structure and stability & [110] \\
\hline $\mathrm{Zn} / \mathrm{Pd}(111)$ & $\begin{array}{l}\text { LEED, HREELS, } \\
\text { TPD }\end{array}$ & structure, $\mathrm{CO}$ adsorption & [111] \\
\hline $\mathrm{Zn} / \mathrm{Pd}(111)$ & LEED & structure, $\mathrm{H}_{2}, \mathrm{CO}$ adsorption & [112] \\
\hline $\begin{array}{c}\text { Zn on sulfur-covered } \\
\operatorname{Pd}(111)\end{array}$ & AES, TPD & sticking coefficient & {$[113]$} \\
\hline $\mathrm{Zn} / \mathrm{Pd}(111)$ & STM, LEED, DFT & $\begin{array}{c}\text { growth mode, structure, } \\
\text { stability }\end{array}$ & [108] \\
\hline $\mathrm{Zn} / \mathrm{Pd}(111)$ & LEIS & $\begin{array}{l}\text { growth mode, structure, } \\
\text { stability valence band }\end{array}$ & {$[107]$} \\
\hline $\begin{array}{c}\mathrm{Zn} / \mathrm{Pd}(111) \\
\mathrm{Zn} / \mathrm{Pd} \text { foil }\end{array}$ & $\begin{array}{l}\text { XPS, LEIS, PM- } \\
\text { IRAS }\end{array}$ & $\begin{array}{l}\text { growth mode, stability, steam } \\
\text { reforming }\end{array}$ & {$[114]$} \\
\hline $\mathrm{Zn} / \mathrm{Pd}(111)$ & LEIS, AES & composition, stability & {$[102]$} \\
\hline $\mathrm{Zn} / \mathrm{Pd}(111)$ & DFT, STM & $\begin{array}{c}\text { growth mode, structure, } \\
\text { stability }\end{array}$ & {$[109]$} \\
\hline $\mathrm{Zn} / \mathrm{Pd}(111)$ & Monte Carlo & growth mode & [115] \\
\hline $\mathrm{Zn} / \mathrm{Pd}(110)$ & $\begin{array}{c}\text { LEIS-ICISS, LEED, } \\
\text { AES, TPD }\end{array}$ & $\begin{array}{l}\text { growth mode, structure, } \\
\text { stability }\end{array}$ & {$[116]$} \\
\hline diethyl zinc/Pd(100) & UPS, AES, TDS & growth and reactivity & [105] \\
\hline
\end{tabular}

AES: Auger electron spectroscopy

DFT: Density functional theory

HREELS: High-resolution energy electron loss spectroscopy

LEED: Low-energy electron diffraction

LEIS: Low-energy ion scattering

LEIS-ICISS: Low-energy ion scattering - impact-collision ion scattering spectroscopy

PM-IRAS: Polarization-modulation infrared adsorption spectroscopy

STM: Scanning tunneling microscopy

TPD: Temperature programed desorption

TDS: Temperature desorption spectroscopy

UPS: Ultraviolet photoelectron spectroscopy

XPS: X-ray photoelectron spectroscopy

In contrast to the bulk, supported and nanoparticulate samples where the structure description as CuTi type of structure is used, the surface alloys, as well as the quantum chemical calculations usually refer to the structure description as CuAu type of structure. To be able to directly relate the different studies, it is worthwhile to have a look at the 
relationship of the low indexed surfaces of elemental palladium and $\mathrm{ZnPd}$ and the relation of the different descriptions. Throughout this text, we will use the two different structural descriptions as described above. Since the bulk structure of $\mathrm{ZnPd}$ is closely related to the structure of bulk palladium by distortion of one principal axis, two possible arrangements result of the overlaying $\mathrm{ZnPd}$ layer for each low indexed palladium surface (see Table 2). Comparing the structural descriptions of $\mathrm{ZnPd}$ as face-centered and body-centered tetragonal unit cells, the face-centered (111) surface corresponds to the (110) or (101) surface in the body-centered descriptions. This allows a direct calculation of the lattice mismatch of $\operatorname{Pd}(111)$ and $\mathrm{ZnPd}(110)$ or $\mathrm{ZnPd}(101)$. The palladium (111) surface is described by plane group p6mm with $a=2.7510 \AA$. On the other hand, the bulk-like terminated $\mathrm{ZnPd}$ surfaces form rectangular lattices with plane group $p 2 \mathrm{~mm}$ with $a_{\mathrm{ZnPd}(110)}=3.3426 \AA$ and $b_{\mathrm{ZnPd}(110)}=4.0915$ $\AA$ and $a_{\mathrm{ZnPd}(101)}=2.8931 \AA$ and $b_{\mathrm{ZnPd}(101)}=4.4207 \AA$. Transformation of the palladium unit mash to the corresponding rectangular unit mash of $\mathrm{ZnPd}$ results in $a_{\operatorname{Pd}(111)}=2.7510 \AA$ and $b_{\operatorname{Pd}(111)}=3.8905 \AA$. The other $\mathrm{ZnPd} / \mathrm{Pd}$ low-index surfaces are compared in Table 2. DFTbased calculations on bulk ZnPd show, that the (101) and (110) surfaces exposing zinc and palladium atoms in an equimolar ratio are more stable than the (100) and (001) surfaces which comprise alternating palladium and zinc layers ${ }^{[61]}$. Usually, the lattice-mismatch caused by the topotaxial reaction is large in at least one direction, thus a strong influence of the underlying substrate on the surface structure is expected for ZnPd NSIPs on the different palladium surfaces. 
Table 2: comparison of lattice parameters of the different $\mathrm{ZnPd}$ and elemental palladium surfaces.

\begin{tabular}{|c|c|c|c|c|c|c|c|}
\hline & $\mathrm{ZnPd}(101) / \operatorname{Pd}(111)$ & $\mathrm{ZnPd}(110) / \operatorname{Pd}(111)$ & $\operatorname{ZnPd}(100) / \operatorname{Pd}(110)$ & $\mathrm{ZnPd}(001) / \operatorname{Pd}(110)$ & $\mathrm{ZnPd}(112) / \operatorname{Pd}(110)$ & $\operatorname{ZnPd}(101) / \operatorname{Pd}(100)$ & $\mathrm{ZnPd}(110) / \mathrm{Pd}(100)$ \\
\hline $\begin{array}{l}\text { plane } \\
\text { group } \\
\mathrm{ZnPd}\end{array}$ & $p 2 m m$ & $p 2 m m$ & $p 2 m m$ & $p 4 m m$ & $p 2 m m$ & $p 2 m m$ & $p 2 m m$ \\
\hline $\begin{array}{l}a_{\mathrm{ZnPd}} \\
a_{\mathrm{Pd}}\end{array}$ & $\begin{array}{l}a_{\mathrm{ZnPd}(101)}=a_{\mathrm{ZnPd}}= \\
2.8931 \AA \\
a_{\mathrm{Pd}(111)}=2.7510 \AA\end{array}$ & $\begin{array}{l}a_{\mathrm{ZnPd}(110)}=c_{\mathrm{ZnPd}}= \\
3.3426 \AA \\
a_{\mathrm{Pd}(111)}=2.7510 \AA\end{array}$ & $\begin{array}{l}a_{\mathrm{ZnPd}(100)}=c_{\mathrm{ZnPd}}= \\
3.3426 \AA \\
a_{\mathrm{Pd}(110)}=a_{\mathrm{Pd}}= \\
3.8905 \AA\end{array}$ & $\begin{array}{l}a_{\mathrm{ZnPd}(001)}=a_{\mathrm{ZnPd}}= \\
2.8931 \AA \\
a_{\mathrm{Pd}(110)}=a_{\mathrm{Pd}}= \\
3.8905 \AA\end{array}$ & $\begin{array}{l}a_{\mathrm{ZnPd}(112)}= \\
\sqrt{ } 2 \times a_{\mathrm{ZnPd}}=4.0915 \\
\AA \\
a_{\mathrm{Pd}(110)}=a_{\mathrm{Pd}}= \\
3.8905 \AA\end{array}$ & $\begin{array}{l}a_{\mathrm{ZnPd}(101)}=a_{\mathrm{ZnPd}}= \\
2.8931 \AA \\
a_{\mathrm{Pd}(100)}=a_{\mathrm{Pd}}= \\
3.8905 \AA\end{array}$ & $\begin{array}{l}a_{\mathrm{ZnPd}(110)}=c_{\mathrm{ZnPd}}= \\
3.3426 \AA \\
a_{\mathrm{Pd}(100)}=a_{\mathrm{Pd}}= \\
3.8905 \AA\end{array}$ \\
\hline $\begin{array}{l}b_{\mathrm{ZnPd}} \\
b_{\mathrm{Pd}}\end{array}$ & $\begin{array}{l}b_{\mathrm{ZnPd}(101)}=4.4207 \\
\AA \\
b_{\mathrm{Pd}(111)}=3.8905 \AA\end{array}$ & $\begin{array}{ll}b_{\mathrm{ZnPd}(110)} & = \\
\sqrt{ } 2 \times * a_{\mathrm{ZnPd}} & = \\
4.0915 \AA & \\
b_{\mathrm{Pd}(111)}=3.8905 \AA\end{array}$ & $\begin{array}{l}b_{\mathrm{ZnPd}(100)}=a_{\mathrm{ZnPd}}= \\
2.8931 \AA^{\mathrm{a}} \\
b_{\mathrm{Pd}(110)}=\sqrt{ } 2 \times a_{\mathrm{Pd}}= \\
5.5020 \AA\end{array}$ & $\begin{array}{l}b_{\mathrm{ZnPd}(001)}=b_{\mathrm{ZnPd}}= \\
2.8931 \AA^{\mathrm{a}} \\
b_{\mathrm{Pd}(110)}=\sqrt{2} \times a_{\mathrm{Pd}}= \\
5.5020 \AA\end{array}$ & $\begin{array}{l}b_{\mathrm{ZnPd}(112)}= \\
\sqrt{ }\left[\left(2 \times a_{\mathrm{ZnPd}}{ }^{2}\right)+\right. \\
\left.c_{\mathrm{ZnPd}}{ }^{2}\right]=5.2833 \AA \\
b_{\mathrm{Pd}(110)}=\sqrt{ } 2 \times a_{\mathrm{Pd}}= \\
5.5020 \AA\end{array}$ & $\begin{array}{l}b_{\mathrm{ZnPd}(101)}=4.4207 \\
\AA \\
b_{\mathrm{Pd}(100)}=a_{\mathrm{Pd}}= \\
3.8905 \AA\end{array}$ & $\begin{array}{l}b_{\mathrm{ZnPd}(110)}=\sqrt{2 \times a_{\mathrm{ZnPd}}} \\
=4.0915 \AA \\
b_{\mathrm{Pd}(100)}=a_{\mathrm{Pd}}= \\
3.8905 \AA\end{array}$ \\
\hline $\begin{array}{l}\text { mismatch } \\
a \\
\text { mismatch } \\
b\end{array}$ & $\begin{array}{l}5 \% \\
14 \%\end{array}$ & $\begin{array}{l}22 \% \\
5 \%\end{array}$ & $\begin{array}{l}16 \% \\
5 \%\end{array}$ & $\begin{array}{l}34 \% \\
5 \%\end{array}$ & $\begin{array}{l}5 \% \\
4 \%\end{array}$ & $\begin{array}{l}34 \% \\
14 \%\end{array}$ & $\begin{array}{l}16 \% \\
5 \%\end{array}$ \\
\hline
\end{tabular}

${ }^{\mathrm{a}}$ for comparison to the palladium (110) surface, the $b$ parameters of $\mathrm{ZnPd}$ have to be doubled 
The growth of zinc on $\operatorname{Pd}(111)$ has been studied in a wide range of substrate temperatures and coverages. Bayer et al. ${ }^{[101]}$ were the first to study the growth of zinc on $\operatorname{Pd}(111)$ surface at various conditions by XPS, LEED, and UPS and showed that a pseudo-morphic zinc monolayer is formed when $1 \mathrm{ML}$ of zinc is deposited at a substrate temperature of $105 \mathrm{~K}$. Annealing of the zinc monolayer at $550 \mathrm{~K}$ yielded SA-1, an ordered ZnPd NSIP with $\mathrm{p}(2 \times 1)$ surface structure with two layers of $\mathrm{ZnPd}$ and an atomic ratio of Pd:Zn of approximately $1: 1$. XPS indicated that NSIP formation already begins at temperatures slightly above $300 \mathrm{~K}$. A more homogeneous ZnPd SA-1 could be obtained by depositing 1-3 ML zinc at $550 \mathrm{~K}$, which is above the desorption temperature of multilayer zinc films ${ }^{[101]}$. By combining LEED and STM, Weirum et al. confirmed the same underlying structure of the NSIP but with domains aligned along the three degenerate high symmetry axes of the substrate ${ }^{[108]}$. The three differently orientated $\mathrm{p}(2 \times 1)$ multi-domains produce a LEED pattern equivalent to a $\mathrm{p}(2 \times 2)$ structure (Figure $7 \mathrm{~d}$ ). The $\mathrm{p}(2 \times 2)$ LEED patterns observed earlier ${ }^{[110-112]}$ from the same NSIP can be understood in terms of such a $p(2 \times 1)$ multi domain structure. The LEIS analysis has further revealed that the topmost surface layer is slightly buckled with zinc atoms located at about $0.25 \AA$ above the palladium atoms ${ }^{[107]}$ (Fig. 7). Recent work by STM ${ }^{[108]}$, LEIS ${ }^{[102 ; 107]}$ and AES ${ }^{[114]}$ have confirmed the formation of bilayer islands of the $\mathrm{ZnPd}$ at $300 \mathrm{~K}$ (Fig. 8). One exception was reported by Gabasch et al. ${ }^{[110]}$. They excluded alloy formation at temperatures up to $600 \mathrm{~K}$, based on TPD experiments. However, this observation is questioned by the other studies using more powerful techniques like XPS.

DFT-based quantum chemical calculations show that homogeneous bilayer ZnPd films, modeled by the $\mathrm{Zn}_{2} \mathrm{Pd}_{2} / \mathrm{Zn}_{2} \mathrm{Pd}_{2}$ configuration of the four-atom surface unit cell used in the calculation, deposited on either $\mathrm{Pd}(111), \mathrm{Zn}(0001)$ or $\mathrm{ZnPd}(111)$, are more stable than segregated $\mathrm{Pd}$ or $\mathrm{Zn}$ films ${ }^{[117]}\left(\mathrm{Pd}_{4} / \mathrm{Zn}_{4}\right.$ or $\mathrm{Zn}_{4} / \mathrm{Pd}_{4}$ configurations). At a first glance, this result is surprising since there is a large difference between the surface energies of elemental palladium $\left(1.92 \mathrm{Jm}^{-2}\right)$ and zinc $\left(0.99 \mathrm{Jm}^{-2}\right)^{[118]}$. The main reason why segregation is unfavorable in stoichiometric $\mathrm{ZnPd}$ bilayer films is the large energy cost required to break the Pd-Zn bonding (see section 4.d)) ${ }^{[40]}$. The situation is different if the bilayer $\mathrm{ZnPd}$ film is enriched in one component: formation energy calculations of $1: 3$ and 3:1 bilayer alloy films on $\mathrm{ZnPd}(111)$ show that the segregation of the dominant component becomes energetically favorable ${ }^{[117]}$. Indeed, when deposited on $\mathrm{ZnPd}(111)$ (i) the segregated bilayer $\mathrm{Zn}_{4} / \mathrm{Zn}_{2} \mathrm{Pd}_{2}$ is more stable than the $\mathrm{Zn}_{3} \mathrm{Pd} / \mathrm{Zn}_{3} \mathrm{Pd}$ bilayer and (ii) the segregated bilayer $\mathrm{Pd}_{4} / \mathrm{Zn}_{2} \mathrm{Pd}_{2}$ is more stable than the $\mathrm{ZnPd}_{3} / \mathrm{ZnPd}_{3}$ bilayer ${ }^{[117]}$. 
To get a deeper understanding of the NSIP formation, Monte Carlo simulations of zinc on $\mathrm{Pd}(111)$ were calculated. The structure and composition of the $\mathrm{ZnPd}$ surface alloy film was obtained by the deposition and depends on the zinc coverage ${ }^{[108 ; 115]}$. For sub-monolayer zinc coverage, Monte Carlo simulations show that most of the zinc atoms are exchanged with the substrate Pd atoms: at a total $\mathrm{Zn}$ coverage of $0.12 \mathrm{ML}$, only $25 \%$ of the deposited $\mathrm{Zn}$ atoms lie on the surface ${ }^{[115]}$. Between 1 and 3 ML Zn coverage, Monte Carlo calculations demonstrate that a multilayer 1:1 ZnPd surface alloy is formed ${ }^{[115]}$, the structure of the surface alloy being more disordered if the temperature is high $(500 \mathrm{~K})$. Experimentally, a $\mathrm{p}(2 \mathrm{x} 1)$ surface structure is identified between 0.8 and 1.5 ML Zn coverage in good agreement between the experimental high resolution images and the corresponding simulated images calculated using a $\mathrm{p}(2 \times 1)$ model surface ${ }^{[108]}$. According to Weirum et al., only one half of the deposited atoms should be present on the film surface in order to match the $1: 1 \mathrm{ZnPd}$ ratio, the remaining $\mathrm{Zn}$ atoms being located in the sub-surface, after having exchanged their positions with the sub-surface Pd atoms.

On heating SA-1 to temperatures above $550 \mathrm{~K}$ a monolayer surface alloy (SA-2) is formed. The surface of SA-2 is again buckled, but in contrast to SA-1, now the palladium atoms are sticking out of the surface (Fig. 7) ${ }^{[108 ; 119]}$. The observation of such a buckled surface is in agreement with DFT calculations ${ }^{[108 ; 109]}$. Further, the transition from SA-1 to SA-2 by heating is supported by the lower value $\left(1.22 \mathrm{Jm}^{-2}\right)$ of the surface energy of a bilayer $\mathrm{ZnPd}$ on $\mathrm{Pd}(111)$ compared to that of a monolayer $\left(1.40 \mathrm{Jm}^{-2}\right)$. The difference results in different electronic structures for the bilayer SA-1 and monolayer SA-2 surface alloy (see section 4.a)). The calculated Bader charges per atom and per layer have been shown to be different for the $\mathrm{ZnPd}(111)$ surface of stoichiometric $\mathrm{ZnPd}$ and the ZnPd surface alloy SA-2 ${ }^{[109]}$. Thus, the thickness of the NSIP is decisive for the electronic structure, thus strongly influencing the catalytic properties as shown in section 5.c). 

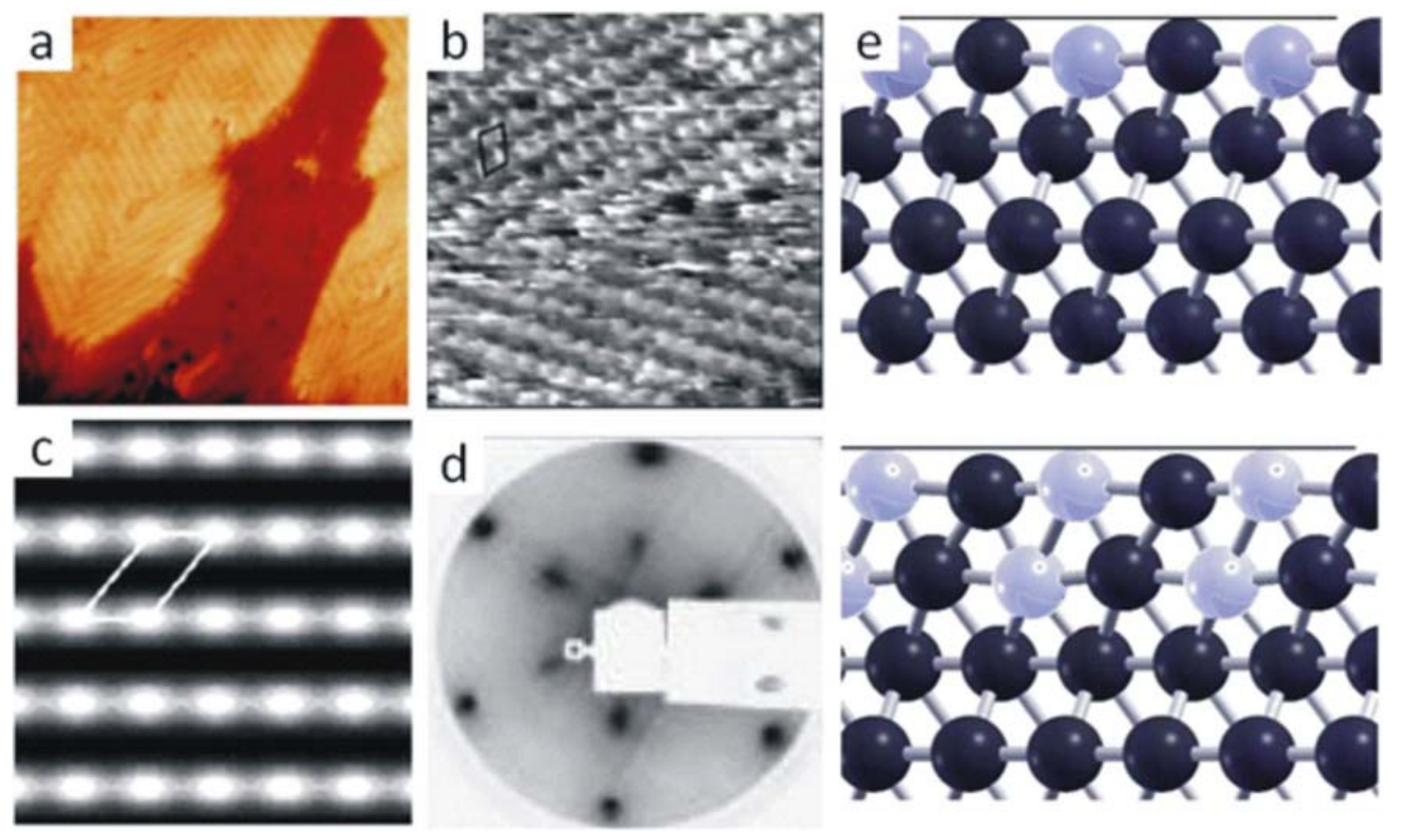

Figure 7: (a) STM image of the ZnPd surface alloy formed by depositing zinc on Pd(111), showing a multi-domains structure $(2 \mathrm{~nm} \times 2 \mathrm{~nm})$. (b) High resolution and (c) simulated STM images with $(2 \times 1)$ unit cells marked. Inset: calculated structure of ZnPd surface alloy (size view) demonstrating buckled surface layer (gray: Zn, black: palladium atoms). (d) $p(2 \times 2)$ LEED pattern taken from the same surface alloy. (e) Structure of the ZnPd surface alloy (grey: Zn, black: Pd) with 1 ML (top) and 2 ML (bottom) Zn obtained by DFT calculations ((a) from ${ }^{[109]}$, (b-e) from $\left.{ }^{[108]}\right)$.

Higher temperatures lead first to a depletion of the surface in zinc, which is going subsurface, before zinc desorbs from palladium at temperatures above $800 \mathrm{~K}^{[110]}$. The upper panel in Fig. 8 summarizes the various states of zinc on $\mathrm{Pd}(111)$ at different temperatures in a schematic way. The lower panel of the figure shows the variation of zinc intensity in LEIS and AES after annealing of the $2.2 \mathrm{ML} \mathrm{Zn} / \mathrm{Pd}(111)$ at different temperatures. 


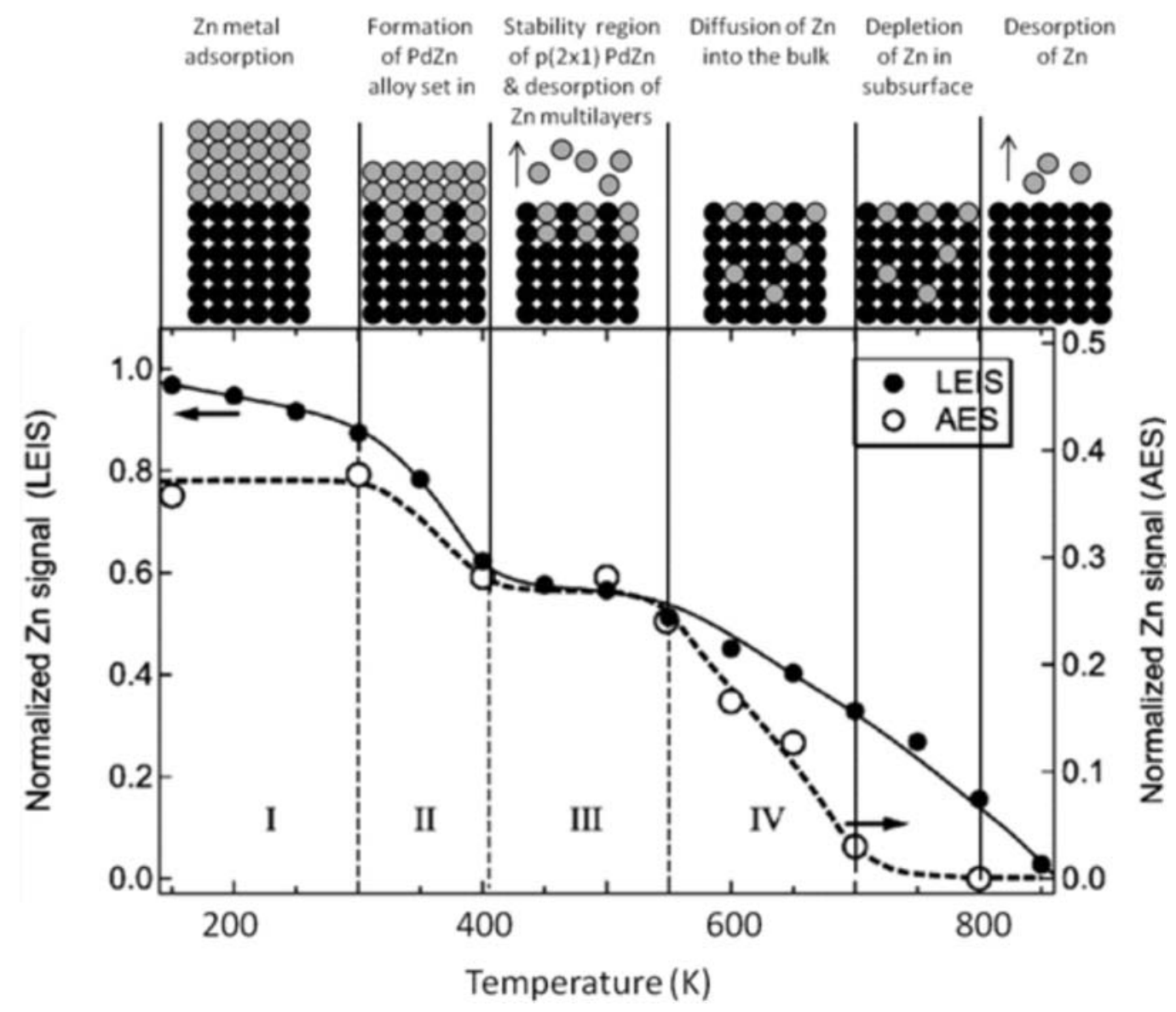

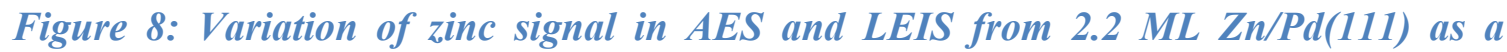
function of annealing temperatures. Upper panel shows states of the overlayer at different temperature regimes (Black: Pd, grey: Zn). State III represents SA-1, while state IV corresponds to $S A-2$. From $^{[102]}$.

Very recently, the growth of $\mathrm{Zn}$ on $\operatorname{Pd}(110)$ surface has been studied ${ }^{[116]}$. As in the case of $\operatorname{Pd}(111)$, intermixing of the deposited zinc and palladium occurs at room temperature but in difference, no long-range ordered structure is formed at this temperature up to $3 \mathrm{ML}$. At higher coverages a $\mathrm{p}(1 \times 3)$ LEED pattern is observed, which is assigned to overgrown zinc layers with a distorted hexagonal close-packed structure. Heating the sample after deposition to $600 \mathrm{~K}$ leads to a $\mathrm{p}(2 \times 1)$ LEED pattern, resulting from a monolayer near-surface intermetallic phase with a Pd:Zn ratio of 1:1 (SA-5) irrespective of the amount of zinc initially deposited (up to $5 \mathrm{ML}$ ). SA-5 shows a small Pd-up/Zn-down buckling. Interestingly, the surface structure does not resemble the (100) or (001) surfaces of ZnPd, but represents the (112) surface of ZnPd (ZnPd(101) in the fcc- 
derived structure description). This can be understood by the much better lattice fit (Table 2) as well as by considering, that the (112) surface has a $\mathrm{Pd}: \mathrm{Zn}$ ratio of $1: 1$ and is thus not polar. On this surface, the rectangular unit mash is formed by alternating rows of palladium and zinc atoms at a distance of $2.6416 \AA$ while the homoatomic distance between the rows is $4.0915 \AA$.

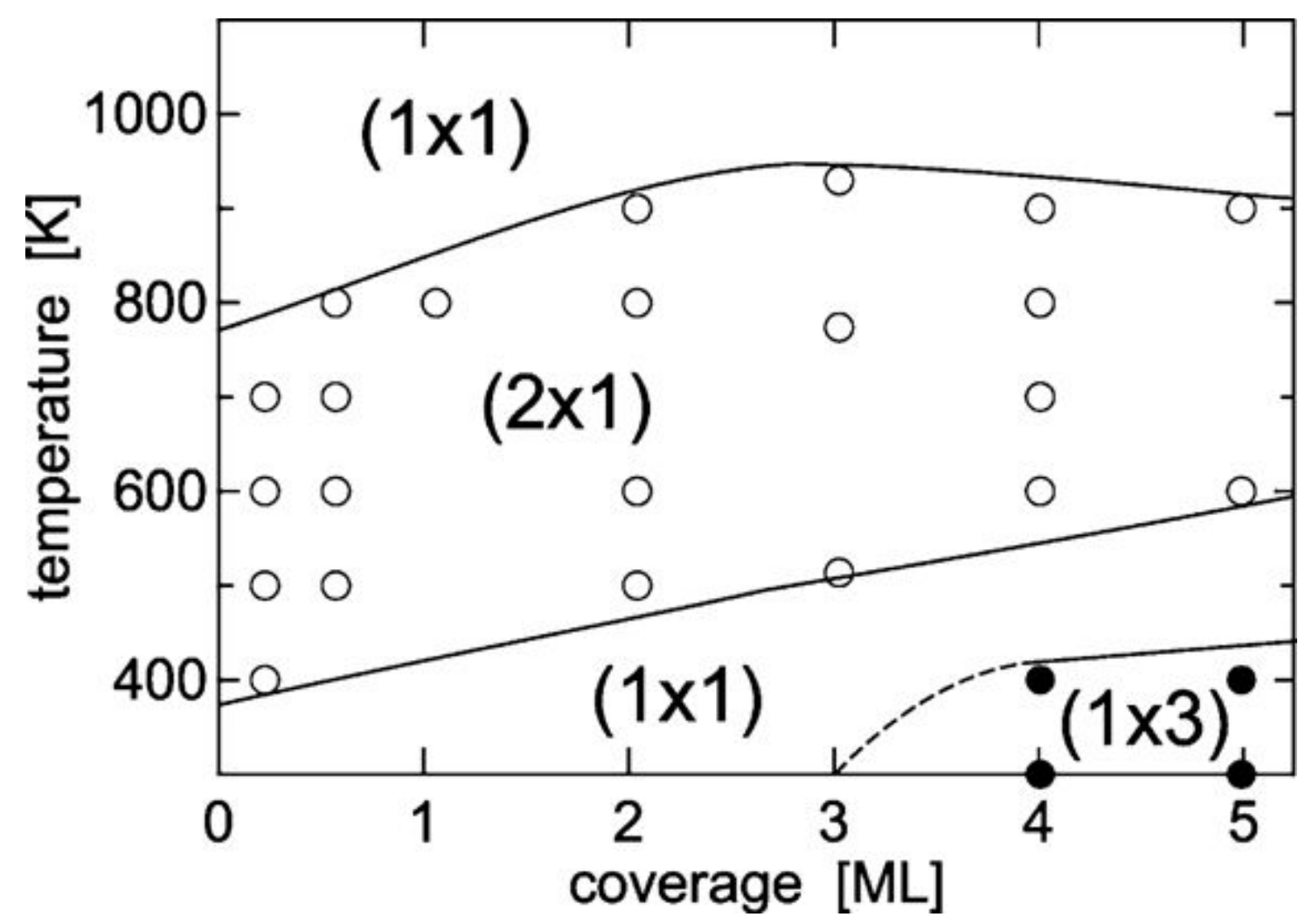

Figure 9: Range of existence for SA-5 with a $p(2 \times 1)$ structure on Pd(110) depending on zinc coverage and annealing temperature. From ${ }^{[116]}$.

In contrast to $\operatorname{Pd}(111)$, only one NSIP was detected so far on $\operatorname{Pd}(110)$. Figure 9 shows the range of existence for the NSIP SA-5 depending on the zinc coverage and the annealing temperature ${ }^{[116]}$. In conclusion, $\operatorname{Pd}(111)$ and $\operatorname{Pd}(110)$ behave differently upon deposition of zinc. Especially on $\operatorname{Pd}(111)$ precise control of growth parameters is required to form the aimed-for ZnPd NSIP in a form suitable to study the processes during the steam reforming of methanol. A bulk single crystal of the intermetallic compound $\mathrm{ZnPd}$ is highly desirable to minimize the influence of growth conditions on the characteristics of the NSIP and to characterize the surfaces of the bulk compound. 


\section{Physical and chemical properties of the materials}

This section collates the chemical and physical properties of different forms of $\mathrm{ZnPd}$. Knowledge of physical properties enables the detection of the formation of intermetallic compounds, e.g. by XPS or magnetic measurements. The chemical properties on the other hand, reveal differences between the different forms, which helps to understand their different catalytic behavior.

\section{4.a) Electronic structure}

The most important in heterogeneous catalysis is the electronic properties of the surface. Reaction between chemical elements modifies their electronic structure, thus changing significantly their properties like activity, selectivity and stability compared to the individual elements ${ }^{[58 ; 120-123]}$.

Electronic properties, in particular the valence band region at the Fermi edge of catalytically active species are difficult to investigate on conventional supported catalysts by means of photoelectron spectroscopy (XPS, UPS, AES) because of the following: i) the large excess of the support, leading to a decrease of intensity of the desired core level spectra and/or overlapping signals of different species containing the same element and ii) usually the isolating behaviour of the support, inducing almost zero intensity at the Fermi edge and causing effects like charging, which makes proper energy calibration challenging ${ }^{[124]}$. The use of model catalysts like surface alloys/NSIPs or unsupported intermetallic compounds can deal with these drawbacks, being able to reveal many details of the catalyst, like the quantification of different species, metal-to-metal ratios, depth-depending effects etc. These advantages usually come at the cost of losing direct correlation to the real-life catalyst, often referred to as the so-called materials gap $^{[41]}$.

The electronic properties of unsupported bulk ZnPd were first reported by Tsai et al., who performed UHV XPS studies to investigate the valence band region of the intermetallic compound, wherein the Pd4d level was shifted away from the Fermi edge, compared to elemental palladium ${ }^{[123]}$. Recently, the same group investigated unsupported ZnPd compounds in more detail, regarding the Pd4d level in UHV depending on the bulk composition of the phase. Therein, the band width of the $\mathrm{Pd} 4 d$ level is reduced in the order $\mathrm{Zn}_{45} \mathrm{Pd}_{55}<\mathrm{Zn}_{50} \mathrm{Pd}_{50}<\mathrm{Zn}_{55} \mathrm{Pd}_{45}$, 
being caused by the increased number of neighboring Pd-Zn pairs, which was supported by DFT band structure calculations ${ }^{[125]}$ (Fig. 10). Furthermore, the resolution of the data allows only a rough estimation of the binding energy of $\mathrm{Zn} 3 d_{5 / 2}$, being ca. $9.8 \mathrm{eV}$ for all three compositions.

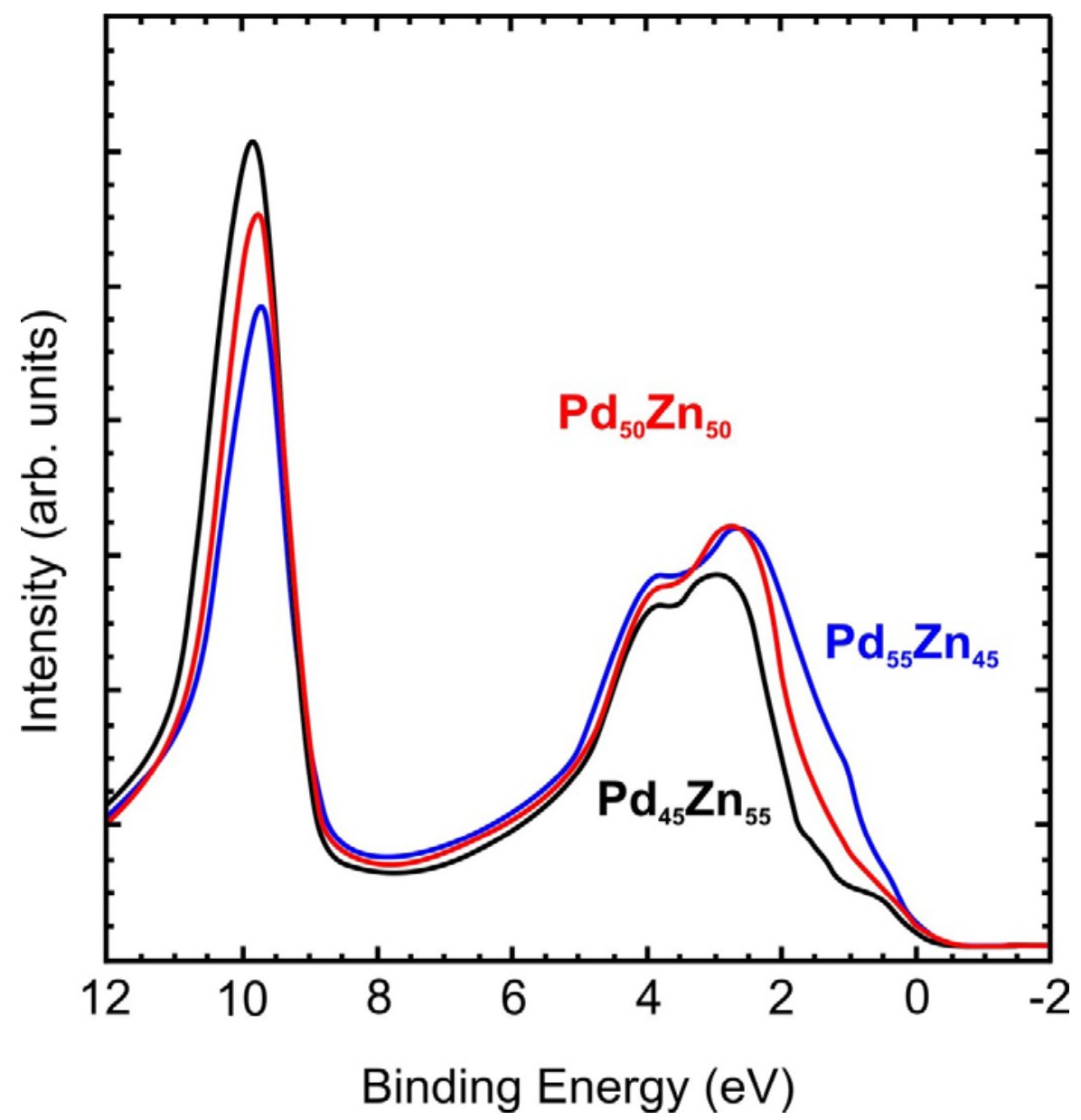

Figure 10: XPS valence band spectra measured at $300 \mathrm{~K}$ for ZnPd with three different compositions in $U H V$. The lines represent $Z n P d$ with Pd:Zn ratios of 50:50, 55:45 and 45:55. Redrawn from ${ }^{[125]}$.

To study the in situ stability, the dependence of the electronic properties on the composition of ZnPd was investigated under MSR conditions, as well as depth-dependent using synchrotron radiation ${ }^{[62]}$. The experiments showed that the $d$-band of the $\mathrm{Pd} 4 d$ level in the valence band region is shifted to higher binding energies the more zinc is contained in the compound (Fig. 11), which is in agreement to the UHV investigations of Tsai et al. ${ }^{[125]}$. The shift is explained by the increasing number of valence electrons due to the increasing zinc content and leads to a lower density of states (DOS) near the Fermi energy. Besides, investigation of the Pd3d core level 
region showed that the peak shape of the intermetallic palladium signal $\left(\mathrm{Pd}_{\mathrm{IMC}}\right)$ became much more symmetric compared to the asymmetric peak shapes usually observed for elemental palladium $^{[126]}$.

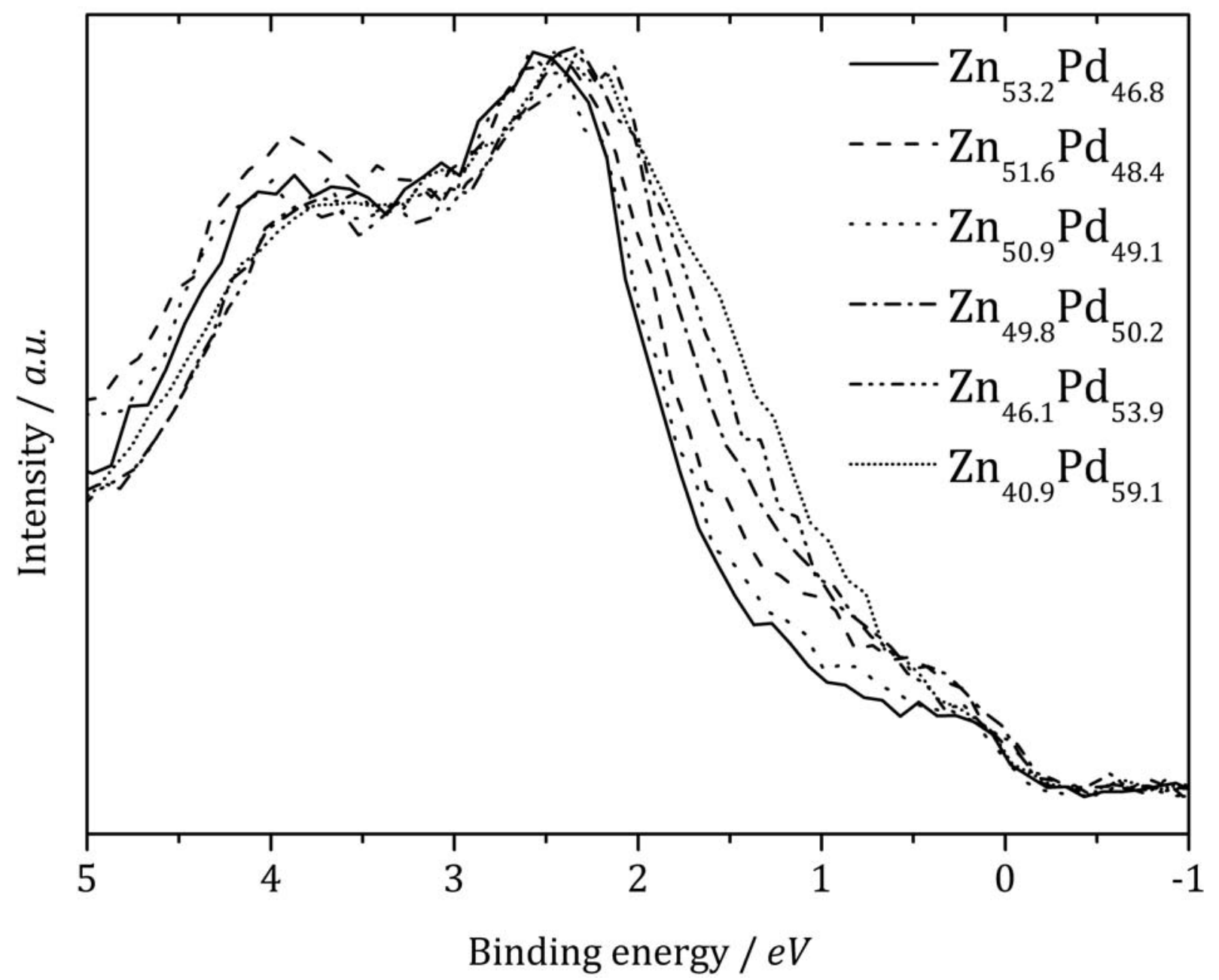

Figure 11: XPS valence band region of $Z n_{100-x} P d_{x}$ samples with different compositions under MSR conditions (0.2 mbar, $\left.\mathrm{H}_{2} \mathrm{O}: \mathrm{MeOH}=2: 1\right)$. Reproduced from ${ }^{[62]}$.

Unsupported $\mathrm{ZnPd}$ particles were also prepared on the submicron and the nano scale by either an aerosol-based synthesis with subsequent reduction or a wet-chemical precipitation method, respectively ${ }^{[65 ; 127]}$. Characterization of the resulting metallic powders by XPS in UHV revealed a Pd3d signal at $335.7 \mathrm{eV}$ for the submicron powders and ca. $335 \mathrm{eV}$ for the nanoparticles. Comparing these values to the ones obtained for the bulk materials over the whole homogeneity range of $\mathrm{ZnPd}$, it is doubtful whether the formation of the intermetallic compound could be achieved in the latter case. 
With the knowledge about the intrinsic electronic properties, the observations on supported materials can be brought into larger context. Before $\mathrm{Pd} / \mathrm{ZnO}$ was recognized as a promising precursor for highly-selective methanol steam reforming catalysts, its reduction behavior was studied by XPS and AES ${ }^{[32 ; 33 ; 128]}$. The essential information of the performed studies was the formation of the intermetallic compound $\mathrm{ZnPd}$ on the support in $\mathrm{H}_{2}$ atmospheres, accompanied by a shift to lower binding energy than PdO, but still higher than elemental Pd.

Iwasa et al. investigated the stepwise reduction of $\mathrm{Pd} / \mathrm{ZnO}$ ( $\mathrm{Pd}$ loading 10 wt.-\%) to $\mathrm{ZnPd} / \mathrm{ZnO}$ via $\mathrm{PdO} / \mathrm{ZnO}$ by XPS measurements ${ }^{[88 ; 129]}$. Figure 12 shows the Pd3d core level region during the hydrogen pretreatment, clearly allowing discrimination of three different palladium signals that are assigned to elemental palladium, $\mathrm{PdO}$ and the intermetallic compound $\mathrm{ZnPd}$. Nevertheless, the provided resolution and the resulting peak widths do not allow for detection of peak asymmetry or contribution of minor species (i.e. as small shoulders). While the signal for elemental palladium is reported at ca. $335 \mathrm{eV}$, the formation of the intermetallic compound is accompanied by a shift of the signal by $0.6 \mathrm{eV}$ to higher binding energy.

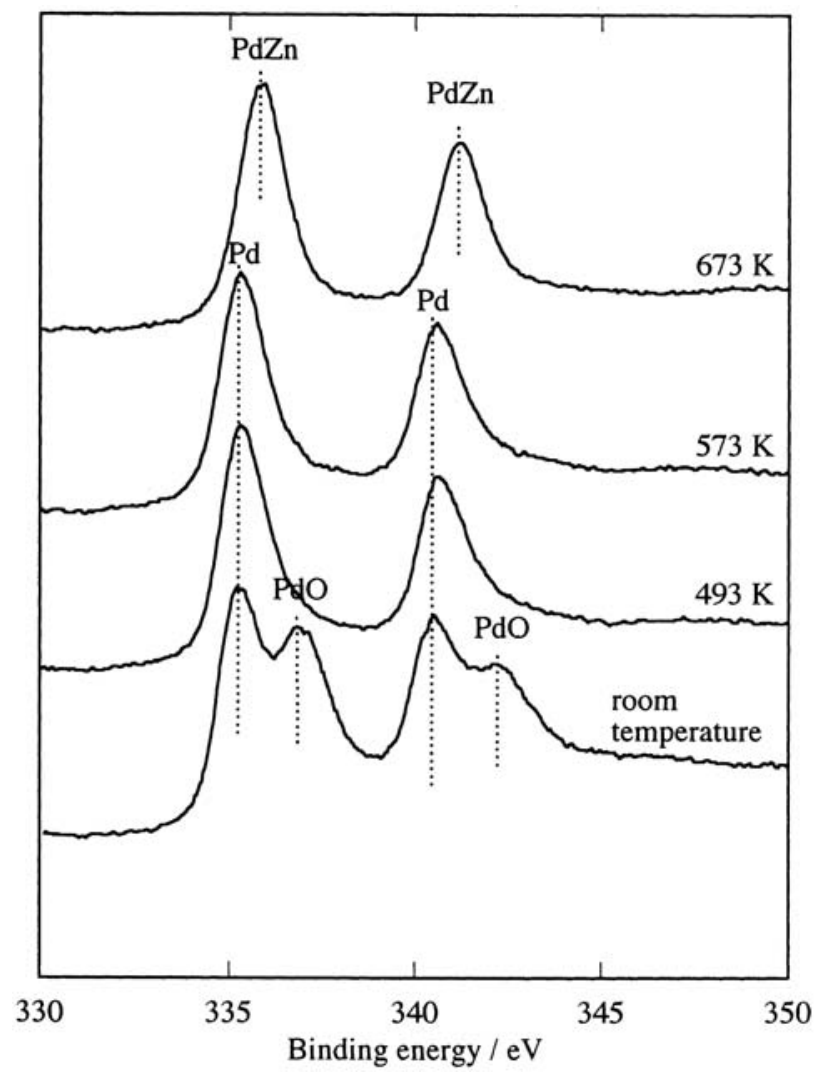

Figure 12: XP spectra of $\mathrm{Pd} / \mathrm{ZnO}$ after reduction in 4\% $\mathrm{H}_{2}$ at different temperatures. Reduction temperatures of the catalysts are indicated in the figure. (Reproduced from ${ }^{[88]}$ ). 
The main differences between conventionally supported nanoparticles and the near-surface intermetallic phases or surface alloys used in many UHV investigations are the thin nature of the NSIPs and the conductivity of the supporting crystal such as $\mathrm{Pd}(111)$. Since $\mathrm{ZnPd}$ is also an electronic conductor, the underlying palladium can influence the electronic structure of the NSIP. The preparation of Pd-Zn surface alloys was first reported by Rodriguez, who deposited zinc and palladium onto a $\mathrm{Ru}(001)$ single crystal ${ }^{[103]}$. The recorded valence band spectra show the difference between the alloyed surface and pure palladium by showing less intensity at the Fermi edge (Fig. 13), in agreement with the other Pd-Zn materials. Both DFT bulk calculations ${ }^{[61]}$ and UPS results ${ }^{[101]}$ have shown that the valence band of the ZnPd NSIP resembles that of $\mathrm{Cu}(111)$, in terms of relative energy, band width and DOS at the Fermi level. The valence band properties of the NSIP are additionally influenced by the Pd4d states. As a result of NSIP formation, the DOS at the Fermi level reduces significantly and the Pd4d states are shifted to higher binding energies compared to pure palladium metal and coincide with the relative position of the $\mathrm{Cu} 3 d$ states. The binding energy of the $\operatorname{Pd} 3 d$ signal is reported to increase the more zinc is contained in the surface layers: For a $\mathrm{Zn}: \mathrm{Pd}$ ratio of 0.9 , the shift compared to elemental palladium is +0.62 $\mathrm{eV}$, which is very similar to the value reported for $\mathrm{ZnPd} / \mathrm{ZnO}$ (see also ${ }^{[124]}$ and Fig. 12). Nevertheless, CO temperature desorption spectroscopy (TDS) gave hints for strong zinc enrichment in the topmost surface layer ${ }^{[103]}$. 

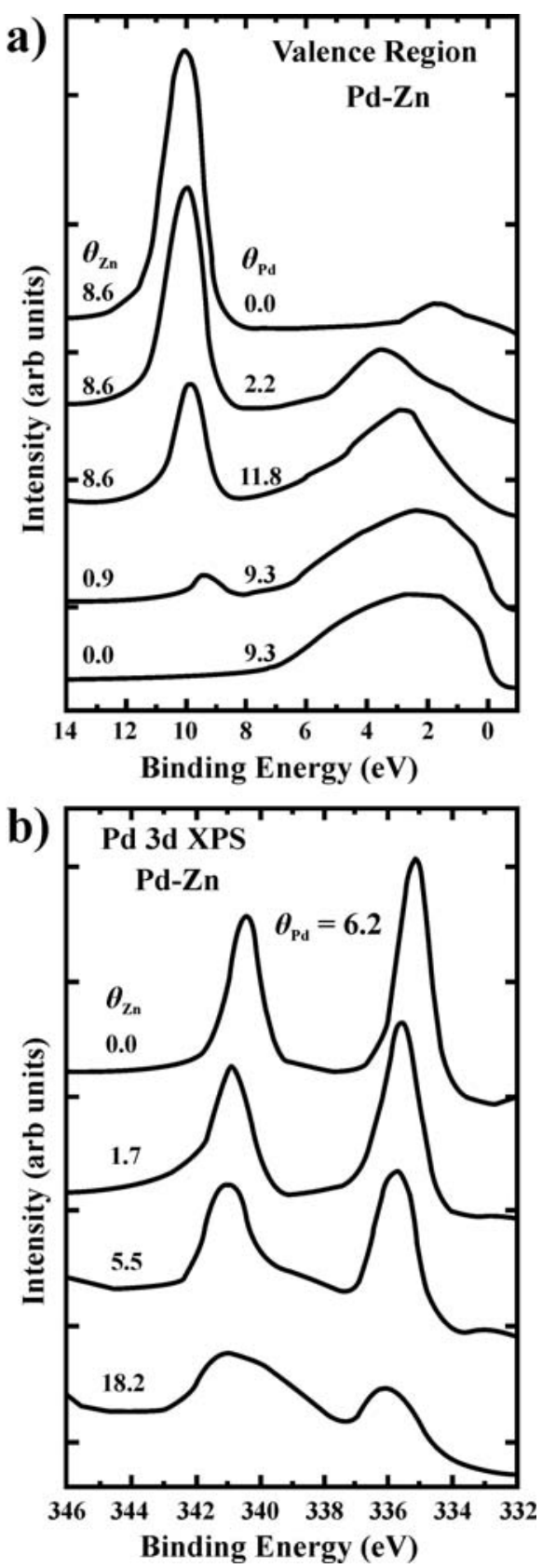

Figure 13: a) Valence photoemission spectra of a zinc multilayer (top), a palladium multilayer (bottom), and Pd-Zn NSIPs. b) Pd3d XPS spectra of a palladium multilayer (top) and Pd-Zn NSIPs. In these experiments, the coverage ( $\theta$ ) of palladium was $6.2 \mathrm{ML}$. All spectra were acquired at $300 \mathrm{~K}$ after vapor depositing palladium and zinc on the Ru(001) substrate at $350 \mathrm{~K}$. The electrons were excited using $\mathrm{Mg}$ Ka radiation. Redrawn from ${ }^{[103]}$.

Recently, zinc deposited on Pd(111) and Pd(110) surfaces (Pd-Zn NSIPs), were investigated in several studies with respect to their thickness, structure and thermal stability using surface- 
sensitive analysis methods like LEIS, XPS, AES, LEED, STEM, ICISS and TDS $[101 ; 107 ; 108 ; 110 ; 112 ; 113 ; 116]$. XPS studies proved that the shift of the binding energy and the shape of the Pd3d signal are strongly dependent on the composition of the NSIP and its thickness. The latter one is responsible for electronic influence or electronic isolation from the palladium substrate. Hence, Pd3d binding energies of 335.5 - 336.5 eV are observed for palladium located in the NSIP.

It can be concluded that the above-mentioned $\mathrm{Pd}-\mathrm{Zn}$ materials reveal different electronic properties, visible from valence band as well as core level spectra. The reason lies a) in the composition of the materials and $b$ ) in the synthesis and handling of these materials under certain conditions. Thus, it is hard to extract electronic properties of the bare $\mathrm{ZnPd}$, because the materials are influenced by either elemental palladium (e.g. in surface alloys and supported $\mathrm{ZnPd}$ ) or $\mathrm{ZnO}$ (in supported $\mathrm{ZnPd}$ ). Unsupported samples prepared by metallurgical methods reveal a strong dependence of the intrinsic electronic properties on the composition. Higher zinc contents lead to a shift to higher binding energies for the Pd3d signals $(336.2$ to $336.6 \mathrm{eV}$, photon energy $=$ $1162 \mathrm{eV}$ ) as well as lower intensity at the Fermi level in comparison to elemental palladium ${ }^{[62]}$. Supported as well as unsupported nanoparticulate materials can be synthesized to show a similar shift of the Pd3d signals, while in the NSIPs the corresponding shift is only $+0.62 \mathrm{eV}$ for a $\mathrm{Zn}$ to Pd ratio of about $0.9^{[103]}$. Besides the shift, formation of the $\mathrm{ZnPd}$ is also accompanied by symmetric Pd3d signals. Single crystals of $\mathrm{ZnPd}$ would be suitable to reduce these influences to a minimum, but the challenging synthesis is still preventing the availability of large specimen.

\section{4.b) Magnetic properties}

Only very little data exists on magnetic properties of $\mathrm{ZnPd}$ materials, nevertheless this might help to identify the intermetallic compound by corresponding measurements. Armbrüster investigated parts of the $\mathrm{Pd}-\mathrm{Zn}$ phase diagram, including $\mathrm{ZnPd}$ at an equimolar composition, by means of SQUID measurements ${ }^{[46]}$. Therein, the magnetic susceptibility of $\mathrm{ZnPd}$ is $-1.52 \times 10^{-2}$ $\mathrm{cm}^{3} \mathrm{~mol}^{-1}$. Being strongly diamagnetic, which is in line with earlier reports ${ }^{[45]}$, indicates a large fraction of paired electrons in the compound, which results from the covalent bonding (see below). For comparison, the magnetic susceptibilities of elemental zinc and palladium are $1.15 \times 10^{-4} \mathrm{~cm}^{3} \mathrm{~mol}^{-1}$ and $6.79 \times 10^{-3} \mathrm{~cm}^{3} \mathrm{~mol}^{-1}$, respectively ${ }^{[130]}$. Very recently, Nozawa et al. also investigated the magnetic properties of the intermetallic compound $\mathrm{ZnPd}$, along with $\mathrm{CdPd}$, $\mathrm{ZnNi}, \mathrm{ZnPt}$ and elemental $\mathrm{Pd}^{[125]}$. Exhibiting diamagnetism, $\mathrm{ZnPd}$ is similar to $\mathrm{Cu}$, which served 
as strong evidence for the authors to explain the alike $\mathrm{CO}_{2}$ selectivities of $\mathrm{Cu}$ and $\mathrm{ZnPd}$ in methanol steam reforming.

4.c) Thermodynamic properties

Thermodynamic properties have been investigated for unsupported bulk compounds in the PdZn system [50;51;56;57]. Kou and Chiang applied isopiestic methods to determine the thermodynamic activities of zinc in the Pd-Zn system in the range of 50-58 at.-\%, and thus calculated an enthalpy of formation of $-100.4 \mathrm{kJmol}^{-1}$ for $\mathrm{ZnPd}{ }^{[56 ; 57]}$. Follow-up work extended the measurements of the zinc vapor pressures by isopiestic methods during the synthesis to the range of $0-83$ at.- $\%$ and allowed the determination of the activities of zinc and palladium in the samples [50;51]. The observation of discontinuities of the activities in the investigated compositional range was interpreted as phase boundaries at the respective temperatures (Fig. 14), which have been considered when drawing the revised phase diagram in Fig. 2. The computational description of the partial molar Gibbs energy and enthalpy confirmed the experimentally determined data sets.

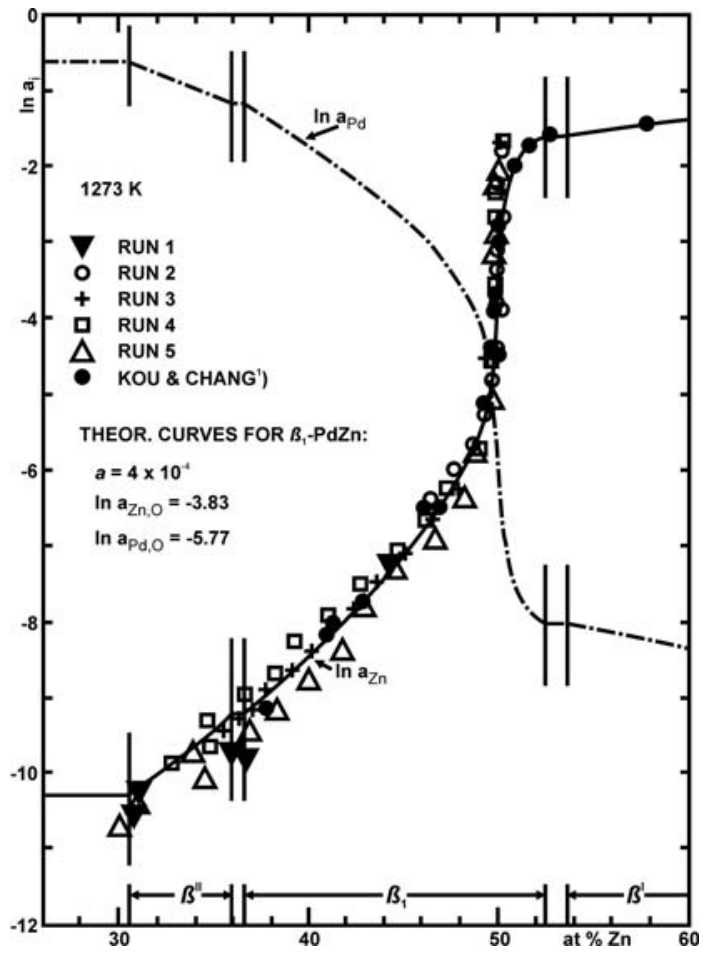

Figure 14: Activities (ln a) of zinc and palladium between 30 and 60 at.-\% zinc at $1273 \mathrm{~K}$ with experimental data points. The $\beta_{1}$ phase corresponds to the tetragonal compound (CuAu type of crystal structure). Redrawn from ${ }^{[51]}$. 


\section{4.d) Chemical bonding}

Chemical bonding in the intermetallic compound $\mathrm{ZnPd}$ has been a subject of debate for many decades, in particular in the context of the tetragonal distortion of the cubic crystal structure of binary compounds exhibiting the CuAu-type of crystal structure. Johansson and Linde were the first to discuss the formation of the tetragonal lattice by ascribing the reason for the distortion to the different atomic radii of copper and gold ${ }^{[131]}$. This argument was challenged by Schubert, who screened a lot of binary compounds possessing the respective crystal structure, showing that there is no linear correlation between the axis ratio and the ratio of the atomic radii ${ }^{[132]}$. Wang and Iwasaki provided high-pressure data on $\mathrm{CuAu}$ which assigned only a minor contribution of the atomic size ratio to the driving force for tetragonal distortion ${ }^{[133]}$. Other suggestions, like the preference of atom $A$ to be surrounded by as many as possible atoms $B$ like in $\mathrm{ZnNi}^{[132]}$ or the formation of new Brillouin zones due to the distortion to accommodate electrons in an energetically favored manner ${ }^{[134]}$, were invalidated by the existence of counter-examples. Schubert's own model of the Ortskorrelation tried to explain the tetragonal structure by the contribution of a certain number of valence electrons of each atom to stabilize the crystal structure $^{[132]}$. Neumann et al. analyzed ZnPd and other Pd- and Pt-based compounds (CuAu-type of crystal structure) and concluded that the tetragonal distortion of these phases is related to the contribution of ionic bonding, resulting in an electron transfer from zinc to palladium in $\mathrm{ZnPd}{ }^{[58]}$. However, this is contradictory since ionic bonding should favor the more isotropic CsCl-type of crystal structure due to the non-directional forces. Electron transfer from zinc to palladium was also suggested by Kou and Chang, who examined the thermodynamic behavior of the tetragonal ZnPd phase and found it to be highly stable ${ }^{[56]}$. Both Schubert ${ }^{[132]}$ and Neumann et al. ${ }^{[58]}$ suggested that a single argument is not sufficient to explain the tetragonal distortion of all the representatives of the CsCl-type.

First quantum chemical calculations concerning the chemical bonding were performed on the CuAu-type compound TiAl, which was found to exhibit covalently bonded titanium $4^{4}$ nets in the structure that were held responsible for the tetragonal distortion ${ }^{[135 ; 136]}$. Quantum chemical calculations on the chemical bonding in bulk ZnPd were performed by Friedrich et al. ${ }^{[40]}$. Calculation of the DOS (Fig. 15) and total energy calculations of both the tetragonal lowtemperature and the cubic high-temperature modification revealed first hints of the instability of the cubic structure compared to the tetragonal structure due to a local maximum in the DOS close to the Fermi energy of the cubic structure. Analysis of the chemical bonding by means of the 
electron localizability indicator (ELI) identified direct Pd-Pd interactions in the (001) plane to be the main reason for the tetragonal distortion (Fig. 16). In general, Pd-Zn as well as Pd-Pd interactions contained covalent contributions, mostly present as multi-center bonding. Furthermore, the charge transfer was quantified to be 0.4 electrons from zinc to palladium, which is in line with the electronegativities of $\mathrm{Zn} \mathrm{(1.65)} \mathrm{and} \mathrm{Pd}(2.20)$ according to Pauling, but is in contradiction to calculations on a diatomic ZnPd molecule, showing a small charge transfer from palladium to zinc ${ }^{[103]}$. The chemical bonding analysis thus results in a similar type of bonding as in TiAl, with palladium atoms forming $4^{4}$ nets in the (001) plane. These nets are connected to the interjacent zinc layers by covalent as well as ionic interactions.

While ELI calculations indicate the presence of covalent bonding in the structure, they do not provide information on the strength of the interactions. Pressure dependent determination of the lattice parameters of a $\mathrm{Zn}_{47} \mathrm{Pd}_{53}$ sample up to $24 \mathrm{GPa}$ reveal a higher compressibility along the $a$ axis compared to the $c$ axis up to $10 \mathrm{GPa}{ }^{[137]}$. Further increasing the pressure causes no change to the $c / a$ ratio. Since the structure is build up by homoatomic "layers" stacked along $c$, it can be concluded that the heteroatomic interactions are harder to compress than the homoatomic ones. The chemical bonding within $\mathrm{ZnPd}$ is thus best described as rather weak covalent homoatomic Pd-Pd interactions, while the mixed ionic and covalent interactions between palladium and zinc lead to the higher stiffness along the $c$ axis. 


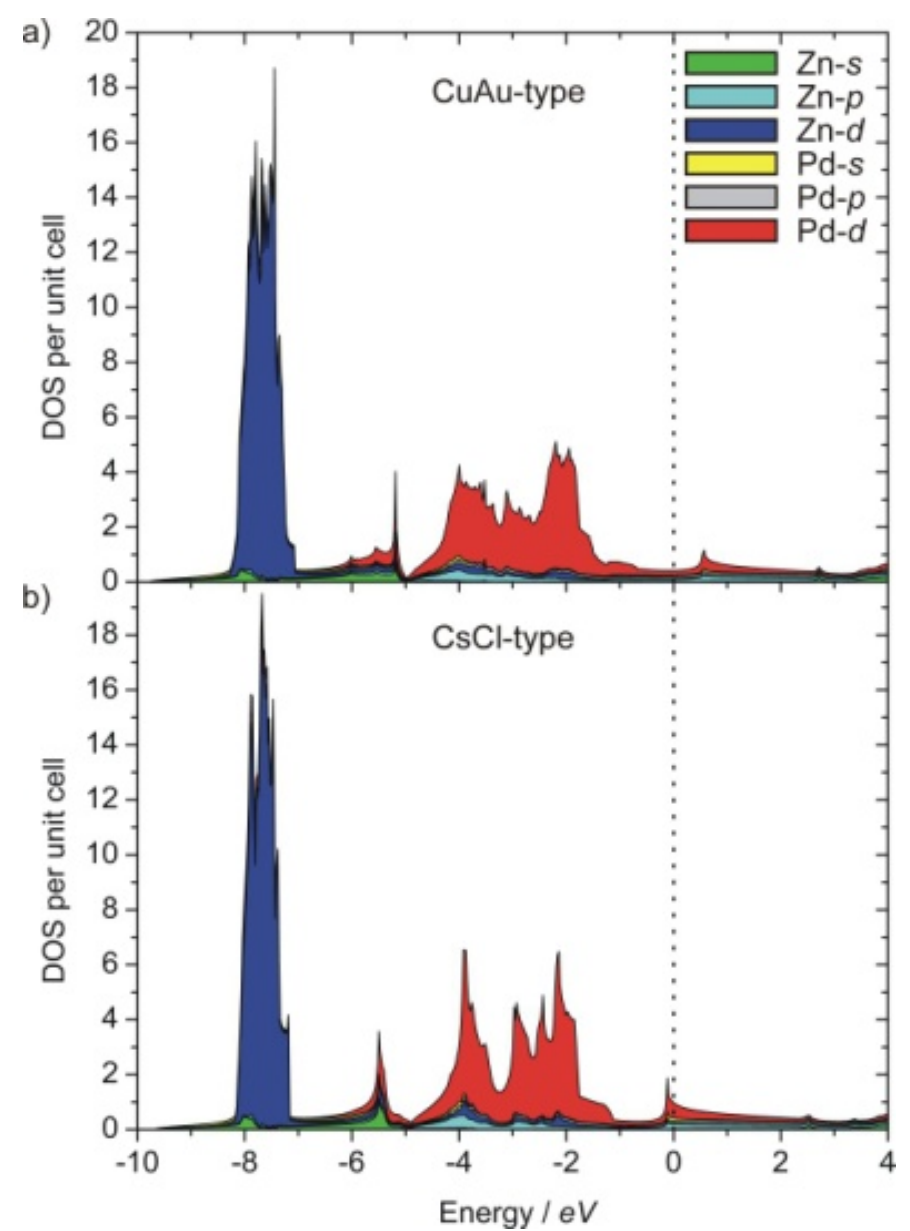

Figure 15: Total and partial electronic DOS for a) tetragonal ZnPd (CuAu type of structure) and b) cubic ZnPd (CsCl type of structure) as obtained by TB-LMTO-ASA. Significant differences around the Fermi edge are obvious (image taken from ref. ${ }^{[40]}$ ). 


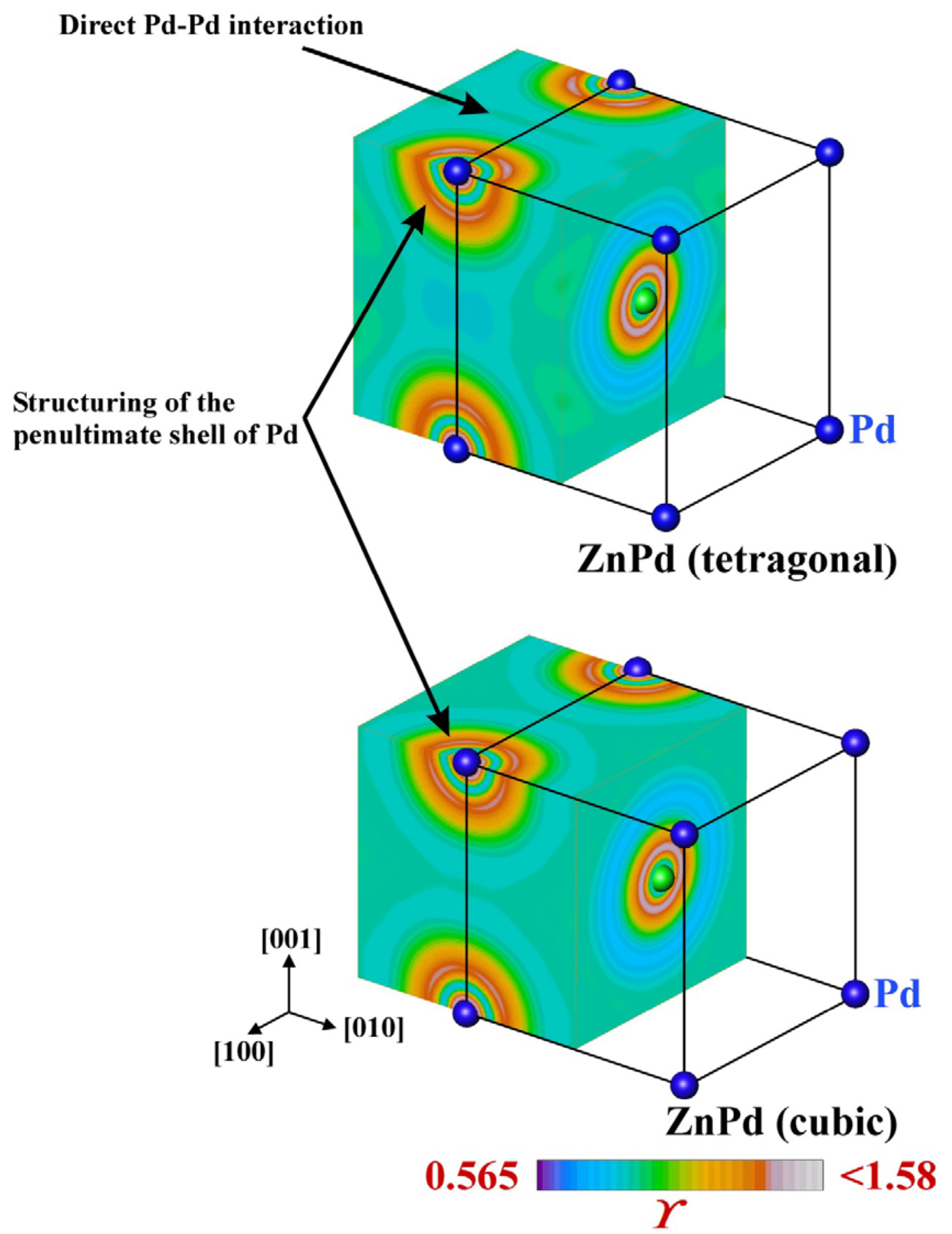

Figure 16: Chemical bonding in ZnPd: (top) ELI distribution in the (100), (010) and (001) planes in tetragonal ZnPd shows strong structuring of the penultimate shell of palladium in the (001) plane as well as small ELI maxima between palladium atoms along [100]. (bottom) ELI distribution in the (100), (010) and (001) planes in cubic ZnPd shows weaker structuring of the penultimate shell in all three directions (image reproduced form ${ }^{[40]}$ ). 


\section{4.e) Adsorption properties}

The chemical properties of the surface of the intermetallic compound $\mathrm{ZnPd}$ are very different from elemental palladium and zinc which form the compound. The large differences are due to the strongly modified electronic and crystal structure, turning each intermetallic compound with its unique adsorption properties into a "new element" with respect to its catalytic properties. The factors that determine the surface chemical properties, and thus the catalytic properties, of $\mathrm{ZnPd}$ are of significance and are characterized by chemisorption of simple probe molecules such as carbon monoxide (CO) in combination with suitable analytical techniques, like vibrational spectroscopy. For example, the CO adsorbed infrared (IR) spectroscopy probes the vibrational mode of $\mathrm{CO}$ that is sensitive to the electronic and geometric structure of the adsorption site on a metal surface and hence provides information to which extent the $\mathrm{CO}$ molecule is perturbed. The spectroscopic signature of the vibrational frequency of the adsorbed $\mathrm{CO}$ molecule (with respect to the gaseous CO molecule stretching frequency $2143 \mathrm{~cm}^{-1}{ }^{[138]}$ ) can be understood by a simple molecular orbital approach. This involves an electron transfer from the anti-bonding $\mathrm{CO} \sigma^{*}-$ orbital to the $s$ - or $p$-orbitals of the metal and back donation from the metal $d$-states to the antibonding $\pi^{*}$-orbital of $\mathrm{CO}{ }^{[139-141]}$. The former strengthens the $\mathrm{C}-\mathrm{O}$ bond while the latter weakens the bond. Often a progressive shift of the $\mathrm{CO}$ stretching frequency to higher wave numbers is observed upon increasing the surface coverage. This effect is attributed to lateral dipole-dipole interactions between the adsorbed $\mathrm{CO}$ molecules and its absence indicates isolated adsorption sites ${ }^{[142]}$. Such studies have been performed by a variety of vibrational spectroscopic techniques such as diffuse reflectance IR spectroscopy (DRIFTS), reflection absorption infrared spectroscopy (RAIRS), sum frequency generation spectroscopy (SFGS) and high resolution electron energy loss spectroscopy (HREELS). Among these techniques, DRIFTS is commonly used for studying high surface area supported palladium and ZnPd catalysts, while RAIRS, SFGS and HREELS are employed for characterizing palladium single crystal surfaces and ZnPd NSIPs. Besides, temperature programmed desorption of CO (CO-TPD) is also widely applied to understand the surface chemical properties of the intermetallic compounds.

The relevant DRIFTS studies on supported monometallic palladium and intermetallic ZnPd catalysts are summarized in Table 3. From these studies, three main $\mathrm{C}-\mathrm{O}$ stretching frequency regions can be identified depending on the number of palladium atoms involved in the interaction with the $\mathrm{CO}$ molecule. They are assigned to (i) $v\left(\mathrm{CO}_{\mathrm{L}}\right)=2060-2090 \mathrm{~cm}^{-1}$ : linearly (on-top) 
adsorbed CO molecules on to a single palladium atom; (ii) $v\left(\mathrm{CO}_{\mathrm{B}}\right)=1920-2000 \mathrm{~cm}^{-1}$ : $\mathrm{CO}$ molecules bridging two palladium atoms; and (iii) $v\left(\mathrm{CO}_{\mathrm{H}}\right)=1800-1920 \mathrm{~cm}^{-1}$ : CO molecules adsorbed on three-fold hollow palladium sites. Collectively, these CO stretching frequencies reflect the surface structure of supported palladium nanoparticles ${ }^{[143-145]}$.

Table 3: CO-DRIFTS data of supported palladium and ZnPd catalysts.

\begin{tabular}{|c|c|c|c|c|c|c|c|}
\hline Catalyst & $\begin{array}{l}\mathrm{Pd} \\
\mathrm{wt} \%\end{array}$ & $\begin{array}{l}\mathrm{Pd} \\
\text { particle } \\
\text { size / nm }\end{array}$ & $\begin{array}{l}\text { Pretreatment } \\
\text { with } \mathrm{H}_{2} / \mathrm{K}\end{array}$ & $v\left(\mathrm{CO}_{\mathrm{L}}\right)$ & $v\left(\mathrm{CO}_{\mathrm{B}}\right)$ & $v\left(\mathrm{CO}_{\mathrm{H}}\right)$ & Ref. \\
\hline $\mathrm{Pd} / \mathrm{Al}_{2} \mathrm{O}_{3}$ & $\begin{array}{l}0.93 \\
7.3 \\
2.5 \\
\end{array}$ & $\begin{array}{l}1.2 \\
8.5 \\
8-15 \\
\end{array}$ & $\begin{array}{l}473 \\
623 \\
\end{array}$ & $\begin{array}{l}2065 \\
2070 \\
\end{array}$ & $\begin{array}{l}1915 \\
1984 \\
1920 \\
\end{array}$ & $\begin{array}{l}1830 \\
1923\end{array}$ & $\begin{array}{l}{[145]} \\
{[145]} \\
{[83]} \\
\end{array}$ \\
\hline $\mathrm{Pd} / \mathrm{ZnO}$ & 7.5 & 30 & $\begin{array}{l}303 \\
623\end{array}$ & $\begin{array}{l}2090 \\
2074\end{array}$ & 1995 & & $\begin{array}{l}83] \\
{[83]} \\
\end{array}$ \\
\hline $\begin{array}{l}\mathrm{Pd} / \mathrm{ZnO} / \mathrm{Al}_{2} \mathrm{O}_{3} \\
\mathrm{ZnPd} / \mathrm{ZnO} / \mathrm{Al}_{2} \mathrm{O}_{3}\end{array}$ & 8.8 & $\begin{array}{l}2.5 \\
3.7 \\
\end{array}$ & $\begin{array}{l}300 \\
693 \\
\end{array}$ & $\begin{array}{l}2065 \\
2076 \\
\end{array}$ & 1985 & & $\begin{array}{l}{[82]} \\
{[82]} \\
\end{array}$ \\
\hline $\mathrm{ZnPd} / \mathrm{ZnO} / \mathrm{Al}_{2} \mathrm{O}_{3}$ & 8.8 & & $\begin{array}{l}300 \\
773 \\
\end{array}$ & $\begin{array}{l}2069 \\
2071 \\
\end{array}$ & 1975 & & $\begin{array}{l}{[146]} \\
{[146]}\end{array}$ \\
\hline $\begin{array}{l}\mathrm{Pd} / \mathrm{CeO}_{2} / \mathrm{ZrO}_{2} \\
\mathrm{ZnPd} / \mathrm{CeO}_{2} / \mathrm{ZrO}_{2}\end{array}$ & 1 & & 523 & $\begin{array}{l}2069 \\
2062 \\
\end{array}$ & 1958 & 1898 & $\begin{array}{l}{[147]} \\
{[147]}\end{array}$ \\
\hline
\end{tabular}

Palladium particles with a size of around $30 \mathrm{~nm}$ supported on $\mathrm{ZnO}$ exhibit striking differences in the $\mathrm{CO}$ stretching frequencies as a function of reductive pretreatment temperature due to the formation of the intermetallic compound $\mathrm{ZnPd}^{\left[{ }^{[83]}\right.}$ (see also Figure 17 and Table 3).

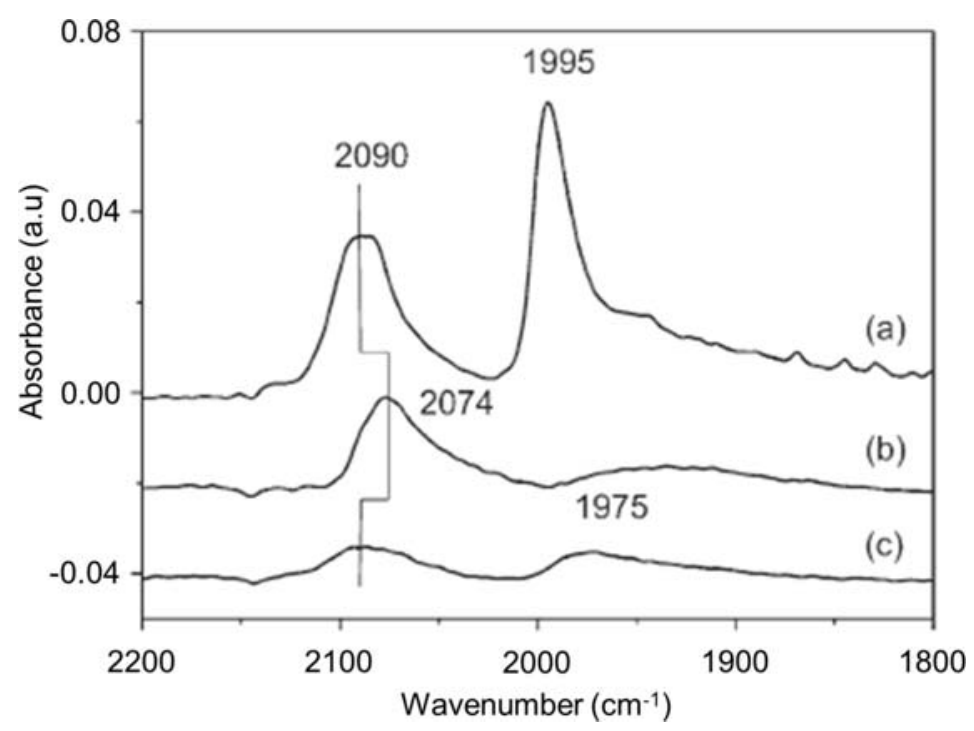

Figure 17: CO adsorbed FTIR spectra of Pd/ZnO. CO adsorption was performed at 303 $\mathrm{K}$ at 5 mbar $\mathrm{CO}$ after different pretreatments: a) after reduction at $303 \mathrm{~K}$, b) after reduction at $623 \mathrm{~K}$, and d) after oxidation at $573 \mathrm{~K}$ followed by reduction at $303 \mathrm{~K}$. From $^{\text {[83]. }}$ 
After reductive pretreatment at room temperature, the catalyst exhibits bands $v\left(\mathrm{CO}_{\mathrm{L}}\right)$ and $v\left(\mathrm{CO}_{\mathrm{B}}\right)$ at 2090 and $1995 \mathrm{~cm}^{-1}$, respectively. These two CO stretching frequencies are similar to the ones observed on monometallic $\mathrm{Pd} / \mathrm{Al}_{2} \mathrm{O}_{3}$. In a marked contrast, the same catalyst after reductive pretreatment at $623 \mathrm{~K}$ shows only $v\left(\mathrm{CO}_{\mathrm{L}}\right)$ band at $2074 \mathrm{~cm}^{-1}$. The $\mathrm{CO}$ stretching frequency of $v\left(\mathrm{CO}_{\mathrm{L}}\right)$ band is red-shifted by $16 \mathrm{~cm}^{-1}$ compared to the catalyst after reductive pretreatment at room temperature. These results suggest modified electronic and thus chemical properties of the palladium sites in the $\mathrm{Pd} / \mathrm{ZnO}$ catalyst after reductive pretreatment at $623 \mathrm{~K}$, in accordance with the formation of the intermetallic compound ZnPd ${ }^{[83 ; 148]}$. Transforming palladium into the intermetallic compound by RMSI results in a) an ordered crystal structure and b) a strongly modified electronic structure. This is markedly different to alloy formation, where atoms are randomly distributed on the crystallographic positions of the majority component and hence changes to the electronic structure are small and gradual. In terms of surface properties two main effects can be observed: i) an ensemble effect and ii) an electronic effect ${ }^{[149 ; 150]}$. The first effect leads to the formation of only linearly adsorbed CO molecules on the surface - if the compound formation is complete - by the site-isolation of the palladium atoms in $\mathrm{ZnPd}$ with a Pd-Pd distance of $2.891 \AA^{[83]}$. The second effect decreases the $\mathrm{C}-\mathrm{O}$ bond strength which results in the decreased $v\left(\mathrm{CO}_{\mathrm{L}}\right)$. This can be understood by the transfer of 0.4 electrons (compare section 4.d)) from zinc to palladium upon $\mathrm{ZnPd}$ formation. This increases the back donation of electrons from palladium to the antibonding $\pi^{*}$-state of the $\mathrm{C}-\mathrm{O}$ bond, thus weakening the bond.

Likewise, reductive-pretreatment temperature dependent behavior of $\mathrm{CO}$ stretching frequencies was also observed for a $\mathrm{Pd} / \mathrm{ZnO} / \mathrm{Al}_{2} \mathrm{O}_{3}$ catalyst which is similar to the composition of a commercial methanol steam reforming catalyst ${ }^{[82]}$. After reductive pretreatment at room temperature, the catalyst shows $v\left(\mathrm{CO}_{\mathrm{L}}\right)$ and $v\left(\mathrm{CO}_{\mathrm{B}}\right)$ at 2065 and $1985 \mathrm{~cm}^{-1}$, respectively ${ }^{[82]}$. The $\mathrm{CO}$ stretching frequencies of these two bands are different from that reported for $\mathrm{Pd} / \mathrm{ZnO}$, however these frequencies are often observed for monometallic palladium supported on $\mathrm{Al}_{2} \mathrm{O}_{3}$ (Table 3). The observed differences in the $\mathrm{CO}$ stretching frequencies on $\mathrm{Pd} / \mathrm{ZnO} / \mathrm{Al}_{2} \mathrm{O}_{3}$ and $\mathrm{Pd} / \mathrm{ZnO}$ can be attributed to the particle size ${ }^{[145]}$ and/or to the support effects ${ }^{[151]}$. When the reductive pretreatment was conducted at $693 \mathrm{~K}$, the catalyst exhibits only the $v\left(\mathrm{CO}_{\mathrm{L}}\right)$ band at $2076 \mathrm{~cm}^{-1}$ which is typically assigned to the formation of the intermetallic compound $\mathrm{ZnPd}$. A similar behavior was observed by reduction of $\mathrm{Pd} / \mathrm{ZnO} / \mathrm{Al}_{2} \mathrm{O}_{3}$ at room temperature and at $773 \mathrm{~K}$ to obtain monometallic palladium and the intermetallic compound $\mathrm{ZnPd}$, respectively ${ }^{[146]}$. The 
characteristic $v\left(\mathrm{CO}_{\mathrm{L}}\right)$ band at $2071 \mathrm{~cm}^{-1}$ was observed after formation of the intermetallic compound $\mathrm{ZnPd}$, whereas both $v\left(\mathrm{CO}_{\mathrm{L}}\right)$ and $v\left(\mathrm{CO}_{\mathrm{B}}\right)$ were reported for the elemental palladium catalyst. Similarly, the influence of $\mathrm{ZnPd}$ formation on the $\mathrm{CO}$ stretching frequencies on $\mathrm{Pd} / \mathrm{CeO}_{2} / \mathrm{ZrO}_{2}$ and $\mathrm{ZnPd} / \mathrm{CeO}_{2} / \mathrm{ZrO}_{2}$ is reported in ${ }^{[147]}$. The reported $\mathrm{CO}$ stretching frequencies are, in general, in good agreement with other studies on different catalysts summarized in Table 3. The monometallic $\mathrm{Pd} / \mathrm{CeO}_{2} / \mathrm{ZrO}_{2}$ shows $v\left(\mathrm{CO}_{\mathrm{L}}\right), v\left(\mathrm{CO}_{\mathrm{B}}\right)$ and $v\left(\mathrm{CO}_{\mathrm{H}}\right)$ at 2069,1958 and 1898 $\mathrm{cm}^{-1}$, respectively. Whereas, the intermetallic compound $\mathrm{ZnPd}$ on $\mathrm{CeO}_{2} / \mathrm{ZrO}_{2}$ exhibits only a single $v\left(\mathrm{CO}_{\mathrm{L}}\right)$ at $2062 \mathrm{~cm}^{-1}$. These reported differences in the $\mathrm{CO}$ stretching frequencies for $v\left(\mathrm{CO}_{\mathrm{L}}\right)\left(2062-2076 \mathrm{~cm}^{-1}\right)$ between the two catalysts may result from different electronic and hence surface chemical surface properties of $\mathrm{ZnPd}$. These might be either result of the different supports or variation in the electronic structure of $\mathrm{ZnPd}$ due to the composition as discussed in section 4.a).

This question is approached by vibrational studies performed on ZnPd NSIPs in comparison to palladium single crystals by RAIRS, SFGS and HREELS. While an oxide support is absent in these experiments, one still has to consider a possible influence of the underlying palladium single crystal on the ZnPd NSIPs. One also has to keep in mind that the applied experimental conditions such as temperature and equilibrium pressure are largely different from those discussed above for the supported palladium and ZnPd catalysts by DRIFTS. The evolution of $\mathrm{CO}$ stretching frequencies on model $\mathrm{Pd}(h k l)$ single crystals is dependent, under given experimental conditions, on the surface coverage as reported in several publications ${ }^{[140 ; 142 ; 152 ; 153]}$ (Figure 18). 


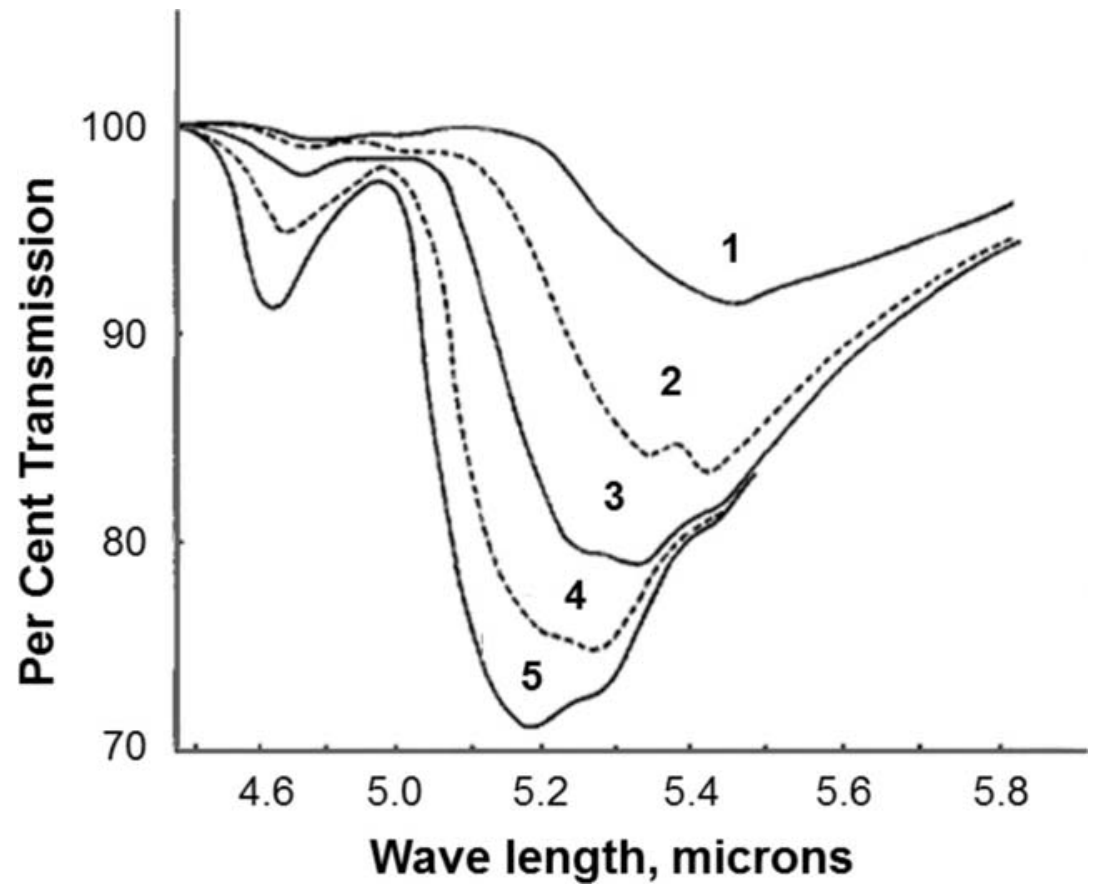

Figure 18: IR spectra of CO chemisorbed on Pd as a function of surface coverage. The surface CO coverage increases in the same order as the number. From ${ }^{[142]}$.

At the lowest $\mathrm{CO}$ coverages, $\mathrm{CO}$ primarily occupies a hollow site of $\operatorname{Pd}(111)$ surface exhibiting a distinctly low $v\left(\mathrm{CO}_{\mathrm{H}}\right)$ of around $1850 \mathrm{~cm}^{-1}$. Upon increasing the $\mathrm{CO}$ coverage from low to intermediate levels, more complex vibrational spectra are reported. At the saturation $\mathrm{CO}$ coverage, $\mathrm{CO}$ mainly occupies on-top and hollow sites giving rise to vibrational bands at around 2110 and $1895 \mathrm{~cm}^{-1}$, respectively ${ }^{[140 ; 152 ; 153]}$. By comparison, the evolution of CO structures is less complicated on $\mathrm{Pd}(100)$ surface as it exhibits only bridge bound $\mathrm{CO}$ adsorption in the entire surface coverage range (from the lowest to the saturation coverage). However, the stretching frequency of the band $v\left(\mathrm{CO}_{\mathrm{B}}\right)$ continuously increases from around $1895 \mathrm{~cm}^{-1}$ to $1995 \mathrm{~cm}^{-1}$ upon increasing the coverage ${ }^{[140 ; 152 ; 153]}$. By comparing the $\mathrm{CO}$ adsorbed polarization-modulation (PM)-RAIR spectra of Pd(111) single crystal and the ZnPd NSIP SA-1, marked differences in the CO stretching frequencies are also observed between the two surfaces ${ }^{[102]}$. At $195 \mathrm{~K}$ and comparable CO pressures, $\mathrm{Pd}(111)$ surface exhibits mainly bridge bound CO at $1946 \mathrm{~cm}^{-1}$, while the $\mathrm{ZnPd} \mathrm{SA-1}$ with a $\mathrm{p}(2 \mathrm{x} 1)$ structure shows a single CO stretching frequency at $2070 \mathrm{~cm}^{-1}$ attributable to $v\left(\mathrm{CO}_{\mathrm{L}}\right)$. Coverage dependent spectra were recently reported ${ }^{[154]}$. At low $\mathrm{CO}$ coverage $(100 \mathrm{~K}, 0.1 \mathrm{~L})$ a broad band at $2048 \mathrm{~cm}^{-1}$ and a sharper band at $2068 \mathrm{~cm}^{-1}$ were detected. The latter dominates the spectra at high coverage, while the band at $2048 \mathrm{~cm}^{-1}$ 
disappeared at $10 \mathrm{~L} \mathrm{CO}$ dosage. These frequencies were attributed to adsorbed $\mathrm{CO}$ species without $\left(2048 \mathrm{~cm}^{-1}\right)$ and with $\left(2068 \mathrm{~cm}^{-1}\right) \mathrm{CO}$ molecules on adjacent adsorption sites. The different frequencies arise from dipole-dipole interactions and reduced back donation from the metal at higher coverages. This is in accordance with the supported intermetallic ZnPd catalysts discussed above. Such surface structure sensitive spectral features are also evident from the spectra taken after annealing the ZnPd NSIP at $673 \mathrm{~K}$ (under either $1 \times 10^{-6}$ mbar or 5 mbar $\mathrm{CO}$ ) where decomposition of the ZnPd NSIP takes place ${ }^{[114 ; 119]}$. The corresponding spectra show mainly two bands at around $2080 \mathrm{~cm}^{-1}$ and $1950 \mathrm{~cm}^{-1}$ associated to on-top and bridge bound CO. This is identical to the spectrum of a $\operatorname{Pd}(111)$ single-crystalline surface taken at a CO-coverage of around $0.7^{[140 ; 155]}$. These results indicate that the decomposition of the ZnPd NSIPs lead to the exposure of the bulk Pd(111) surface ${ }^{[102 ; 114 ; 119]}$. They qualitatively agree with CO adsorbed vibrational sum frequency generation spectroscopy (SFGS) data ${ }^{[156 ; 157]}$. The studies show that vibrational frequency of $\mathrm{CO}$ is sensitive to the surface morphology of $\operatorname{Pd}(111)$ single crystal or supported palladium nanoparticles surface, revealing intrinsic differences in the chemical properties of the surface palladium sites on the two surfaces. It is noteworthy that, in general, the difference between the relative intensities of the bridge bound and on-top adsorbed $\mathrm{CO}$ bands is more significant in SFGS as compared to in RAIRS. It appears that SFGS underestimates the bridge bound $\mathrm{CO}$, especially $\mathrm{CO}$ adsorbed on a hollow site. These differences between the vibrational spectra of SFGS and RAIRS can be attributed to the different selection rules of the techniques ${ }^{[155-157]}$.

Another class of studies dedicated to understand the surface chemical properties of $\operatorname{Pd}(111)$ single crystals and ZnPd NSIPs are based upon high resolution electron energy loss spectroscopy (HREELS). In line with the above discussion, the bonding configuration of CO on the $\mathrm{Pd}(111)$ surface is dependent on the surface coverage and temperature. For example, at $100 \mathrm{~K}$ the evolution of $\mathrm{CO}$ bonding configuration is a function of surface coverage. At lower CO coverage, $\mathrm{CO}$ preferentially adsorbs on the hollow site as reflected by a peak $v\left(\mathrm{CO}_{\mathrm{H}}\right)$ at $1860 \mathrm{~cm}^{-1}$. At or above the saturation coverage, an additional signal evolves at $2090 \mathrm{~cm}^{-1}$ and is attributed to $v\left(\mathrm{CO}_{\mathrm{L}}\right)$. Interestingly at $300 \mathrm{~K}$ and at any $\mathrm{CO}$-coverage, only the signal $v\left(\mathrm{CO}_{\mathrm{B}}\right)$ of bridge bound CO was observed ${ }^{[111]}$. The CO stretching frequency of this band shifts from 1885 to $1910 \mathrm{~cm}^{-1}$ with the lowest to the highest coverage, respectively. However, this is not always the case. For instance, SFG spectra of CO adsorbed on Pd(111) surface at $300 \mathrm{~K}$ show almost both bridge and on-top bound $\mathrm{CO}$ configuration in a wide range of surface coverage ${ }^{[157]}$, which is comparable to 
the one reported by RAIRS ${ }^{[143]}$. Such differences in the CO adsorption configuration on the model Pd(111) crystals can be attributed to the different surface structure of palladium sites and hence to their chemical properties. Based on the CO adsorbed HREELS of $\operatorname{Pd}(111)$, the influence of zinc coverage on $\mathrm{Pd}(111)$ surface properties was investigated at constant temperature $(100 \mathrm{~K})$ and CO pressure $(0.5 \mathrm{~L})^{[111 ; 158]}$. With increasing zinc coverage, two main observations can be made from the corresponding $\mathrm{CO}$ adsorbed HREELS: (i) CO bonding configuration gradually changes from the hollow site on the clean $\operatorname{Pd}(111)$ surface to on-top sites after depositing 0.5 and $0.8 \mathrm{ML}$ of $\mathrm{Zn}$ on the $\mathrm{Pd}(111)$ surface and (ii) the total intensity of the CO bands decreases. The former confirms that the local chemical environment of palladium sites changes upon zinc coverage due to the formation of the NSIP SA-1 after annealing at $550 \mathrm{~K}$. The strong geometrical and electronic changes of the surface upon NSIP formation are likely to influence the CO sticking coefficient - which may result in the decreased CO band intensity. This has been the subject of debate as shown in the following by summarizing temperature programmed desorption of $\mathrm{CO}$ on ZnPd materials.

CO-TPD is a widely used technique to study the number, strength, nature and distribution of surface palladium adsorption sites. The clean $\operatorname{Pd}(111)$ single crystal surface is often compared with the surface of ZnPd NSIPs for better understanding of the ZnPd chemical surface properties in relation to the elemental $\mathrm{Pd}(111)$ surface. In some reports, bulk $\mathrm{Pd}(111)$ exhibits a broad CO desorption peak between 300 and $520 \mathrm{~K}$ with a maximum at around $480 \mathrm{~K}^{[103 ; 110]}$. The broad band may indicate the heterogeneity of the surface sites which is also evident from the $\mathrm{CO}$ adsorbed vibration spectroscopy of some $\operatorname{Pd}(111)$ surfaces as discussed above ${ }^{[157]}$. Differently, a narrower $\mathrm{CO}$ desorption peak between 420 and $520 \mathrm{~K}$ with a maximum at around $480 \mathrm{~K}$ was also reported on $\mathrm{Pd}(111)$ surface implying a higher degree of homogeneity of the surface sites ${ }^{[111]}$. This is evident from the CO adsorbed HREELS of the same $\operatorname{Pd}(111)$ surface that shows, under these experimental conditions, only the hollow site bound CO configuration ${ }^{[111]}$. By increasing the zinc coverage on the $\mathrm{Pd}(111)$ surface from 0 to $1 \mathrm{ML}$ at $300 \mathrm{~K}$, the CO desorption profile passes through a complex series of signals (Figure 19). 


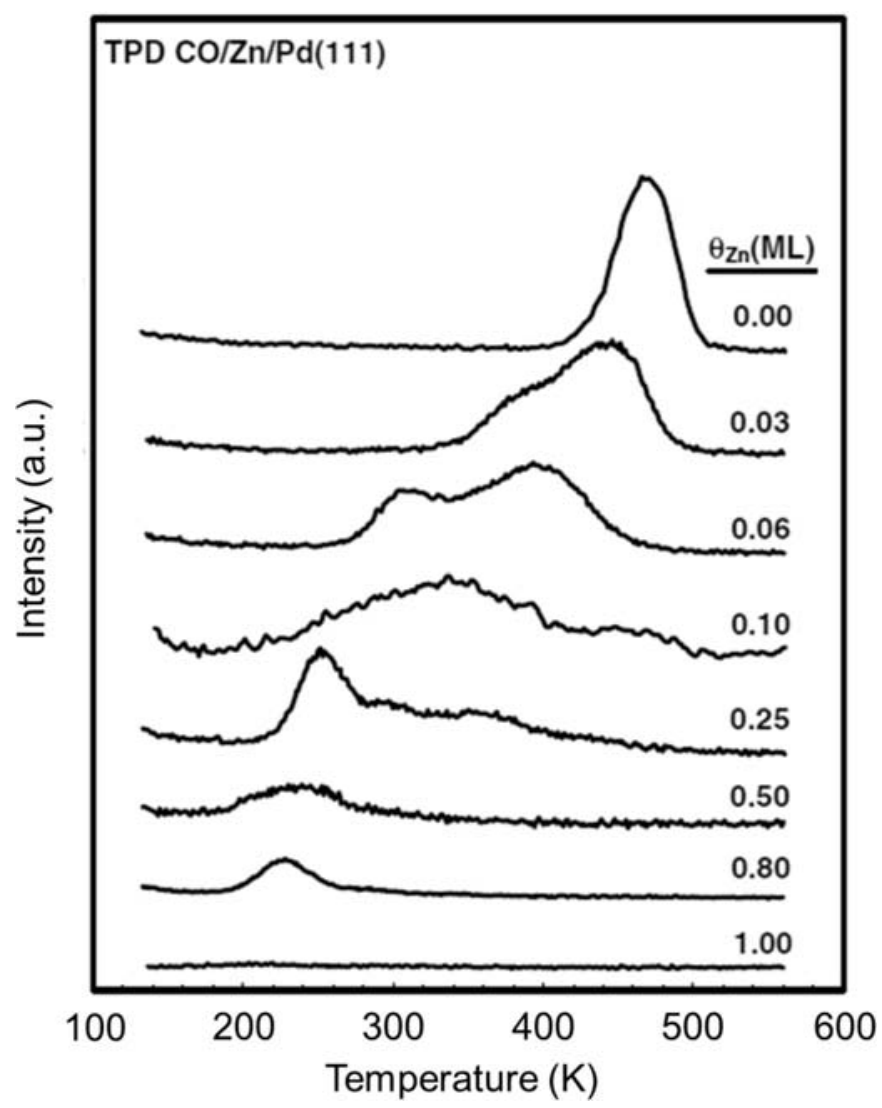

Figure 19: CO TPD profiles of $\mathrm{Zn} / \mathrm{Pd}(111)$ as a function of $\mathrm{Zn}$ coverage. From ${ }^{\text {[111]. }}$

This indicates the formation of $\mathrm{Pd}-\mathrm{CO}$ bonds with different strengths as a function of zinc coverage, in line with vibrational spectroscopy investigations [111;140;152;153]. At low zinc coverages, the main $\mathrm{CO}$ desorption peak at around $480 \mathrm{~K}$ decreases in intensity and a new peak at around $360 \mathrm{~K}$ appears as a shoulder to the main peak. With increasing zinc coverage, the high temperature peak diminishes and a low temperature peak establishes. This suggests that the strength of the Pd-CO bond decreases on the surface of the ZnPd NSIPs compared to that on the $\operatorname{Pd}(111)$ surface ${ }^{[103 ; 111]}$. Specifically, it was reported that the bond is around $67 \mathrm{kJmol}^{-1}$ weaker on the $\mathrm{ZnPd} \mathrm{p}(2 \mathrm{x} 1) \mathrm{SA}-2$ surface than on the clean $\mathrm{Pd}(111)$ surface ${ }^{[103]}$. Consequently, a typical $\mathrm{CO}$ desorption peak on the surface of the ZnPd SA-2 was found at around $220 \mathrm{~K}{ }^{[103 ; 111]}$. It should be noted that the $\mathrm{CO}$ uptake decreases with increasing zinc coverage. These observations are in agreement with the vibrational spectroscopy results ${ }^{[111 ; 158]}$. A single $\mathrm{C}-\mathrm{O}$ frequency of $\mathrm{CO}$ adsorbed either on a hollow site of the Pd(111) surface or on an on-top site of the ZnPd surface of the NSIP SA-2 was observed under ideal conditions ${ }^{[111 ; 158]}$. Therefore, the high temperature CO desorption peak at around $480 \mathrm{~K}$ observed on the $\operatorname{Pd}(111)$ surface is attributed to the most stable 
$\mathrm{CO}$ species which is adsorbed on a hollow site. The CO desorption peak at around $220 \mathrm{~K}$ of the ZnPd SA-2 is assigned to the on-top adsorbed CO species observed by vibrational spectroscopy. In a very recent work $\mathrm{CO}$ coverages and binding energies were determined from CO TPD spectra and compared to the results of DFT calculations ${ }^{[154]}$. The saturation coverage on $\mathrm{ZnPd} / \mathrm{Pd}(111)$ (multilayer) was $0.5 \mathrm{ML}$. Desorption energies of $58-68 \mathrm{kJmol}^{-1}$ at saturation coverage were obtained from both experimental data and from DFT calculations, in very good agreement.

In summary, vibrational spectroscopy (DRIFTS, RAIRS, SFGS and HREELS) on CO adsorbed on supported ZnPd nanoparticles and ZnPd NSIPs in combination with TPD provides precise knowledge of the surface chemical properties of the intermetallic ZnPd surfaces. A strong modification of the adsorption properties of $\operatorname{Pd}(111)$ is observed when it reacts with zinc and forms $\mathrm{ZnPd}$ near-surface intermetallic phases. In contrast to $\mathrm{CO}$, experimental studies using other small molecules are scarce. According to Kuanyshev et al. unsupported ZnPd bounds hydrogen more strongly than palladium black ${ }^{[159]}$. While hydrogen desorbs completely from palladium black above $473 \mathrm{~K}$, temperatures above $773 \mathrm{~K}$ are needed to desorb hydrogen from ZnPd. The dramatic change in the adsorption properties of $\mathrm{Pd}$ upon interaction with $\mathrm{Zn}$ by $\mathrm{ZnPd}$ formation also led to numerous theoretical studies to understand the underlying mechanism. The calculated adsorption energies of $\mathrm{C}, \mathrm{H}$ and $\mathrm{O}$ atoms as well as molecules involved in MSR are presented in Table 4. 
Table 4: Calculated adsorption energies (eV) of various species relevant to MSR in the most stable adsorption sites.

\begin{tabular}{|c|c|c|c|c|c|c|c|c|}
\hline & $\operatorname{ZnPd}(111)$ & $\mathrm{ZnPd}(100)$ & $\mathrm{ZnPd}(221)^{\mathrm{Pd}}$ & $\mathrm{ZnPd}(221)^{\mathrm{Zn}}$ & $\begin{array}{l}\text { ZnPd NSIP } \\
\text { SA-1 }\end{array}$ & $\begin{array}{l}\text { ZnPd NSIP } \\
\text { SA-2 }\end{array}$ & $\begin{array}{c}1 \mathrm{ML} \\
\mathrm{ZnPd}(221)^{\mathrm{Zn}}\end{array}$ & $\begin{array}{c}1 \mathrm{ML} \\
\mathrm{ZnPd}(221)^{\mathrm{Pd}}\end{array}$ \\
\hline $\mathrm{C}$ & $\begin{array}{c}\mathrm{H}^{\mathrm{ZnPd} 2} \\
448 \\
{[150 ; 160]}\end{array}$ & & & & & & & \\
\hline $\mathrm{H}$ & $\begin{array}{c}\mathrm{H}^{\mathrm{ZnPd} 2} \\
241-249 \\
{[150 ; 160 ; 161]}\end{array}$ & $\begin{array}{c}\mathrm{H}^{\mathrm{ZnPd} 2} \\
231-237 \\
{[150 ; 161 ; 162]} \\
4 \mathrm{H}^{\mathrm{Zn} 2 \mathrm{Pd} 2} \\
231 \\
{[150 ; 162]} \\
\\
\mathrm{B}^{\mathrm{Pd}} \\
236 \\
{[161]}\end{array}$ & $\begin{array}{c}\text { step }^{\mathrm{Pd} 2} \\
253 \\
{[150 ; 163 ; 164]}\end{array}$ & $\begin{array}{c}\mathrm{H}^{\mathrm{ZnPd} 2} \\
229 \\
{[150 ; 164]}\end{array}$ & & & & \\
\hline $\mathrm{O}$ & $\begin{array}{c}\mathrm{H}^{\mathrm{Zn} 2 \mathrm{Pd}} \\
449 \\
{[150 ; 160]}\end{array}$ & $\begin{array}{c}4 \mathrm{H}^{\mathrm{Zn} 2 \mathrm{Pd} 2} \\
458 \\
{[150 ; 162]}\end{array}$ & $\begin{array}{c}\mathrm{H}^{\mathrm{Zn} 2 \mathrm{Pd}} \\
407 \\
{[150 ; 163 ; 164]}\end{array}$ & $\begin{array}{c}\mathrm{H}^{\mathrm{Zn} 2 \mathrm{Pd}} \\
472 \\
{[150 ; 164]}\end{array}$ & & & & \\
\hline $\mathrm{CO}$ & $\begin{array}{c}\mathrm{T}^{\mathrm{Pd}} \\
96 \\
{[150 ; 160]} \\
\\
\mathrm{B}^{\mathrm{Pd}} \\
96 \\
{[160]}\end{array}$ & & $\begin{array}{c}\mathrm{T}^{\mathrm{Pd}} \\
124 \\
{[163 ; 164]} \\
\mathrm{B}^{\mathrm{Pd}} \\
120 \\
{[163 ; 164]}\end{array}$ & & $\begin{array}{l}\mathrm{B}^{\mathrm{Pd}} \\
160 \\
{[165]}\end{array}$ & $\begin{array}{l}\mathrm{B}^{\mathrm{Pd}} \\
151 \\
{[166]}\end{array}$ & & \\
\hline $\mathrm{H}_{2} \mathrm{O}$ & $\begin{array}{c}\mathrm{B}^{\mathrm{ZnPd}} \\
24 \\
{[161]}\end{array}$ & $\begin{array}{l}\mathrm{T}^{\mathrm{Zn}} \\
22 \\
{[161]}\end{array}$ & $\begin{array}{c}\text { step// } \\
47 \\
{[167]}\end{array}$ & $\begin{array}{l}\text { step// } \\
35 \\
{[167]}\end{array}$ & $\begin{array}{c}\mathrm{T}^{\mathrm{Pd}} \\
19 \\
{[167]}\end{array}$ & $\begin{array}{c}\mathrm{T}^{\mathrm{Pd}} \\
19 \\
{[166]}\end{array}$ & $\begin{array}{c}\text { step// } \\
34 \\
{[167]}\end{array}$ & $\begin{array}{c}\text { step// } \\
41 \\
{[167]}\end{array}$ \\
\hline
\end{tabular}




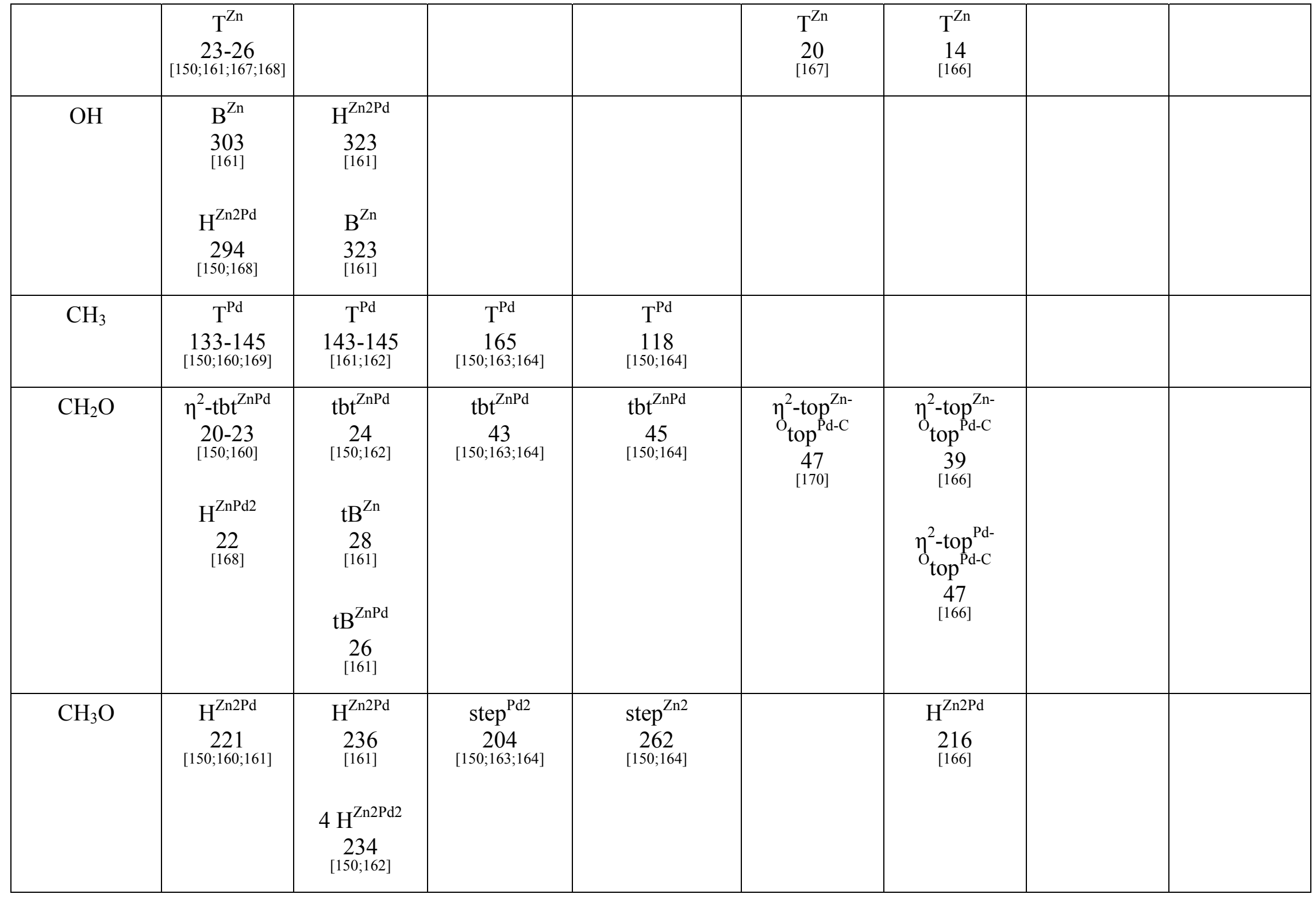




\begin{tabular}{|c|c|c|c|c|c|c|c|c|}
\hline $\mathrm{CH}_{3} \mathrm{OH}$ & $\begin{array}{c}\mathrm{T}^{\mathrm{Zn}} \\
31 \\
{[161]}\end{array}$ & $\begin{array}{c}\mathrm{B}^{\mathrm{ZnPd}} \\
20 \\
{[161]}\end{array}$ & & $\begin{array}{c}\mathrm{ST}^{\mathrm{Zn}} \\
41 \\
{[161]}\end{array}$ & $\begin{array}{c}\mathrm{T}^{\mathrm{Zn}} \\
23 \\
{[170]}\end{array}$ & $\begin{array}{c}\mathrm{T}^{\mathrm{Zn}} \\
24 \\
{[166]}\end{array}$ & & \\
\hline $\mathrm{CHO}$ & $\begin{array}{c}\eta^{2}-\mathrm{tbt}^{\mathrm{ZnPd}} \\
167 \\
{[150 ; 163]}\end{array}$ & & $\begin{array}{c}\eta^{2}-\text { tbt }^{\mathrm{Pd} 2} \\
186 \\
{[150 ; 163 ; 164]}\end{array}$ & & $\begin{array}{c}\eta^{2}-\mathrm{C}-\eta^{1}-\mathrm{O} \\
230 \\
{[170]}\end{array}$ & & & \\
\hline $\mathrm{CHO}_{2}$ & $\begin{array}{c}\mathrm{H}^{\mathrm{Zn} 2 \mathrm{Pd}} \\
257 \\
{[168]}\end{array}$ & & & & & $\begin{array}{c}\eta^{3(3 \mathrm{Zn})} \\
263 \\
{[109]}\end{array}$ & & \\
\hline $\mathrm{CH}_{2} \mathrm{OH}$ & $\begin{array}{c}\mathrm{tB}^{\mathrm{ZnPd}} \\
139 \\
{[161]}\end{array}$ & $\begin{array}{c}\mathrm{tB}^{\mathrm{ZnPd}} \\
149 \\
{[161]}\end{array}$ & & & & & & \\
\hline $\mathrm{CH}_{2} \mathrm{OOCH}_{3}$ & $\begin{array}{c}\mathrm{H}^{\mathrm{Zn} 2 \mathrm{Pd}} \\
214 \\
200^{\mathrm{Z}} \\
{[169]}\end{array}$ & & & & & & & \\
\hline $\mathrm{CHOOCH}_{3}$ & $\begin{array}{c}4 \mathrm{H}^{\mathrm{Zn} 2 \mathrm{Pd} 2} \\
14 \\
13^{\mathrm{Z}} \\
{[169]}\end{array}$ & & & & & & & \\
\hline $\mathrm{CHOOCH}_{2}$ & $\begin{array}{c}\eta^{2} \text {-top } \\
C_{\text {top }}^{\text {Zn-O }} \\
136 \\
126^{\mathrm{Z}} \\
{[169]}\end{array}$ & & & & & & & \\
\hline $\mathrm{CHOOHOCH}_{3}$ & $\begin{array}{c}\mathrm{H}^{\mathrm{Zn} 2 \mathrm{Pd}} \\
236-240 \\
225-229^{Z} \\
{[169]}\end{array}$ & & & & & & & \\
\hline
\end{tabular}


$\mathrm{B}^{\mathrm{Pd}}$ - Pd-rich bridge site (2-fold)

$\mathrm{B}^{\mathrm{Zn}}$ - Zn-rich bridge site (2-fold)

$\mathrm{B}^{\mathrm{ZnPd}}$ - bridge site between palladium and zinc

$\mathrm{H}^{\mathrm{Zn} 2 \mathrm{Pd}}$ - hollow site composed of two zinc and one palladium atom

$\mathrm{H}^{\mathrm{ZnPd} 2}$ - hollow site composed of one zinc and two palladium atoms

$\mathrm{ST}^{\mathrm{Zn}}$ - on top of a zinc atom at a step edge

step $^{\mathrm{Pd} 2}$ - bridge position at a step edge, bound to two edge palladium atoms

step $^{\mathrm{Zn} 2}$ - bridge position at a step edge, bound to two edge zinc atoms

step// - molecular plane is parallel to the step

$\mathrm{T}^{\mathrm{Pd}}-$ on top of a palladium atom

$\mathrm{T}^{\mathrm{Zn}}-$ on top of a zinc atom

$\mathrm{tB}^{\mathrm{Zn}}$ - top-bridged, oxygen atom bisects two zinc atoms in a $\mathrm{B}^{\mathrm{Zn}}$ site

$\mathrm{tB}^{\mathrm{ZnPd}}$ - top-bridged, oxygen is close to the zinc atom in a $\mathrm{B}^{\mathrm{ZnPd}}$ site

$\mathrm{tb}^{\mathrm{Pd} 2}$ - top-bridge-top configuration via two palladium atoms

$\mathrm{tbt}^{\mathrm{ZnPd}}$ - top-bridge-top configuration via one zinc and one palladium atom

$\mathrm{Z}-\mathrm{ZPE}$ corrected values 
Various models for bulk ZnPd or the surface alloys are considered. Most studies consider the (111) surface of bulk ZnPd ${ }^{[61 ; 150 ; 160 ; 161 ; 167 ; 168]}$, which is the most stable surface ${ }^{[61]}$. Few studies focus on the (100) surface ${ }^{[150 ; 161 ; 162]}$, that is almost as stable as the (111) surface ${ }^{[61]}$, showing comparable results for the calculated adsorption energies on the two surfaces. Some studies consider the ZnPd surface alloys, modeling the bilayer SA-1 ${ }^{[170]}$ or the monolayer SA-2 ${ }^{[109 ; 165]}$ on $\operatorname{Pd}(111)$. An essential point is that the binding energies on bulk $\mathrm{ZnPd}(111)$ are very similar to the ones on $\mathrm{Cu}(111)$, due to the comparable electronic structure of these two materials $[61 ; 150 ; 160 ; 163 ; 165]$ (for a detailed comparison between the $\mathrm{ZnPd}(111)$ and $\mathrm{Cu}(111)$, see Ref. ${ }^{[61]}$ ). The trends in the adsorption energies between $\mathrm{ZnPd}(111), \mathrm{Cu}(111)$ and $\mathrm{Pd}(111)$ can also be rationalized on the basis of the $d$-band center model ${ }^{[171]}$ : the binding energy (BE) of a carbon atom adsorbed at top sites ( $\mathrm{Pd}$ top site for $\mathrm{ZnPd}$ ) depends linearly on the position of the $d$-band center.

Molecules involved in the MSR interact with the surface via their carbon atom $\left(\mathrm{CO}, \mathrm{CH}_{3}\right)$, or oxygen atom $\left(\mathrm{OH}, \mathrm{CH}_{3} \mathrm{O}\right)$, or via both atoms. Atomic adsorption of $\mathrm{C}, \mathrm{H}$ and $\mathrm{O}$ on $\mathrm{ZnPd}(111)$ show that $\mathrm{C}$ and $\mathrm{H}$ interacts more with palladium than with $\mathrm{Zn}$, while $\mathrm{O}$ interacts more with zinc than with palladium ${ }^{[160]}$. In consequence, oxygen bonded molecules prefer $\mathrm{Zn}$-rich adsorption sites (bridge zinc or hollow $\mathrm{Zn}_{2} \mathrm{Pd}$ for $\mathrm{OH}$, hollow $\mathrm{Zn}_{2} \mathrm{Pd}$ for $\mathrm{CH}_{3} \mathrm{O}$ ) while carbon bonded molecules prefer Pd-rich sites (top or bridge palladium for $\mathrm{CO}$ and top palladium for $\mathrm{CH}_{3}$ ) [109;150;160;161;163-165;170]. Among the molecules involved in the MSR, $\mathrm{H}_{2} \mathrm{O}, \mathrm{CH}_{2} \mathrm{O}, \mathrm{CO}_{2}$ and $\mathrm{CH}_{3} \mathrm{OH}$ are weakly adsorbed, the $\mathrm{H}_{2} \mathrm{O}$ and $\mathrm{CH}_{2} \mathrm{O}$ molecules lying roughly parallel to the surface $[150 ; 165 ; 168]$. The $\mathrm{BE}$ of $\mathrm{H}_{2} \mathrm{O}, \mathrm{CH}_{2} \mathrm{O}, \mathrm{CO}_{2}, \mathrm{CH}_{3} \mathrm{OH}$ are evaluated to be less than $31 \mathrm{kJmol}^{-1}$ on all considered models for $\mathrm{ZnPd}\left(4 \mathrm{kJmol}^{-1}\right.$ for the $\mathrm{BE}$ of $\mathrm{CO}_{2}$ on $\left.\mathrm{ZnPd}(111)^{[168]}\right)$. Van der Waals interactions are predominant, there might then be differences between the calculated binding energy and the experimentally measured ones, because density functional theory gives poor description of dispersive forces. Although its $\mathrm{BE}$ is small, the interaction between the $\mathrm{CH}_{2} \mathrm{O}$ molecule and the surface has been demonstrated by density of state calculations: the DOS of the $\mathrm{C}$ and $\mathrm{O}$ atoms of formaldehyde bonded to the surface are quite different from the corresponding atoms in the gaseous molecule ${ }^{[109]}$. The situation is slightly different for the $\mathrm{CH}_{3} \mathrm{OH}$ molecule, for which the shape of the DOS of the adsorbed molecule is quite similar to the gaseous molecule ${ }^{[109]}$. On stepped surfaces, the binding energy of all these weakly adsorbed molecules increases (34 $\mathrm{kJmol}^{-1}<\mathrm{BE}<48 \mathrm{kJmol}^{-1}$ for $\mathrm{H}_{2} \mathrm{O}$ and $\mathrm{CH}_{2} \mathrm{O}$ molecules ${ }^{[163 ; 164 ; 167]}$, compare Table 4), highlighting that the geometry of the surface and the presence of surface defects might have an 
influence on the reactivity. The binding energies of the adsorbates may vary also with coverage: the adsorption energies of $\mathrm{H}, \mathrm{O}$ and $\mathrm{OH}$ were calculated at various coverages on a four-layer slab model of $(2 \times 3) \mathrm{PdZn}(111)$ showing a decrease with increasing surface coverage. For atomic oxygen, the adsorption energy varies between $-1 \mathrm{kJmol}^{-1}$ and $-143 \mathrm{kJmol}^{-1}$ when the coverage decreases from 1 to $1 / 6$. On the other hand, the adsorption energy of $\mathrm{H}_{2} \mathrm{O}$ on the same slab model is enhanced for a coverage of $2 / 3$, due to the formation of a $2 \mathrm{D}$ ice-like structure ${ }^{[172]}$. More complicated adsorbates were recently considered on $\mathrm{ZnPd}(111)$ following several suggestions in literature that methyl formate may play a role as intermediate ${ }^{[169]}$ (Table 4). In conclusion, the authors find it unlikely that methyl formate is an intermediate in the reaction due to the low binding energy of only $13 \mathrm{kJmol}^{-1}$.

In sections 3 and 4, we have seen that the atomic and the electronic structure of the $\mathrm{ZnPd}$ NSIPs depend on the thickness of the surface alloy. The adsorption properties are therefore affected by the thickness of the $\mathrm{ZnPd}$ surface alloy: for the $\mathrm{C}$-bonded molecules $\mathrm{CO}$ and $\mathrm{CH}_{2} \mathrm{O}$, the $\mathrm{BE}$ is higher for the surface alloy than for surfaces of bulk $\mathrm{ZnPd}$. This can be related to the influence of the subsurface on adsorption. This is also shown by the difference of $29 \mathrm{kJmol}^{-1}$ of the BE calculated for bulk ZnPd ${ }^{[160 ; 161 ; 168]}$ and the NSIP SA-1 ${ }^{[170]}$.

The influence of the surface zinc composition on the binding energies has further been studied by systematic $\mathrm{BE}$ evaluations for structural models containing various surface/subsurface zinc amounts ${ }^{[165 ; 170]}$. The interaction of the different adsorbates with the ZnPd metallic surface can be discussed in terms of an ensemble effect, associated with specific atomic arrangements of the substrate, and a ligand effect, associated with electronic effects by the neighbors of a surface atom that a given adsorbate binds to. In the case of the 1:1 $\mathrm{ZnPd}(111)$ surface, the ligand effect has been shown to be notably smaller than the corresponding ensemble effect $\left(30-54 \mathrm{kJmol}^{-1}\right.$ for atomic oxygen ${ }^{[160]}$ ). This ensemble effect is also highlighted by the variation of the BE of the $\mathrm{CH}_{3} \mathrm{O}$ molecule as a function of the surface zinc composition ${ }^{[170]}$ : for the $\mathrm{CH}_{3} \mathrm{O}$ molecule, that interacts with the surface via the oxygen atom, the BE increases linearly with the number of surface zinc atoms, in agreement with the statement that oxygen bonded molecules prefer $\mathrm{Zn}$-rich adsorption sites. For the $\mathrm{CH}_{2} \mathrm{O}$ and the $\mathrm{CHO}$ molecules, that bind to the substrate by both $\mathrm{C}$ and $\mathrm{O}$ atoms, the situation is different: the BE decreases linearly with the number of subsurface zinc atoms, meaning that the ensemble effect is not responsible for the variation of the $\mathrm{BE}$, and showing that subsurface zinc atoms have a non-negligible influence on the BE. In the same way, the influence of the surface zinc composition has been evaluated by systematic evaluation of 
energy barriers and exothermicities for structural models containing various surface/subsurface zinc amounts ${ }^{[170]}$. Increasing the surface zinc composition reduces the activation energy of $\mathrm{O}-\mathrm{H} / \mathrm{C}-\mathrm{H}$ bond breaking of $\mathrm{CH}_{3} \mathrm{OH} / \mathrm{CHO}$ while it raises the energy barriers of dehydrogenation of $\mathrm{CH}_{3} \mathrm{O}$ and $\mathrm{CH}_{2} \mathrm{O}{ }^{[170]}$.

It is worth noting that experimental studies are missing on metallurgically prepared and unsupported $\mathrm{ZnPd}$. This makes a quantitative correlation between the adsorption properties and the bulk composition difficult. The data retrieved from the different investigations are in accordance with an ordered surface containing only isolated palladium atoms. Nevertheless, the atomic surface structure of any of the materials remains so far unsolved. 


\section{Methanol steam reforming}

Catalytic studies were performed in three different types of reactors: unsupported and conventional supported catalysts were tested in plug-flow reactors, while the NSIPs were studied in a circulated batch reactor. In addition, several investigations employing microstructured reactors have been published with the aim of intensifying the steam reforming process for its future application.

\section{5.a) Unsupported ZnPd}

The idea to measure unsupported samples of the intermetallic compound $\mathrm{ZnPd}$ was created by Iwasa et al. in $2000^{[148]}$. Samples were prepared from the elements and contained some elemental palladium and a phase mixture of $\mathrm{ZnPd}$ and $\mathrm{Zn}_{6.1} \mathrm{Pd}_{3.9}$ ( $\mathrm{CsCl}$ type of structure) as detected by XRD. Before the catalytic tests, the sample was reduced in $4 \%$ hydrogen at $673 \mathrm{~K}$. The catalytic properties were tested at 1 bar total pressure in a methanol/water/nitrogen mixture (no information on the ratio given) with a weighted hourly space velocity (WHSV) of $7600 \mathrm{~h}^{-1}$. The sample reached the highest activity at $623 \mathrm{~K}$ (5\% conversion), while the selectivity increases with temperature even above $623 \mathrm{~K}$. The elemental palladium in the sample leads to decomposition of methanol to $\mathrm{CO}$ and hydrogen. Since the observed catalytic properties are a global property of the sample, i.e. correspond to the mixture of $\mathrm{ZnPd}, \mathrm{Zn}_{6.1} \mathrm{Pd}_{3.9}$ and elemental palladium, the rather low $\mathrm{CO}_{2}$-selectivities of less than $88 \%$ of the samples can be explained. The first measurements on single phase samples were reported by Tsai et al. ${ }^{[123 ; 125]}$ and are collated with other results in Table 5 . 
Table 5: Experimentally determined catalytic properties of the different materials

\begin{tabular}{|c|c|c|c|c|c|c|c|c|c|c|c|c|c|}
\hline Material & $\begin{array}{l}\text { Nominal } \\
\text { Zn:Pd } \\
\text { ratio }\end{array}$ & $\begin{array}{l}\text { Pd content } \\
\text { of } \mathrm{ZnPd} \mathrm{/} \\
\text { at } \%\end{array}$ & Pretreatment & $\begin{array}{l}\text { Phases } \\
\text { present }\end{array}$ & $\begin{array}{l}\text { Specific } \\
\text { surface } \\
\text { area } \\
\mathrm{m}^{2} \mathrm{~g}^{-1}\end{array}$ & $\begin{array}{l}\text { WHSV } \\
/ \mathrm{h}^{-1}\end{array}$ & $\begin{array}{l}\text { Conversion } \\
/ \%\end{array}$ & $\begin{array}{l}\text { Selectivity } \\
/ \%\end{array}$ & $\begin{array}{l}\mathrm{T} / \\
\mathrm{K}\end{array}$ & $\begin{array}{l}\text { Methanol:water:inert } \\
\text { gas ratio } \\
\text { (methanol:water) }\end{array}$ & $\begin{array}{l}\text { TOF } \\
/ \mathrm{s}^{-1} \\
\left(\mathrm{~T}{ }^{\prime} /\right. \\
\mathrm{K})^{\dagger}\end{array}$ & $\begin{array}{l}\mathrm{E}_{\mathrm{A}} \quad / \\
\mathrm{kJmol}^{-} \\
1\end{array}$ & Reference \\
\hline bulk & $50: 50$ & - & $\begin{array}{l}4 \% \mathrm{H}_{2}, 673 \\
\mathrm{~K} \quad \text { with } 5 \\
\mathrm{Kmin}^{-1}\end{array}$ & $\begin{array}{l}\mathrm{ZnPd}, \\
\mathrm{Pd}, \\
\mathrm{Zn}_{6.1} \mathrm{Pd}_{3.9}\end{array}$ & - & 7600 & 5 & 88 & 623 & - & - & - & $\begin{array}{l}{[148]} \\
\end{array}$ \\
\hline bulk & $50: 50$ & 49.7 & $\begin{array}{l}100 \% \quad \mathrm{H}_{2}, \\
513 \mathrm{~K}, 1 \mathrm{~h}\end{array}$ & $\mathrm{ZnPd}$ & $<0.05$ & $20^{*}$ & $5-10$ & 96 & 573 & 2.7:4.0:1.0 (1:1.5) & - & - & {$[123 ; 125]$} \\
\hline bulk & $50: 50$ & 51.6 & $\begin{array}{l}5 \% \mathrm{H}_{2}, 523 \\
\mathrm{~K}, 2 \mathrm{~h}\end{array}$ & $\begin{array}{l}\mathrm{ZnPd} \\
\mathrm{Zn}_{6.1} \mathrm{Pd}_{3.9}\end{array}$ & 5.9 & 10 & 25 & 98 & 523 & $1.6: 1.7: 1.0(1: 1.1)$ & $\begin{array}{l}0.12 \\
(503) \\
0.21 \\
(523) \\
\end{array}$ & 48 & [65] \\
\hline bulk & $\begin{array}{l}46.8 \\
48.4 \\
49.1 \\
50.2 \\
53.9 \\
59.1 \\
\end{array}$ & $\begin{array}{l}46.8 \\
48.4 \\
49.1 \\
50.2 \\
53.9 \\
59.1 \\
\end{array}$ & $\begin{array}{l}100 \% \quad \mathrm{H}_{2} \\
473 \mathrm{~K}, 1 \mathrm{~h}\end{array}$ & $\mathrm{ZnPd}$ & $\sim 0.03$ & $3-5$ & $\begin{array}{l}64 \\
69 \\
4 \\
7 \\
3 \\
1 \\
\end{array}$ & $\begin{array}{l}95.9 \\
94.6 \\
62.9 \\
25.0 \\
17.9 \\
11.7 \\
\end{array}$ & 773 & $1.2: 1.2: 1.0(1: 1)$ & - & $\begin{array}{l}51 \\
69 \\
89 \\
120 \\
\text { n.d. } \\
\text { n.d. }\end{array}$ & [62] \\
\hline $\mathrm{ZnPd} / \mathrm{ZnO}$ & $\begin{array}{ll}1 & \mathrm{wt} \% \\
\mathrm{Pd} & \\
\end{array}$ & - & - & - & - & - & - & 97 & 473 & $0.47: 0.47: 1.0(1: 1)$ & $\begin{array}{l}0.83 \\
(473)\end{array}$ & - & {$[10]$} \\
\hline $\mathrm{ZnPd} / \mathrm{ZnO}$ & $\begin{array}{ll}15 & \text { wt } \% \\
\mathrm{Pd} & \\
\end{array}$ & - & $\begin{array}{ll}100 \% & \mathrm{H}_{2}, \\
673 \mathrm{~K} & \end{array}$ & $\begin{array}{l}\mathrm{ZnPd}, \\
\mathrm{ZnO}, \mathrm{Pd}\end{array}$ & - & 3.4 & 67 & 96 & 523 & $3.25: 3.57: 1.0(1.1: 1)$ & - & - & [69] \\
\hline $\mathrm{ZnPd} / \mathrm{ZnO}$ & $\begin{array}{ll}10 & w t \% \\
P d & \\
\end{array}$ & - & $\begin{array}{ll}10 \% & \mathrm{H}_{2}, \\
698 \mathrm{~K} & \\
\end{array}$ & $\begin{array}{l}\mathrm{ZnPd}, \\
\mathrm{ZnO}\end{array}$ & - & $14400^{\S}$ & 73 & 98 & 548 & $1.07: 1.92: 1(1.8: 1)$ & - & - & $\begin{array}{l}688] \\
\end{array}$ \\
\hline $\mathrm{ZnPd} / \mathrm{ZnO}$ & $\begin{array}{ll}15 & \text { wt } \% \\
\mathrm{Pd} & \\
\end{array}$ & - & $\begin{array}{l}3 \% \mathrm{H}_{2}, 673 \\
\mathrm{~K}\end{array}$ & $\begin{array}{l}\mathrm{ZnPd}, \\
\mathrm{ZnO}\end{array}$ & - & 3.4 & 67 & 96 & 523 & $\begin{array}{l}3.25: 3.57: 1.0 \\
(1.0: 1.1)\end{array}$ & - & - & [77] \\
\hline $\mathrm{ZnPd} / \mathrm{ZnO} / \mathrm{Al}_{2} \mathrm{O}_{3}$ & $\begin{array}{l}72.5: 27.5 \\
8.8 \quad w t \% \\
\mathrm{Pd}\end{array}$ & - & $\begin{array}{l}\mathrm{H}_{2}, 673 \mathrm{~K}, 2 \\
\mathrm{~h}\end{array}$ & $\begin{array}{l}\mathrm{ZnPd}, \\
\mathrm{ZnO}, \\
\mathrm{Al}_{2} \mathrm{O}_{3}\end{array}$ & - & - & 94.7 & 97.1 & 523 & $1.0: 1.1$ & $\begin{array}{l}0.39 \\
(523)\end{array}$ & - & $\begin{array}{l}{[82]} \\
\end{array}$ \\
\hline $\mathrm{ZnPd} / \mathrm{ZnO}$ & $\begin{array}{ll}1.0 & \mathrm{wt} \% \\
\mathrm{Pd} & \\
\end{array}$ & - & $\begin{array}{l}4 \% \mathrm{H}_{2}, 773 \\
\mathrm{~K}\end{array}$ & $\begin{array}{l}\mathrm{ZnPd}, \\
\mathrm{ZnO}\end{array}$ & - & - & 56 & 97 & 493 & $0.13: 0.13: 1.0(1: 1)$ & $\begin{array}{l}0.83 \\
(493)\end{array}$ & - & [129] \\
\hline $\mathrm{ZnPd} / \mathrm{ZnO}$ & $\begin{array}{l}16.7 \\
\mathrm{wt} \% \mathrm{Pd} \\
\end{array}$ & - & $\begin{array}{ll}10 \% & \mathrm{H}_{2}, \\
623 \mathrm{~K} & \end{array}$ & $\begin{array}{l}\mathrm{ZnPd}, \\
\mathrm{ZnO}\end{array}$ & - & $36000^{\S}$ & 100 & 97 & 578 & $1.0: 1.8$ & - & 92.8 & {$[173]$} \\
\hline $\mathrm{ZnPd} / \mathrm{ZnO}$ & $\begin{array}{ll}2 & \text { wt } \% \\
P d & \\
\end{array}$ & - & $\begin{array}{l}4 \% \mathrm{H}_{2}, 773 \\
\mathrm{~K}, 1 \mathrm{~h}\end{array}$ & $\begin{array}{l}\mathrm{ZnPd}, \\
\mathrm{ZnO}^{1}\end{array}$ & $25^{2}$ & 5450 & - & 99 & 503 & $0.15: 0.15: 1.0(1: 1)$ & $\begin{array}{l}0.8 \\
(503)\end{array}$ & - & [174] \\
\hline
\end{tabular}




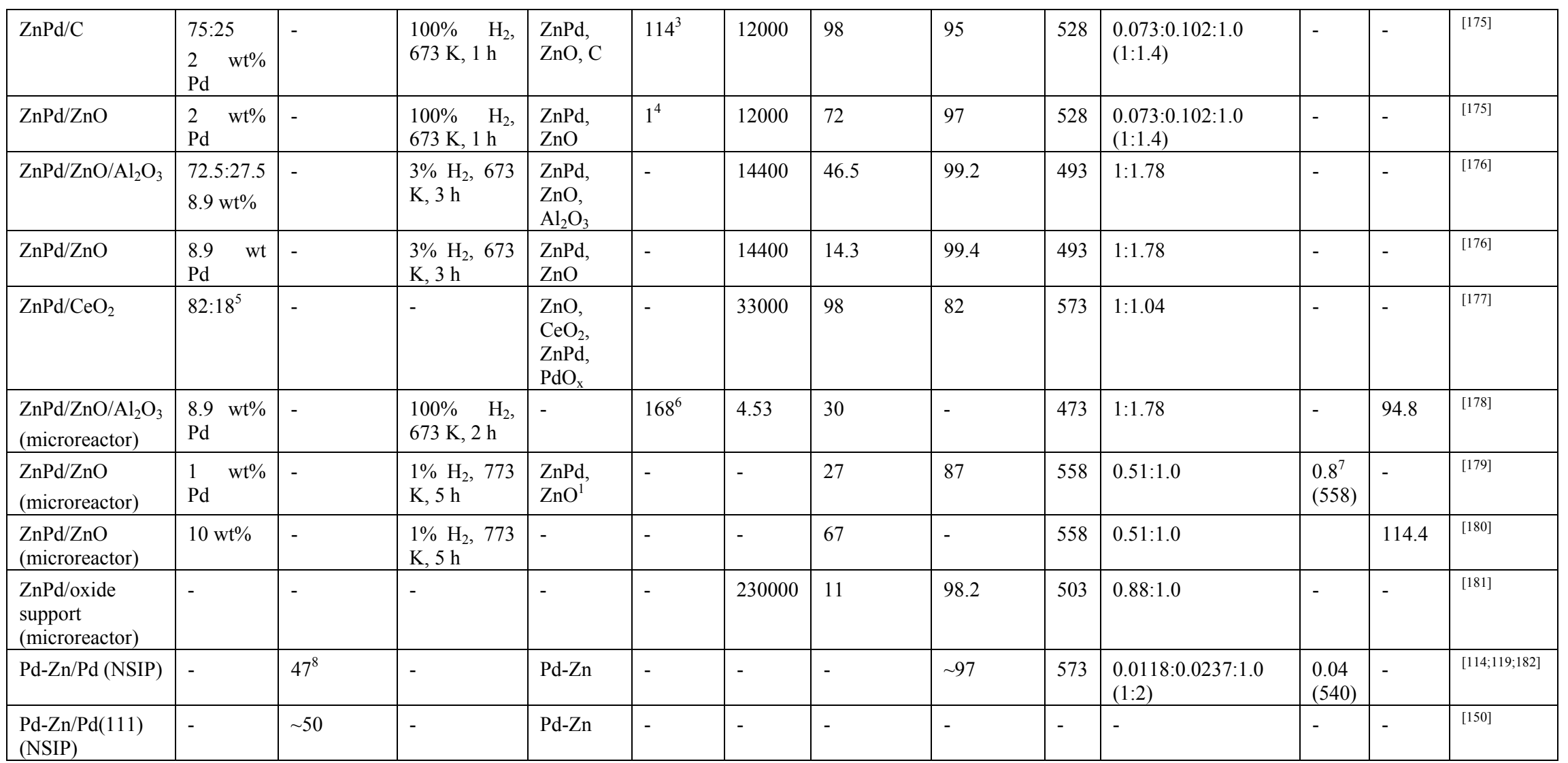

\section{* LHSV}

$\S$ GHSV

\# conversion too low to allow for proper $\mathrm{E}_{\mathrm{A}}$ calculation

$\uparrow^{\dagger}$ TOFs are based on hydrogen uptake

${ }^{1}$ determined on a $10 \mathrm{wt} .-\%$ Pd catalyst

${ }^{2}$ determined by BET of the catalyst reduced in $5 \% \mathrm{H}_{2}$ at $200{ }^{\circ} \mathrm{C}$

${ }^{3}$ after $50 \mathrm{~h}$ time on stream 
${ }^{4}$ after $50 \mathrm{~h}$ time on stream and subsequent calcination $(773 \mathrm{~K}, 1 \mathrm{~h})$ and reduction $(673 \mathrm{~K}, 1 \mathrm{~h})$

${ }^{5}$ near-surface Zn:Pd ratio from XPS on the freshly prepared sample

${ }^{6}$ after calcination

${ }^{7}$ based on $\mathrm{CO}_{2}$ production and $\mathrm{H}_{2}$ or $\mathrm{CO}$ chemisorption, respectively

${ }^{8}$ surface $\mathrm{Zn}$ :Pd ratio from LEIS on the sample after $\sim 300 \mathrm{~K}$ Zn deposition and subsequent annealing at $500 \mathrm{~K}$ (5 min) 
After synthesis, the samples were pretreated at $513 \mathrm{~K}$ with $\mathrm{H}_{2}$ for $1 \mathrm{~h}$ before testing the catalytic properties at 1 bar, a methanol:water ratio of 2:3 and a liquid hourly space velocity (LHSV) of $20 \mathrm{~h}^{-1}$. For the tests $0.5 \mathrm{~g} \mathrm{ZnPd}$ were used to reach $5-10 \%$ conversion at $513-573 \mathrm{~K}$. The single phase sample revealed a $\mathrm{CO}_{2}$-selectivity of approximately $96 \%$, revealing the strong influence on elemental palladium on the catalytic properties of the samples from Iwasa. As shown by this example, metallurgical samples have the drawback of a very low specific surface area. Even grinding or milling leads only to powders with less than $0.05 \mathrm{~m}^{2} \mathrm{~g}^{-1}{ }^{[125]}$, making catalytic measurements expensive. The use of aerosol-derived particles with specific surface areas of $5.9 \mathrm{~m}^{2} \mathrm{~g}^{-1}$ as synthesized by Halevi et al. is one method to increase the activity ${ }^{[65]}$. After synthesis and reduction at $773 \mathrm{~K}$ in $5 \% \mathrm{H}_{2}$ for $2 \mathrm{~h}$, samples showed an additional reflection in XRD, most presumably traces of the cubic neighboring phases. The samples were pre-reduced at $523 \mathrm{~K}$ in $5 \% \mathrm{H}_{2}$ for $2 \mathrm{~h}$ and then tested at ambient pressure with a methanol:water ratio of 1:1.1 and a WHSV of about $10 \mathrm{~h}^{-1}$. Despite the small impurity, the catalytic measurements on these samples revealed $98 \%$ selectivity at around $50 \%$ conversion $(523 \mathrm{~K})$ and a turnover frequency of $0.21 \mathrm{~s}^{-1}\left(0.12 \mathrm{~s}^{-1}\right)$ molecules methanol per surface palladium atom at $523 \mathrm{~K}(503 \mathrm{~K})$ was calculated with an apparent activation energy for methanol steam reforming of $48 \mathrm{kJmol}^{-1}$. These values represent the first reported kinetic values for methanol steam reforming on unsupported $\mathrm{ZnPd}$. In the above studies, the materials were catalytically well characterized, but traces of other phases hinder the determination of the intrinsic catalytic properties of the intermetallic compound ZnPd.

Having shown that single-phase material possesses a high selectivity to $\mathrm{CO}_{2}$ (but still not as high as reported for supported $\mathrm{ZnPd} / \mathrm{ZnO}$ ) two questions arise: a) what influence has the particle size on the catalytic properties? and b) does the composition of the intermetallic compound alter the catalytic properties? While a) has been addressed using supported catalysts (see below), b) has been answered on unsupported powders by Friedrich et al. ${ }^{[62]} \cdot \mathrm{Zn}_{100-x} \mathrm{Pd}_{x}(46.8<x<59.1)$ samples were characterized before the catalytic testing concerning their phase and elemental composition as well as their surface composition by XRD, ICP-OES and XPS measurements, respectively. After metallurgical synthesis, the samples were ground in air to particles smaller than $20 \mu \mathrm{m}$ before catalytic testing with $100-150 \mathrm{mg}$ of sample. Methanol steam reforming was carried out at atmospheric pressure on the unsupported $\mathrm{Zn}_{100-x} \mathrm{Pd}_{x}$ samples. Catalytic measurements were performed between 473 and $773 \mathrm{~K}$ with a methanol:water ratio of $1: 1$ and a WHSV of 3 to 5 . Catalytic experiments on as-prepared powders without any pretreatment 
showed poor activity in methanol steam reforming for most samples, which is due to zinc oxide covering the intermetallic surface. Thus, the $\mathrm{Zn}_{100-x} \mathrm{Pd}_{x}$ samples were pre-reduced hydrogen at $473 \mathrm{~K}$ for one hour. In Fig. 20 the temperature dependent activity of the samples is collated.

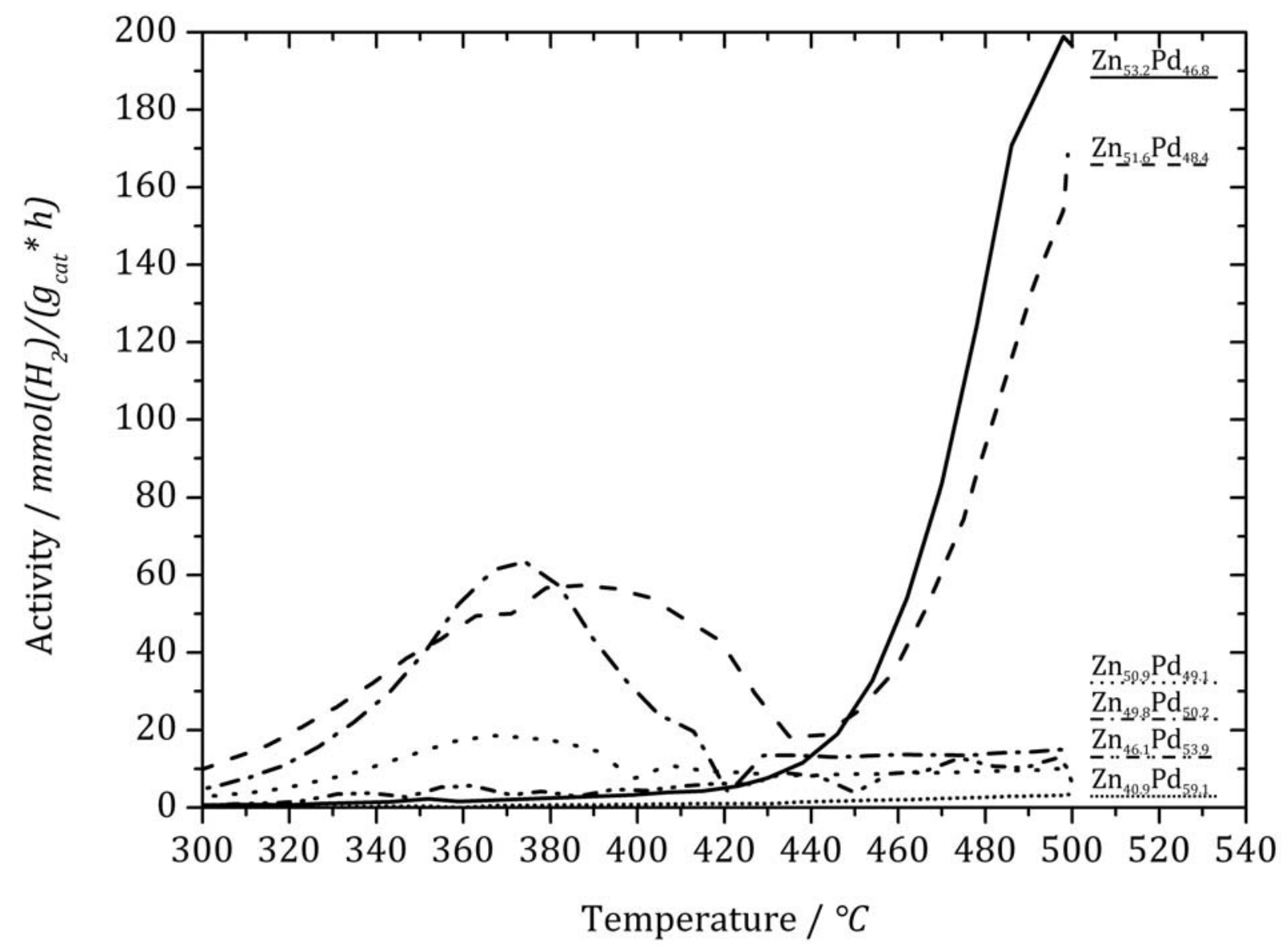

Figure 20: Catalytic activity of $Z n_{100-x} P d_{x}$ samples in methanol steam reforming. From $^{[62]}$.

According to in situ XPS experiments, the major jump in activity at high temperatures by a factor of 10 for samples containing less than 49 at.-\% palladium can be explained by the existence of oxidized zinc atoms on the surface of the Zn-rich samples. This allows for an easier activation of water and thus increases the rate ${ }^{[161]}$. The same effect is even more drastically displayed in the $\mathrm{CO}_{2}$ selectivity of the $\mathrm{Zn}_{100-x} \mathrm{Pd}_{x}$ samples, where also a small effect of the temperature on the selectivity is revealed (Figure 21). 


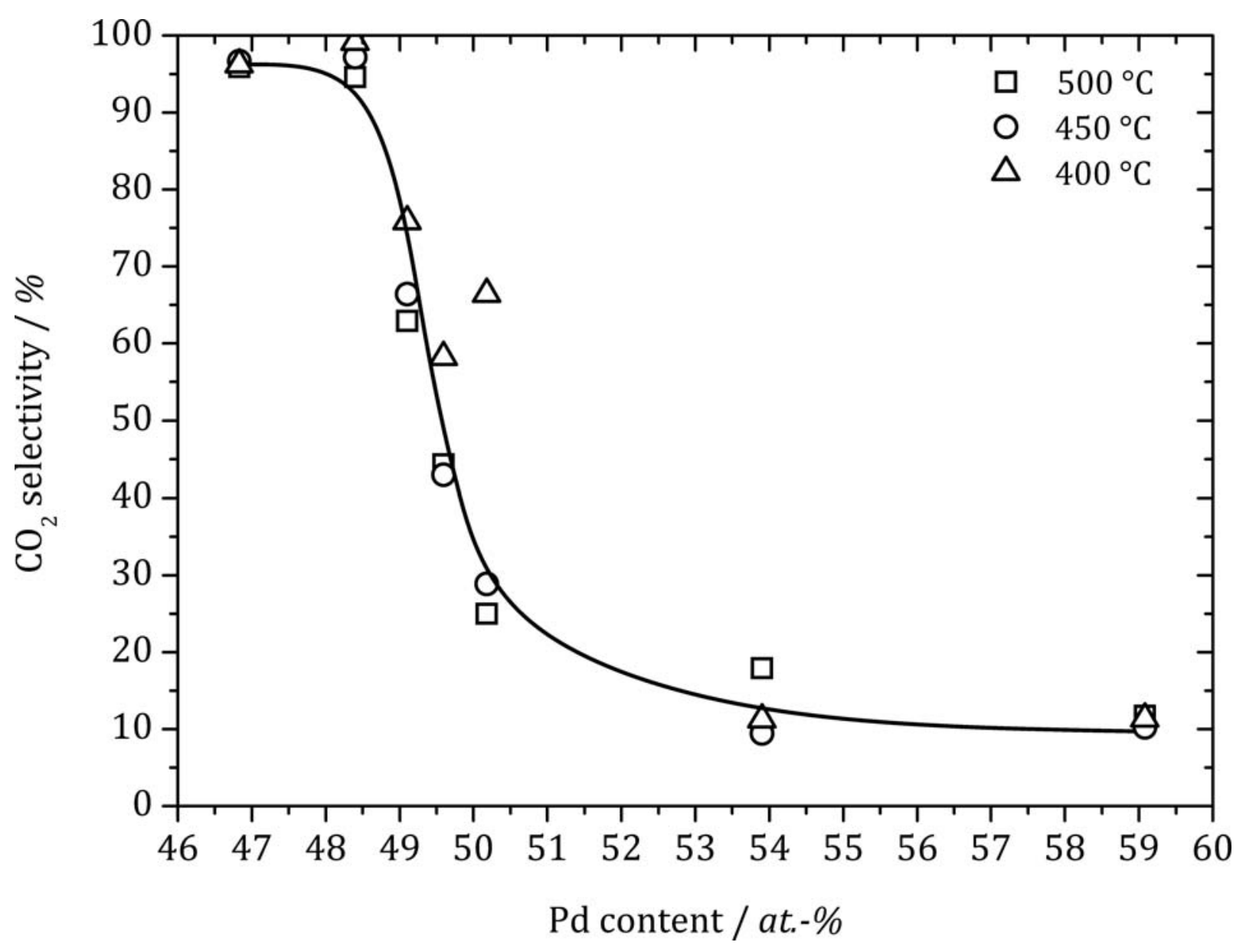

Figure 21: $\mathrm{CO}_{2}$ selectivity of $\mathrm{Zn}_{100-x} P d_{x}$ samples in methanol steam reforming as function of reaction temperature and sample composition (taken from ${ }^{[62]}$ ).

Samples with higher palladium content show decreasing $\mathrm{CO}_{2}$ selectivity down to $10 \%$, making them almost inactive for methanol steam reforming but active for methanol decomposition. As a result of this study, the presence of the intermetallic compound $\mathrm{ZnPd}$ alone is not sufficient for high selectivity in MSR. The reason for the excellent catalytic properties originates from the optimized interaction on the interfaces between the electronically modified palladium atoms and oxidized zinc atoms. This argumentation has been strengthened by recent MSR and formaldehyde steam reforming studies on pure $\mathrm{ZnO}$, showing excellent selectivity to $\mathrm{CO}_{2}$, thus suggesting a strong synergistic effect between $\mathrm{ZnO}$ and $\mathrm{ZnPd}$ in the supported $\mathrm{ZnPd} / \mathrm{ZnO}$ system ${ }^{[182]}$.

Besides the experimental studies a number of quantum theoretical calculations on the catalytic properties of $\mathrm{ZnPd}$ have been published and exothermicities and reaction barriers of various reactions involved in MSR are gathered in Table 6. Published data with and without zero point 
energy (ZPE) correction allows a direct comparison and reveals the strong influence of the ZPE correction on the derived data. Whenever available the more accurate ZPE-corrected values are discussed. Again, similarities between the reaction pathway on $\mathrm{Cu}(111)$ and $\mathrm{ZnPd}(111)$ have been highlighted, due to the comparable electronic structure of these two materials ${ }^{[150 ; 168]}$. Different models are considered for the ZnPd surface: the two most stable (111) and (100) perfect surfaces ( $\mathrm{CuAu}$ type of structure), and surfaces with defects, modeled by the (221) surface at palladium or zinc steps, denoted $\mathrm{ZnPd}(221)^{\mathrm{Pd}}$ and $\mathrm{ZnPd}(221)^{\mathrm{Zn}}$, respectively. In addition, data calculated on NSIPs is included in Table 6, which are discussed in Section 5.c). First, results on methanol or water decomposition on the surfaces are presented. Although three reaction pathways could be considered for the dehydrogenation of methanol - the $\mathrm{C}-\mathrm{H}$ bond breaking, the $\mathrm{C}-\mathrm{O}$ bond breaking and the cleavage of the $\mathrm{O}-\mathrm{H}$ bond - only the latter is favorable on $\mathrm{ZnPd}{ }^{[160]}$, and it is generally accepted that the first step of MSR is the formation of adsorbed methoxy. 
Table 6: Quantum chemically calculated reaction enthalpies and activation energies on different ZnPd materials (in kJmol ${ }^{-1}$ ).

\begin{tabular}{|c|c|c|c|c|c|}
\hline Reaction & $\mathrm{ZnPd}(111)$ & $\mathrm{ZnPd}(100)$ & $\mathrm{ZnPd}(221)^{\mathrm{Pd}}$ & $\mathrm{ZnPd}(221)^{\mathrm{Zn}}$ & ZnPd SA-1 \\
\hline $\mathrm{CH}_{3} \mathrm{OH}^{*} \rightarrow \mathrm{CH}_{3} \mathrm{O}^{*}+\mathrm{H}^{*}$ & $\begin{array}{c}\mathrm{E}_{\mathrm{A}}=91^{[169]} \\
\Delta \mathrm{E}=-12 \text { to } 9^{[160 ; 169]} \\
\mathrm{E}_{\mathrm{A}}^{0}=71-85^{[161 ; 168 ; 169]} \\
\Delta \mathrm{E}^{0}=-5 \text { to } 22^{[161 ; 169]}\end{array}$ & $\begin{array}{l}\mathrm{E}_{\mathrm{A}}^{0}=70^{[161]} \\
\Delta \mathrm{E}^{0}=14^{[161]}\end{array}$ & & $\begin{aligned} \mathrm{E}_{\mathrm{A}}^{0} & =57^{[161]} \\
\Delta \mathrm{E}^{0} & =-36^{[161]}\end{aligned}$ & $\begin{aligned} \mathrm{E}_{\mathrm{A}} & =88^{[170]} \\
\Delta \mathrm{E} & =-25^{[170]} \\
\mathrm{E}_{\mathrm{A}}^{0} & =67^{[170]} \\
\Delta \mathrm{E}^{0} & =-37^{[170]}\end{aligned}$ \\
\hline $\mathrm{CH}_{3} \mathrm{O}^{*} \rightarrow \mathrm{CH}_{2} \mathrm{O}^{*}+\mathrm{H}^{*}$ & $\begin{array}{c}\mathrm{E}_{\mathrm{A}}=113-120^{[150 ; 160 ; 162 ; 169]} \\
\Delta \mathrm{E}=61-90^{[150 ; 160 ; 162 ; 169]} \\
\mathrm{E}_{\mathrm{A}}^{0}=86-101^{[161 ; 168 ; 169]} \\
\Delta \mathrm{E}^{0}=62-76^{[161 ; 169]}\end{array}$ & $\begin{array}{c}\mathrm{E}_{\mathrm{A}}=107^{[162]} \\
\Delta \mathrm{E}=89^{[162]} \\
\mathrm{E}_{\mathrm{A}}^{0}=90-102^{[161 ; 162]} \\
\Delta \mathrm{E}^{0}=75^{[161]}\end{array}$ & $\begin{array}{l}\mathrm{E}_{\mathrm{A}}=50^{[164]} \\
\Delta \mathrm{E}=17^{[164]}\end{array}$ & $\begin{array}{l}\mathrm{E}_{\mathrm{A}}=108^{[164]} \\
\Delta \mathrm{E}=97^{[164]}\end{array}$ & $\begin{array}{l}\mathrm{E}_{\mathrm{A}}=109^{[170]} \\
\Delta \mathrm{E}=60^{[170]} \\
\mathrm{E}_{\mathrm{A}}^{0}=90^{[170]} \\
\Delta \mathrm{E}^{0}=45^{[170]}\end{array}$ \\
\hline $\mathrm{CH}_{2} \mathrm{O}^{*} \rightarrow \mathrm{CHO}^{*}+\mathrm{H}^{*}$ & $\begin{array}{c}\mathrm{E}_{\mathrm{A}}=78-86^{[150 ; 163 ; 169]} \\
\Delta \mathrm{E}=-4 \text { to } 18^{[150 ; 163 ; 169]} \\
\mathrm{E}_{\mathrm{A}}^{0}=62-69^{[163 ; 168 ; 169]} \\
\Delta \mathrm{E}^{0}=-18 \text { to } 4^{[163 ; 169]}\end{array}$ & $\begin{aligned} \mathrm{E}_{\mathrm{A}} & =53^{[163]} \\
\Delta \mathrm{E} & =-10^{[163]} \\
\mathrm{E}_{\mathrm{A}}^{0} & =67^{[163]} \\
\Delta \mathrm{E}^{0} & =-23^{[163]}\end{aligned}$ & $\begin{aligned} \mathrm{E}_{\mathrm{A}} & =76^{[163]} \\
\Delta \mathrm{E} & =-7^{[163]} \\
\mathrm{E}_{\mathrm{A}}^{0} & =63^{[163]} \\
\Delta \mathrm{E}^{0} & =-17^{[163]}\end{aligned}$ & & $\begin{aligned} \mathrm{E}_{\mathrm{A}} & =53^{[170]} \\
\Delta \mathrm{E} & =-10^{[170]} \\
\mathrm{E}_{\mathrm{A}}^{0} & =67^{[170]} \\
\Delta \mathrm{E}^{0} & =-23^{[170]}\end{aligned}$ \\
\hline $\mathrm{CHO}^{*} \rightarrow \mathrm{CO}^{*}+\mathrm{H}^{*}$ & $\begin{array}{c}\mathrm{E}_{\mathrm{A}}=42-44^{[150 ; 163 ; 169]} \\
\Delta \mathrm{E}=-71 \text { to }-43^{[150 ; 163 ; 169]} \\
\mathrm{E}_{\mathrm{A}}{ }^{0}=25-27^{[163 ; 169]} \\
\Delta \mathrm{E}^{0}=-80 \text { to }-58^{[163 ; 169]}\end{array}$ & & $\begin{aligned} \mathrm{E}_{\mathrm{A}} & =41^{[163]} \\
\Delta \mathrm{E} & =-84^{[163]} \\
\mathrm{E}_{\mathrm{A}}^{0} & =22^{[163]} \\
\Delta \mathrm{E}^{0} & =-94^{[163]}\end{aligned}$ & & $\begin{aligned} \mathrm{E}_{\mathrm{A}} & =38^{[170]} \\
\Delta \mathrm{E} & =-76^{[170]} \\
\mathrm{E}_{\mathrm{A}}^{0} & =23^{[170]} \\
\Delta \mathrm{E}^{0} & =-87^{[170]}\end{aligned}$ \\
\hline $\mathrm{CH}_{3} \mathrm{O}^{*} \rightarrow \mathrm{CH}_{3}^{*}+\mathrm{O}^{*}$ & $\begin{array}{c}\mathrm{E}_{\mathrm{A}}=208^{[160 ; 162 ; 168]} \\
\Delta \mathrm{E}=60^{[160 ; 162]} \\
\mathrm{E}_{\mathrm{A}}^{0}=198^{[162]}\end{array}$ & $\begin{array}{l}\mathrm{E}_{\mathrm{A}}=167^{[160 ; 162]} \\
\Delta \mathrm{E}=65^{[160 ; 162]} \\
\mathrm{E}_{\mathrm{A}}^{0}=158^{[162]}\end{array}$ & $\begin{aligned} \mathrm{E}_{\mathrm{A}} & =65^{[164]} \\
\Delta \mathrm{E} & =199^{[164]}\end{aligned}$ & $\begin{array}{l}\mathrm{E}_{\mathrm{A}}=220^{[164]} \\
\Delta \mathrm{E}=105^{[164]}\end{array}$ & \\
\hline $\mathrm{CH}_{3} \mathrm{OH}^{*} \rightarrow \mathrm{OH}^{*}+\mathrm{CH}_{3} *$ & $\mathrm{E}_{\mathrm{A}}^{0}=134^{[161]}$ & $\mathrm{E}_{\mathrm{A}}^{0}=149^{[161]}$ & & & \\
\hline $\mathrm{CH}_{3} \mathrm{OH}^{*} \rightarrow \mathrm{CH}_{2} \mathrm{OH}+\mathrm{H}$ & $\mathrm{E}_{\mathrm{A}}^{0}=117^{[161]}$ & $\mathrm{E}_{\mathrm{A}}^{0}=101^{[161]}$ & & & \\
\hline $\mathrm{H}_{2} \mathrm{O}_{M}^{*} \rightarrow \mathrm{OH}^{*}+\mathrm{H}^{*}$ & $\begin{array}{c}\mathrm{E}_{\mathrm{A}}^{0}=89-91^{[161 ; 167]} \\
\Delta \mathrm{E}^{0}=20^{[161]}\end{array}$ & $\begin{array}{l}\mathrm{E}_{\mathrm{A}}^{0}=71^{[161]} \\
\Delta \mathrm{E}^{0}=23^{[161]}\end{array}$ & $\mathrm{E}_{\mathrm{A}}^{0}=95^{[167]}$ & $\begin{array}{c}\mathrm{E}_{\mathrm{A}}^{0}=59-60^{[161 ; 167]} \\
\Delta \mathrm{E}^{0}=-41^{[161]}\end{array}$ & \\
\hline $\mathrm{H}_{2} \mathrm{O}_{C}^{*} \rightarrow \mathrm{OH}^{*}+\mathrm{H}^{*}$ & & & $\mathrm{E}_{\mathrm{A}}^{0}=95^{[167]}$ & $\mathrm{E}_{\mathrm{A}}^{0}=43^{[167]}$ & \\
\hline $\mathrm{H}_{2} \mathrm{O}_{D}^{*} \rightarrow \mathrm{OH}^{*}+\mathrm{H}^{*}$ & $\mathrm{E}_{\mathrm{A}}^{0}=84^{[167]}$ & & & & \\
\hline $\mathrm{H}_{2} \mathrm{O}_{T}^{*} \rightarrow \mathrm{OH}^{*}+\mathrm{H}^{*}$ & $\mathrm{E}_{\mathrm{A}}^{0}=68^{[167]}$ & & & & \\
\hline $\mathrm{H}_{2} \mathrm{O}_{H}^{*} \rightarrow \mathrm{OH}^{*}+\mathrm{H}^{*}$ & $\mathrm{E}_{\mathrm{A}}^{0}=52^{[167]}$ & & & & \\
\hline $\mathrm{CH}_{2} \mathrm{OOH}^{*} \rightarrow \mathrm{CHOOH}^{*}+$ & $\mathrm{E}_{\mathrm{A}}^{0}=56^{[168]}$ & & & & \\
\hline
\end{tabular}




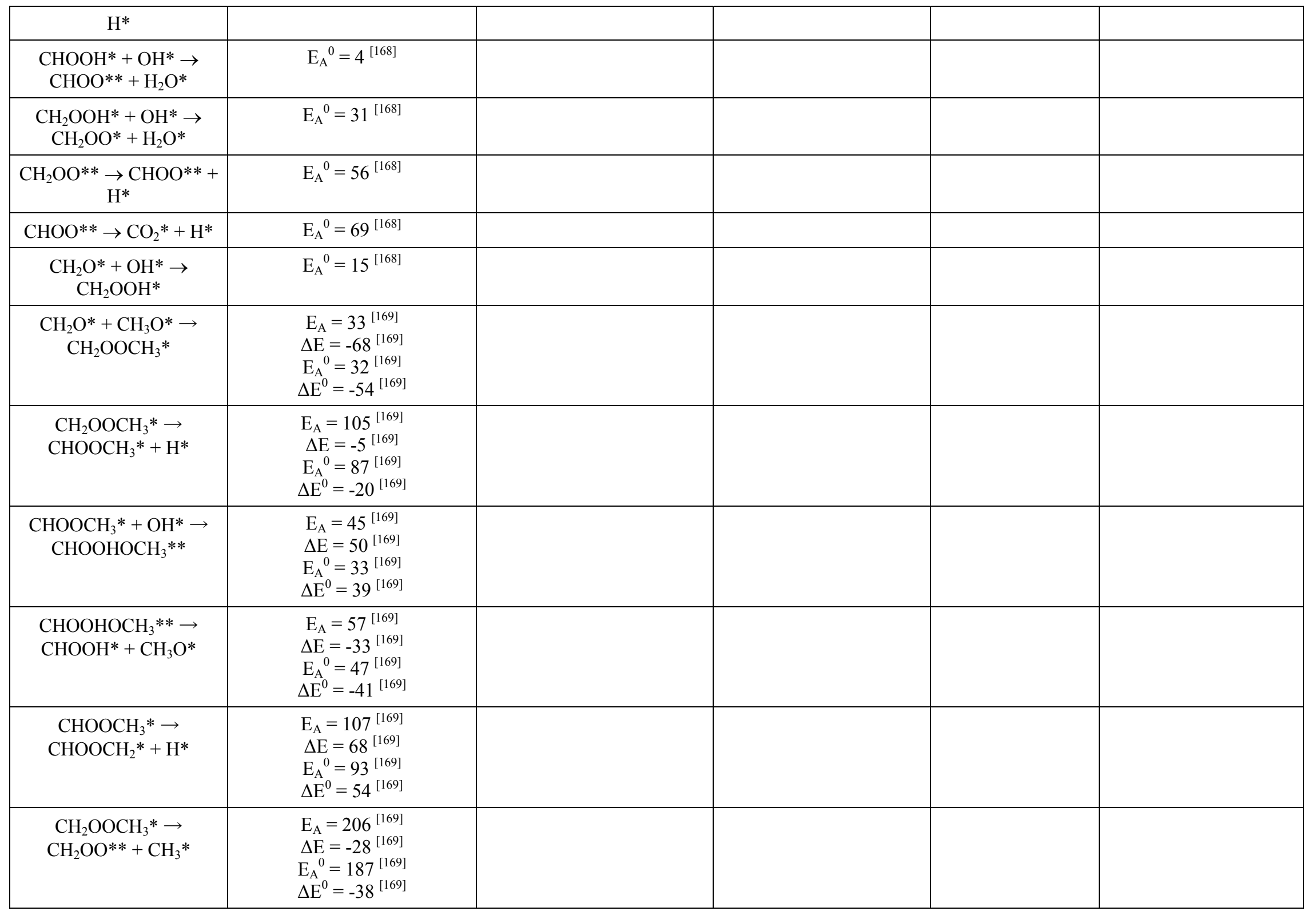


$\triangle \mathrm{E}$ and $\mathrm{E}_{\mathrm{A}}$ are calculated reaction enthalpies and energy barriers (without $\mathrm{ZPE}$ corrections)

$\Delta \mathrm{E}^{0}$ and $\mathrm{E}_{\mathrm{A}}{ }^{0}$ are calculated reaction enthalpies and energy barriers (with ZPE corrections)

$\mathrm{H}_{2} \mathrm{O}_{M}$ : water monomer

$\mathrm{H}_{2} \mathrm{O}_{C}$ : 1-D water chain

$\mathrm{H}_{2} \mathrm{O}_{D}$ : water dimer

$\mathrm{H}_{2} \mathrm{O}_{T}$ : water tetramer

$\mathrm{H}_{2} \mathrm{O}_{H}$ : water hexamer 
Starting from adsorbed methoxy groups, Chen et al. ${ }^{[160 ; 162 ; 164 ; 170]}$ studied the decomposition of methanol on flat (111) and (100) as well as the stepped (221) ${ }^{\mathrm{Zn}}$ and (221) ${ }^{\mathrm{Pd}} \mathrm{ZnPd}$ surfaces (Table 6). In general, C-bound species prefer sites rich in palladium, while O-bound species (like methoxy) prefer Zn-rich adsorption sites ${ }^{[160]}$. The activation energy for $\mathrm{C}-\mathrm{H}$ splitting of methoxy to formaldehyde is more favorable $\left(86-93 \mathrm{kJmol}^{-1}\right)$ than is the decomposition path via $\mathrm{C}-\mathrm{O}$ splitting to methyl $\left(198 \mathrm{kJmol}^{-1}\right)$ on $\mathrm{ZnPd}(111)^{[160]}$. On the $\mathrm{ZnPd}(100)$ surface, both processes are less activated, resulting in $90-102 \mathrm{kJmol}^{-1}$ and $158 \mathrm{kJmol}^{-1}$, respectively ${ }^{[162]}$. The calculated activation energy for $\mathrm{C}-\mathrm{H}$ splitting is further reduced when considering the stepped surfaces $(221)^{\mathrm{Zn}}$ and $(221)^{\mathrm{Pd}}$. Here, values of 108 and $50 \mathrm{kJmol}^{-1}$, respectively, are obtained with the latter close to the experimentally observed value of the overall reaction. Decomposition of the formed formaldehyde to $\mathrm{CHO}$ and further to $\mathrm{CO}$ resulted in activation energies of 62-64 and $25 \mathrm{kJmol}^{-1}$, respectively on $\mathrm{ZnPd}(111)^{[163]}$. The stepped $\mathrm{ZnPd}(221)^{\mathrm{Pd}}$ seems to be only slightly more reactive with activation energies of 63 and $22 \mathrm{kJmol}^{-1}$ for the two reactions ${ }^{[163]}$. The dehydrogenation of formaldehyde was calculated to be kinetically unfavorable on $\mathrm{ZnPd}$ surfaces ${ }^{[163]}$, showing that this step is not the favorable pathway towards $\mathrm{CO}_{2}$ production. When assuming that palladium aggregates may be present on the experimental catalyst surfaces the formation of small amounts of $\mathrm{CO}$ during the reaction could be explained considering that the dehydrogenation of formaldehyde is favorable on $\operatorname{Pd}(111)^{[163]}$.

The other ingredient needed for methanol steam reforming is water - the decomposition of which was studied quantum chemically on $\mathrm{ZnPd}(111), \mathrm{ZnPd}(100), \mathrm{ZnPd}(221)^{\mathrm{Zn}}$ and $\mathrm{ZnPd}(221)^{\mathrm{Pd}}$ ${ }^{[167]}$. Different arrangements of water molecules were considered, i.e. monomeric water, a water chain as well as different water oligomers. Calculations resulted in the $\mathrm{ZnPd}(221)^{\mathrm{Zn}}$ surface having the lowest activation energy for water when adsorbed as a 1-D chain $\left(43 \mathrm{kJmol}^{-1}\right)$. Thus, when considering water and methanol alone, the activation energies of the rate limiting elementary reactions are 43 and $63 \mathrm{kJmol}^{-1}$ and would require the $\mathrm{ZnPd}(221)^{\mathrm{Zn}}$ surface for the activation of water and the $\mathrm{ZnPd}(221)^{\mathrm{Pd}}$ surface for the decomposition of methanol.

Combining water and methanol in a single study, thus considering the whole reaction, was recently done for $\mathrm{ZnPd}(111)^{[168]}$. The results are summarized in Fig. 22, showing that the rate limiting step is the splitting of the methoxy $\mathrm{C}-\mathrm{H}$ bond to form adsorbed formaldehyde on the surface resulting in an activation energy of $86 \mathrm{kJmol}^{-1}$. The monodentate formaldehyde is a key intermediate since the abstraction of one $\mathrm{H}$ atom leads to the $\mathrm{CO}$ pathway, while reaction with adsorbed $\mathrm{OH}$ leads to decomposition to $\mathrm{CO}_{2}$. On $\mathrm{ZnPd}(111)$ the latter is significantly favored by 
nearly $50 \mathrm{kJmol}^{-1}$. Besides being the most comprehensive calculation so far, the activation energy of $86 \mathrm{kJmol}^{-1}$ is significantly higher than many of the reported experimental apparent activation energies (Table 5). This can be understood by taking into account the lower activation energies for this step on other investigated surfaces, e.g. $\mathrm{ZnPd}(221)^{\mathrm{Pd}}$, where the activation energy is calculated to be $57 \mathrm{kJmol}^{-1}$. Considering these surfaces also for the other elementary reactions, the energy landscape changes significantly and the last step, i.e. the abstraction of the last hydrogen atom, becomes rate determining (Fig. 22). The scheme in Fig. 22 also points towards $\mathrm{CH}_{2} \mathrm{O}$ as a hub, decisive for the formation of $\mathrm{CO}$ or $\mathrm{CO}_{2}$. If $\mathrm{OH}$ is provided, the reaction with $\mathrm{CH}_{2} \mathrm{O}$ results in $\mathrm{CO}_{2}$, otherwise $\mathrm{CO}$ is formed. Since experimentally ${ }^{[182]}$ as well as by quantum chemical studies ${ }^{[161]}$ water activation is less activated on $\mathrm{ZnO}$ compared to the $\mathrm{ZnPd}$ surfaces $\left(\mathrm{E}_{\mathrm{A}}^{0}[\mathrm{ZnO}(0001)]=41 \mathrm{kJmol}^{-1}\right.$ vs $\left.\mathrm{E}_{\mathrm{A}}^{0}\left[\mathrm{ZnPd}(221)^{\mathrm{Zn}}\right]=43-59 \mathrm{kJmol}^{-1}\right)$, the experimentally observed synergistic effect between $\mathrm{ZnO}$ and $\mathrm{ZnPd}$ is corroborated by the quantum chemical calculations.

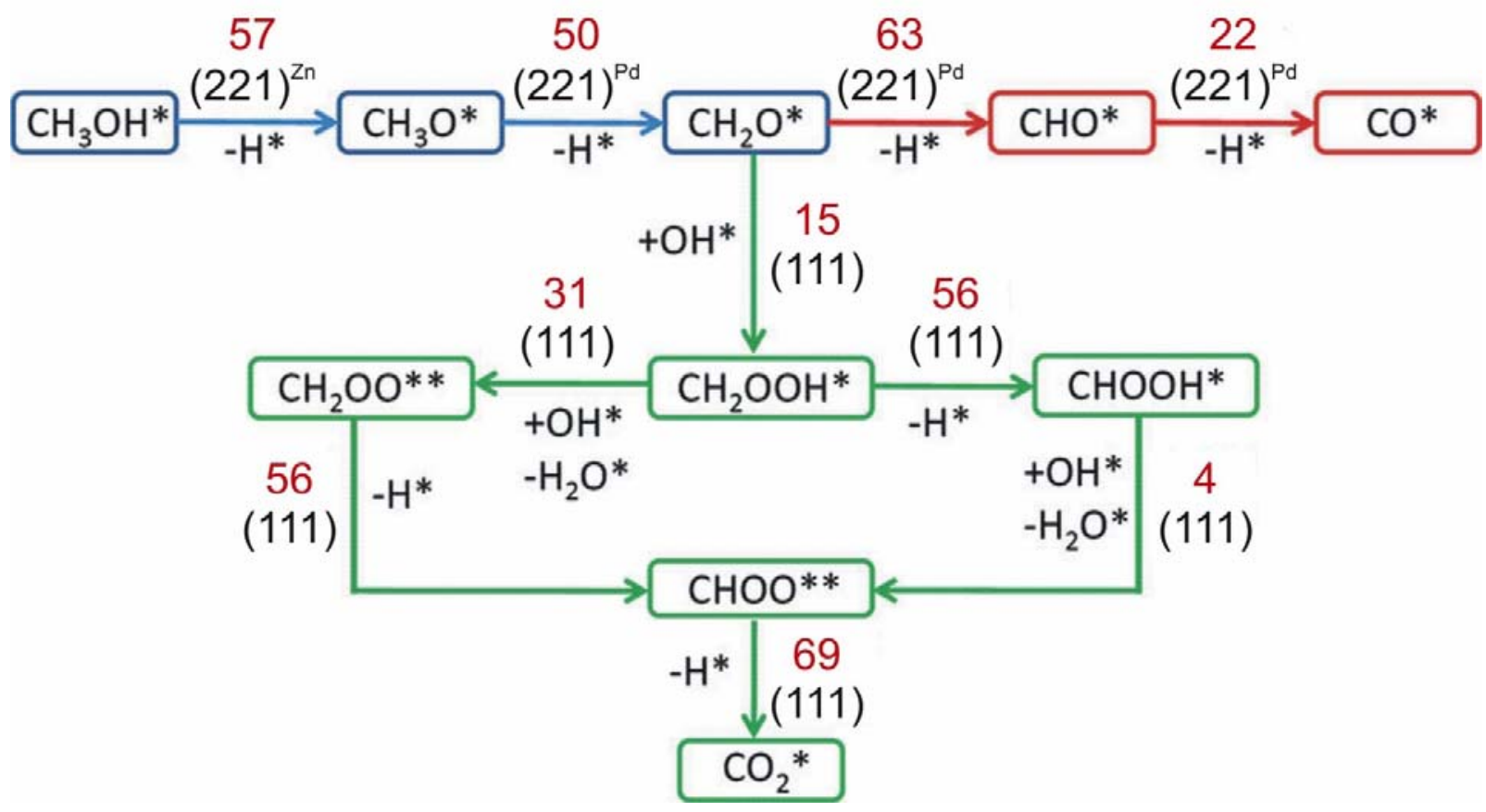

Figure 22: Proposed reaction network for MSR on ZnPd summarizing the quantum chemical calculations. The lowest activation energies (involved surfaces are indicated) for the elementary reaction are given in red (in $\mathrm{kJmol}^{-1}$ ). $\mathrm{CO}$ and $\mathrm{CO}_{2}$ channels are color-coded in red and green, respectively. Adapted from ${ }^{[168]}$. 
Another suggested pathway to $\mathrm{CO}_{2}$-selective steam reforming of methanol involves the formation of methyl formate and provoked a recent DFT study of this pathway on $\mathrm{ZnPd}(111)$ ${ }^{[169]}$. Methyl formate is formed by reaction of formaldehyde and methoxyl and then transformed to formic acid by reaction with adsorbed hydroxyl at a later stage. Finally, the dehydrogenation of formic acid leads to $\mathrm{CO}_{2}$ and $\mathrm{H}_{2}$. In this pathway, the decomposition of the methyl formate is in concurrence with desorption of the molecule, which is only weakly adsorbed $\left(13 \mathrm{kJmol}^{-1}\right)$. This might be an indication of only a minor role of this pathway in MSR. So far, the methyl formate chemistry has not been addressed on $\mathrm{ZnO}$, and it could well be, that if the methyl formate is formed on the interface between $\mathrm{ZnO}$ and $\mathrm{ZnPd}$ it is more strongly adsorbed on the $\mathrm{ZnO}$, thus increasing the probability of decomposition.

\section{5.b) Supported ZnPd}

In the first publication by Iwasa et al. on a supported $\mathrm{ZnPd}$ catalyst in methanol steam reforming, palladium was evaluated on different supports ${ }^{[10]}$. Normally, elemental palladium selectively catalyzes the decomposition of methanol to $\mathrm{CO}$, even in the presence of water, resulting in undesired high CO contents in the product ${ }^{[129]}$. In this study, Takezawa and Iwasa observed that in the case of $\mathrm{Pd} / \mathrm{ZnO}$ the $\mathrm{CO}_{2}$ selectivity improved drastically from 0 to $97 \%$ with prior hydrogen reduction of the catalyst at $673 \mathrm{~K}$ and also the conversion increased from $33 \%$ to $58 \%$. Both effects were attributed to the formation of the intermetallic compound $\mathrm{ZnPd}$. It was suggested that the reason for the selectivity increase are the different reaction pathways for the decomposition of formaldehyde species on palladium and $\mathrm{ZnPd}$. While they are selectively decomposed to $\mathrm{CO}$ and $\mathrm{H}_{2}$ on elemental $\mathrm{Pd}$, the intermetallic compound $\mathrm{ZnPd}$ leads to an effective attack by water and subsequent decomposition to $\mathrm{CO}_{2}$ and $\mathrm{H}_{2}$ similar to the reaction path suggested for $\mathrm{Cu}$-based catalysts.

These initial studies were followed by many others, making $\mathrm{ZnPd} / \mathrm{ZnO}$ the best investigated intermetallic system for the steam reforming of methanol. On supported $\mathrm{ZnPd} / \mathrm{ZnO}$ the apparent activation energy $\mathrm{E}_{\mathrm{A}}$ was determined to $93 \mathrm{~kJ} / \mathrm{mol}^{[173]}$, while the TOF (based on hydrogen uptake) is reported to be $0.8 \mathrm{~s}^{-1}{ }^{[174]}$. This is significantly higher than reported for unsupported materials $\left(0.12 \mathrm{~s}^{-1}\right)$ and may be attributed to the use of a 7-fold higher WHSV. Special interest lies on how the catalytic properties depend on the particle size. The influence of the $\mathrm{ZnPd}$ particle size ( 2 to $34 \mathrm{~nm}$ mean diameter) on the catalytic performance was studied by Dagle et al. ${ }^{[68]}$ and Karim et al. ${ }^{[69]}$. They found, that the intermetallic compound $\mathrm{ZnPd}$ is already 
formed at the relatively mild reduction temperature of $523 \mathrm{~K}$, but at these low temperatures $\mathrm{ZnPd}$ and elemental palladium co-exist on the support. By varying the reduction temperature, the $\mathrm{Pd}: \mathrm{ZnPd}$ ratio was changed, but no monotonic correlation between $\mathrm{ZnPd}$ content and the $\mathrm{CO}_{2}$ selectivity was observed. Instead, small particles showed $\mathrm{CO}_{2}$ selectivities of only $62 \%$ compared to $99 \%$ for the larger ones and highly selective catalysts could be obtained by elimination of the small and unselective particles of the intermetallic compound. The loss in selectivity can be explained with a strong activity increase of small $\mathrm{ZnPd}$ particles in the reverse water-gas-shift reaction, thus, the production of $\mathrm{CO}$ by converting $\mathrm{CO}_{2}$ and $\mathrm{H}_{2}{ }^{[28 ; 29]}$. Interestingly, large $\mathrm{ZnPd}$ particles (diameter of $34 \mathrm{~nm}$ ) show the same catalytic activity as small particles with $9 \mathrm{~nm}$ diameter. This might indicate that not only the intermetallic compound $\mathrm{ZnPd}$, but also the $\mathrm{ZnO}$ support plays an important role during catalysis, e.g. by forming the catalytically active perimeter of the $\mathrm{ZnO}$-supported $\mathrm{ZnPd}$ particles. The morphology of the $\mathrm{ZnO}$ support particles was also reported to affect the catalytic properties of $\mathrm{ZnPd} / \mathrm{ZnO}$ methanol steam reforming catalysts ${ }^{[77]}$.

The influence of $\mathrm{ZnO}$ on the catalytic properties has been studied in more detail by using catalytic systems consisting of palladium and zinc being present on an inert support like carbon or alumina. Suwa et al. ${ }^{[175]}$ compared the deactivation behavior of $\mathrm{ZnPd} / \mathrm{ZnO} / \mathrm{C}$ and $\mathrm{ZnPd} / \mathrm{ZnO}$ catalysts. After $50 \mathrm{~h}$ time on stream, both catalysts showed deactivation from 70 to $60 \%$ and 70 to $40 \%$ conversion, respectively. XRD analysis revealed the presence of $\mathrm{Zn}_{4} \mathrm{CO}_{3}(\mathrm{OH})_{6} \cdot \mathrm{H}_{2} \mathrm{O}$ on the $\mathrm{ZnPd} / \mathrm{ZnO}$ catalyst. It was concluded that the deactivation mechanism is due to $\mathrm{Zn}_{4} \mathrm{CO}_{3}(\mathrm{OH})_{6} \cdot \mathrm{H}_{2} \mathrm{O}$ covering the intermetallic surface. The stronger deactivation of $\mathrm{ZnPd} / \mathrm{ZnO}$ compared to $\mathrm{ZnPd} / \mathrm{ZnO} / \mathrm{C}$ was explained by the higher amount on $\mathrm{ZnO}$ present on the former. Another system on which the influence of $\mathrm{ZnO}$ has been studied is $\mathrm{Pd}-\mathrm{ZnO} / \mathrm{Al}_{2} \mathrm{O}_{3}{ }^{[176]}$. A series of catalysts with different palladium loading and $\mathrm{Pd}: \mathrm{Zn}$ molar ratios was prepared, characterized and tested. The highest selectivity (98.6\%) and activity ( $80 \%$ conversion at $523 \mathrm{~K})$ was revealed at a loading of $8.9 \%$ palladium with a $\mathrm{Pd}: \mathrm{Zn}$ ratio of 0.38 . Doubling the ratio led to a six times higher $\mathrm{CO}$ content, whereas with half the ratio the $\mathrm{CO}$ content reached $1.7 \%$. By XRD, ZnO was observed at low $\mathrm{Pd}: \mathrm{Zn}$ ratios, while at high $\mathrm{Pd}: \mathrm{Zn}$ ratios elemental palladium was observed. These results indicate that an ideal $\mathrm{Pd}: \mathrm{Zn}$ ratio exists. If not enough zinc is present, not all the palladium can be converted to $\mathrm{ZnPd}$, thus catalytically decomposing the methanol to $\mathrm{CO}$ and $\mathrm{H}_{2}$. Too high zinc contents on the other hand result in the formation of too much $\mathrm{ZnO}$, which leads to lower selectivities and deactivation. 
$\mathrm{Pd} / \mathrm{ZnO}$ was also used in the oxidative steam reforming of methanol. Liu et al. ${ }^{[183 ; 184]}$, who were the first to investigate this catalyst in this reaction, studied the effect of the Pd-loading ${ }^{[185]}$, the deactivation ${ }^{[186]}$ and the influence of the presence of third metals ${ }^{[187]}$. In contrast to the steam reforming of methanol, the activity and selectivity increased with palladium loading, most probably due to the use of $\mathrm{ZnO}$ as support, thus not restricting the Pd:Zn ratio. Testing the catalysts over $25 \mathrm{~h}$ resulted in a deactivation behavior superior to $\mathrm{Cu}$-based catalysts, but with continuously increasing amounts of $\mathrm{CO}$ (up to $18 \%$ ) produced with time on stream. The instability of the $\mathrm{CO}_{2}$-selectivity can be seen as an indication of an ongoing modification of the intermetallic surface under the less reducing conditions of oxidative steam reforming. Indeed, by XPS investigations, it could be shown that the increasing CO content is due to a surface oxidation of the intermetallic compound $\mathrm{ZnPd}$ resulting in elemental palladium being present on the support, which leads to the decomposition of methanol. Recently, Föttinger et al. ${ }^{[83]}$ presented in situ XAFS evidence for the decomposition of the intermetallic ZnPd surface into palladium and $\mathrm{ZnO}$ in the presence of oxygen. The decomposition was associated with a loss of $\mathrm{CO}_{2}$-selectivity in methanol steam reforming. Thus it seems that using $\mathrm{ZnPd}$ in oxidative steam reforming is not a promising route to highly selective catalysts due to the decomposition of the intermetallic compound.

On the other hand, a dedicated oxidative treatment at a higher temperature than reaction temperature was shown to help regenerating the catalysts activity. For a $\mathrm{ZnPd} / \mathrm{ZnO} / \mathrm{Al}_{2} \mathrm{O}_{3}$ catalyst ${ }^{[82]}$, this was attributed to the decomposition of the $\mathrm{ZnPd}$ phase by decomposing it into $\mathrm{PdO}$ and $\mathrm{ZnO}$ before forming a re-dispersed $\mathrm{ZnPd}$ phase again when switching back to methanol steam reforming conditions. On a $\mathrm{ZnPd} / \mathrm{ZnO} / \mathrm{CeO}_{2}$ catalyst ${ }^{[177]}$, carbonaceous deposits have been found after methanol steam reforming after long time-on-stream. These deposits can be burned off by treatment in air, which was shown to lead to recovery of the catalytic performance. All these examples show that even after formation of intermetallic $\mathrm{ZnPd}$, the catalysts remain highly dynamic if submitted to changes in the oxidation potential of its surrounding atmosphere.

Considering the potential in industrial applications, the use of supported $\mathrm{ZnPd}$ methanol steam reforming catalysts in microreactors is of high interest as mobile fuel cell applications require a small and to some extent portable periphery ${ }^{[6]}$. Xia et al. have shown how optimization of the $\mathrm{Pd}: \mathrm{Zn}$ ratio and of the $\mathrm{Pd}$ loading can improve the catalytic performance of $\mathrm{Al}_{2} \mathrm{O}_{3^{-}}$ supported $\mathrm{Pd} / \mathrm{ZnO}$ catalysts and leads to an increase in the efficiency of a microscale fuel processor from 9 to $15 \%{ }^{[176]}$. The same group also studied the kinetics of the methanol steam 
reforming reaction in a microchannel reactor using this catalyst material ${ }^{[178]}$. Washcoated $\mathrm{ZnPd} / \mathrm{ZnO}{ }^{[179]}$ was used for another kinetic and mechanistic study in a microstructured reactor and the authors showed that their kinetic models can be extrapolated to low pressures without change in reaction mechanism ${ }^{[180]}$. Ilinich et al. at presented a newly developed $\mathrm{Pd} / \mathrm{ZnO}$-based catalyst on a promoted oxide support that was directly washcoated into the channels of a microreformer ${ }^{[181]}$. Their catalyst formulation exhibited superior stability under simulated start-stop conditions compared to $\mathrm{Cu}$-based catalysts.

In summary, the catalytic system $\mathrm{Pd} / \mathrm{ZnO}$ is quite complex. The different catalytic activities of $\mathrm{ZnO}$, elemental $\mathrm{Pd}, \mathrm{ZnPd}$ and the resulting interfaces may be the reason for the observed large differences in the steam reforming of methanol properties for different $\mathrm{ZnPd} / \mathrm{ZnO}$ catalysts. In addition, different $\mathrm{Pd}: \mathrm{Zn}$ ratios and varying $\mathrm{ZnO}$ contents as well as the particle size affect the catalytic properties of supported $\mathrm{ZnPd}$ catalysts. However, it appears from the literature that there is consensus that the presence of the intermetallic compound $\mathrm{ZnPd}$ markedly improves the catalytic properties as compared to monometallic palladium.

\section{5.c) Surface alloys}

Under methanol steam reforming conditions, the Pd-Zn NSIPs revealed different properties, strongly depending on the subsurface characteristics of the respective system. Surface alloys consisting of 1 ML Pd-Zn ("monolayer alloy") and 5 ML Pd-Zn ("multilayer alloy") on palladium foil possessed the same surface structure, still their performance in methanol steam reforming was completely different, being highly $\mathrm{CO}\left(\mathrm{CO}_{2}\right)$ selective for the monolayer (multilayer) alloy ${ }^{[14 ; 119]}$. The reason is believed to originate from the electronic modification of the subsurface region, which is rather Pd-like for the monolayer alloy due to the underlying palladium foil, thus showing little activity towards MSR (see Fig. 23). Furthermore, the Zn3d region exclusively revealed the existence of oxidized zinc atoms on the surface of the multilayer alloy, which are held responsible for the water activation in MSR, thus effecting the high selectivity towards $\mathrm{CO}_{2}$. This steering of the reaction by the sub-surface can be explained by different electronic structures and differences in surface corrugation between the two types of $\mathrm{ZnPd}$ surface alloys. A beneficial role of the out-sticking zinc atoms in the multilayer material for water activation is vividly discussed ${ }^{[167 ; 170]}$. A combined experimental and theoretical study of the stability and reactivity of different ZnPd surface alloys has been presented by Neyman et al. 
[150]. The authors in particular emphasize the role of low coordinated surface sites for the dehydrogenation of methanol to formaldehyde.
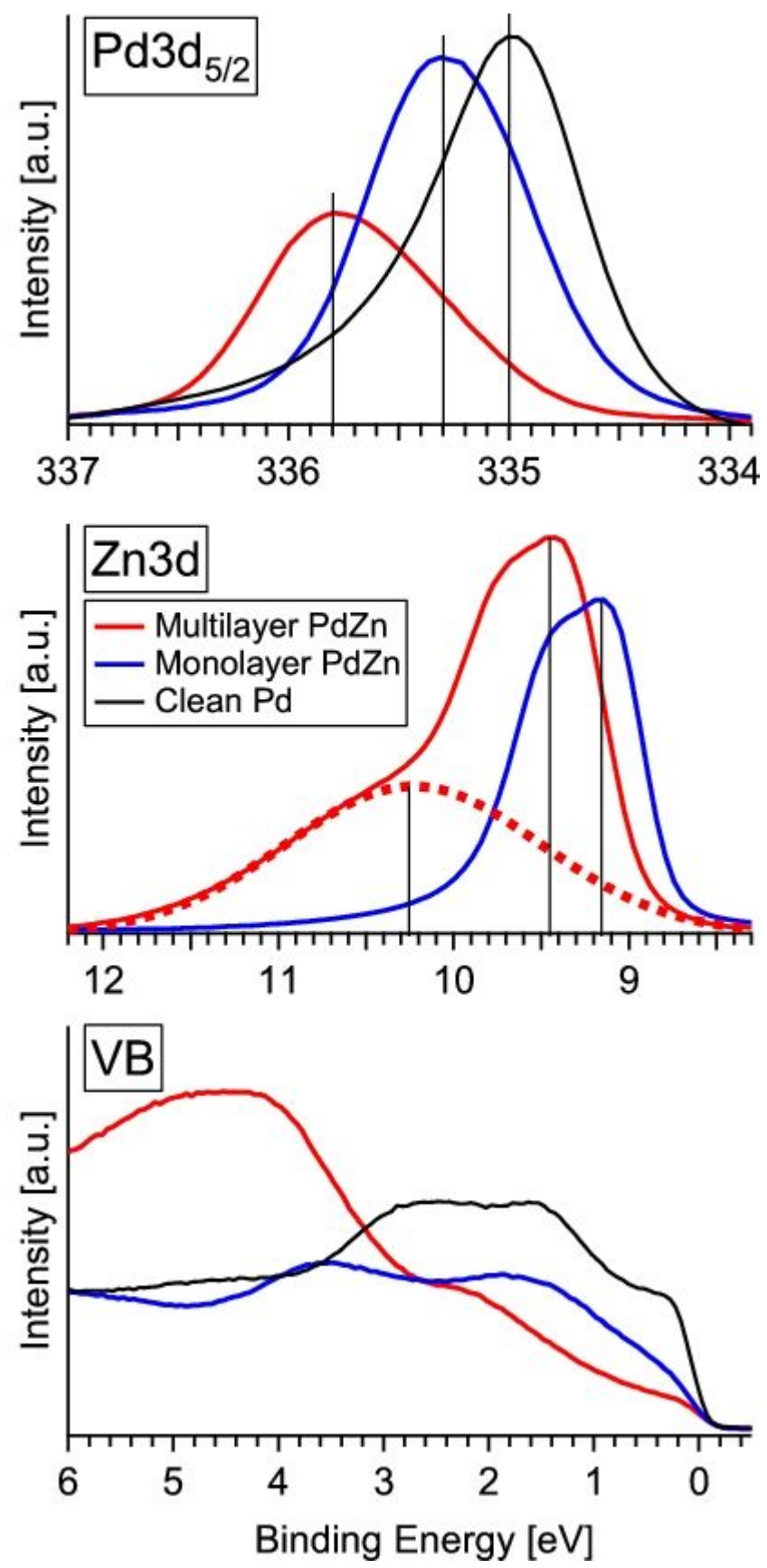

Figure 23: XPS under MSR conditions of the Pd3d, Zn3d and valence band region of Pd-Zn multilayer (red) and monolayer (blue) alloys, as well as of palladium foil (black). The dashed line in the $Z n 3 d$ region represents the oxidized zinc species. Pd3d spectra were recorded at $650 \mathrm{eV}, \mathrm{Zn} 3 \mathrm{~d}$ and valence band spectra were recorded at $120 \mathrm{eV}$. Reaction

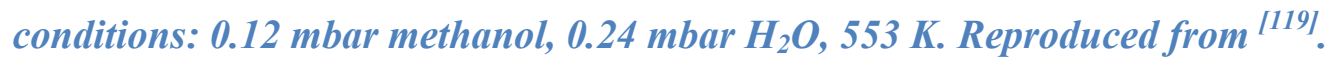


Reviewing the experimental data as well as the quantum chemical results in the literature, a synergistic interaction of the intermetallic compound $\mathrm{ZnPd}$ and $\mathrm{ZnO}$ in MSR is very likely. While the first is activating the $\mathrm{C}-\mathrm{H}$ bonds of methanol, the role of $\mathrm{ZnO}$ is to split the $\mathrm{O}-\mathrm{H}$ bonds of water and methanol. Subsequent reaction of adsorbed $\mathrm{CH}_{2} \mathrm{O}$ and $\mathrm{OH}$ leads then to the formation of $\mathrm{CH}_{2} \mathrm{OOH}$ which is decomposing into $\mathrm{CO}_{2}$. The adsorbed $\mathrm{CH}_{2} \mathrm{O}$ is a key intermediate, since it can be decomposed to $\mathrm{CO}_{2}$ as well as $\mathrm{CO}$ - depending on whether the catalyst is able to provide adsorbed $\mathrm{OH}$ by water activation or not.

Besides this knowledge, many interesting questions are still open: Up to now, it is not clear if a particle size effect exists for MSR on $\mathrm{ZnPd} / \mathrm{ZnO}$. Do the $\mathrm{ZnPd}$ particles possess different compositions under reaction conditions depending on their synthesis conditions? Is it possible to generate a new catalytic system - maybe even noble metal-free - which provides the same selectivity and stability? What is the active site in the material? Is spillover important or is only the $\mathrm{ZnPd} / \mathrm{ZnO}$ interface active? Which elementary reactions take place on the surface? Are there differences to the ones on copper? Running in parallel to investigations addressing these basic research questions, the testing of $\mathrm{ZnPd}$-based materials as catalysts in microstructured reactors reveal already a possible way into mobile energy application, e.g. supplying notebooks with energy. 


\section{Surface behavior in reactive atmospheres}

Several publications have demonstrated the highly dynamic nature of Pd-Zn systems with the surface adapting to the reactive environment that it is exposed to. Thus, the last section of this review is dedicated to the behavior of $\mathrm{Zn}-\mathrm{Pd}$ surfaces - covering the whole range of materials from unsupported materials to surface alloys - and the changes occurring upon exposure to different atmospheres, such as $\mathrm{O}_{2}$ and methanol/water. We will address changes in structure, composition, oxidation state and electronic properties occurring in situ, stability issues and potential segregation effects. In the following, the surface behavior will be discussed by means of selected case studies, which cover phenomena such as in situ oxidation, variations in bulk vs. surface composition and in situ stability.

\section{6.a) Unsupported state}

Friedrich et al. ${ }^{[62]}$ investigated the surface composition in various atmospheres for a series of single phase intermetallic $\mathrm{ZnPd}$ compounds with different bulk compositions $\left(\mathrm{Zn}_{100-\mathrm{x}} \mathrm{Pd}_{x}, x=\right.$ 46.8-59.1). XPS measurements were recorded at mbar pressures in different states of the materials: as prepared, upon reduction in $\mathrm{H}_{2}$ and in reactive MSR environment. The surface of the as prepared samples was enriched in zinc mostly in the oxidized state. This was attributed to grinding of the samples in air before the measurements leading to zinc surface segregation and oxidation. Reduction in $\mathrm{H}_{2}$ at elevated temperatures led to the reduction of oxidized zinc species and to an increase in the intensity of the signal of intermetallic zinc species, as observed in the zinc Auger LMM spectra. However, on the Zn-rich samples (with respect to bulk composition) zinc reduction was not complete even at $693 \mathrm{~K}$ reduction temperature. A significant amount of the zinc at the surface remained in the oxidized state (Fig. 24). In contrast, on the Pd-rich samples no oxidized zinc species was present after reduction under the same conditions and only intermetallic zinc was observed. Under MSR conditions, the Zn3d signals of all samples remained almost unaffected in comparison to the spectra after $\mathrm{H}_{2}$ reduction, the oxidized zinc on the zinc-rich samples was preserved. Figure 25 shows the atomic $\mathrm{Zn} / \mathrm{Pd}$ ratios determined by XPS after reduction in $\mathrm{H}_{2}$ and under MSR conditions and compares them to the bulk composition. The $\mathrm{Zn}: \mathrm{Pd}$ ratio in all samples was higher upon reduction than under MSR conditions. In addition, valence band spectra indicated changes in the electronic structure, with a decrease in the DOS near the Fermi level with decreasing palladium content (Fig. 10). The 
observed variations in surface composition (i.e. the extent of zinc enrichment), zinc oxidation state and in electronic properties were connected to the catalytic properties for MSR, which revealed low selectivity to the desired $\mathrm{CO}_{2}$ and $\mathrm{H}_{2}$ formation on Pd-rich samples and higher activity and substantially higher selectivity on zinc rich samples (Figure 21).

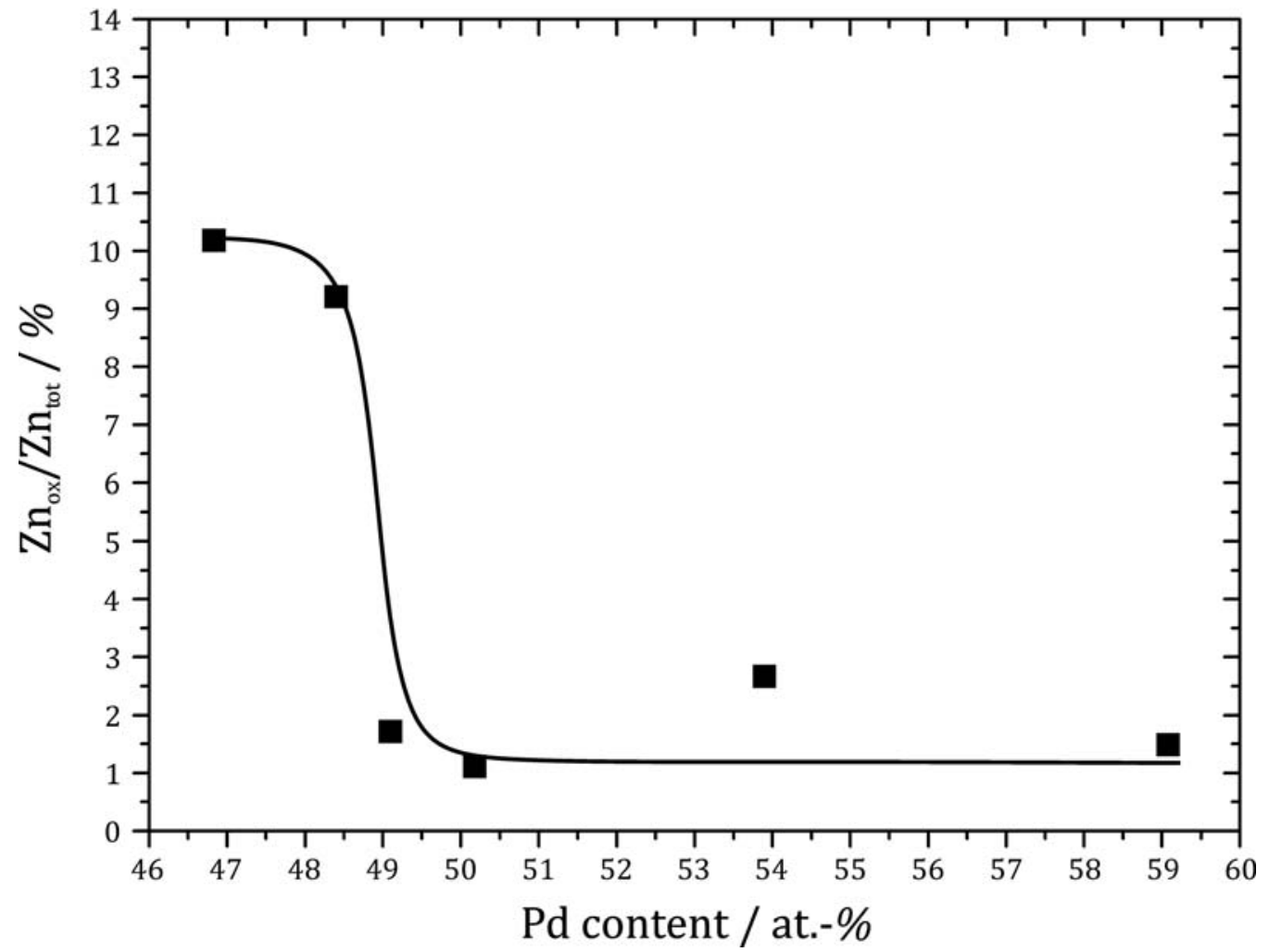

Figure 24: Surface $Z n_{o x}$ content depending on the bulk palladium-content of $Z n_{100-x} P d_{x}$ samples in XPS under MSR conditions (0.2 mbar, $\left.\mathrm{MeOH}: \mathrm{H}_{2} \mathrm{O}=1: 2,693 \mathrm{~K}\right)$. Redrawn from ${ }^{[52]}$.

This work ultimately stresses the significance of in situ determination of the surface and near surface composition in order to be able to answer the open questions concerning the nature of the active sites and reaction mechanism and to interpret the role and interplay of the intermetallic compound $\mathrm{ZnPd}$, of the $\mathrm{ZnPd}-\mathrm{ZnO}$ interface and of the presence of oxidized zinc species during MSR. Even for such small variations in bulk composition significant changes in the surface composition can occur and strongly affect the catalytic properties. 


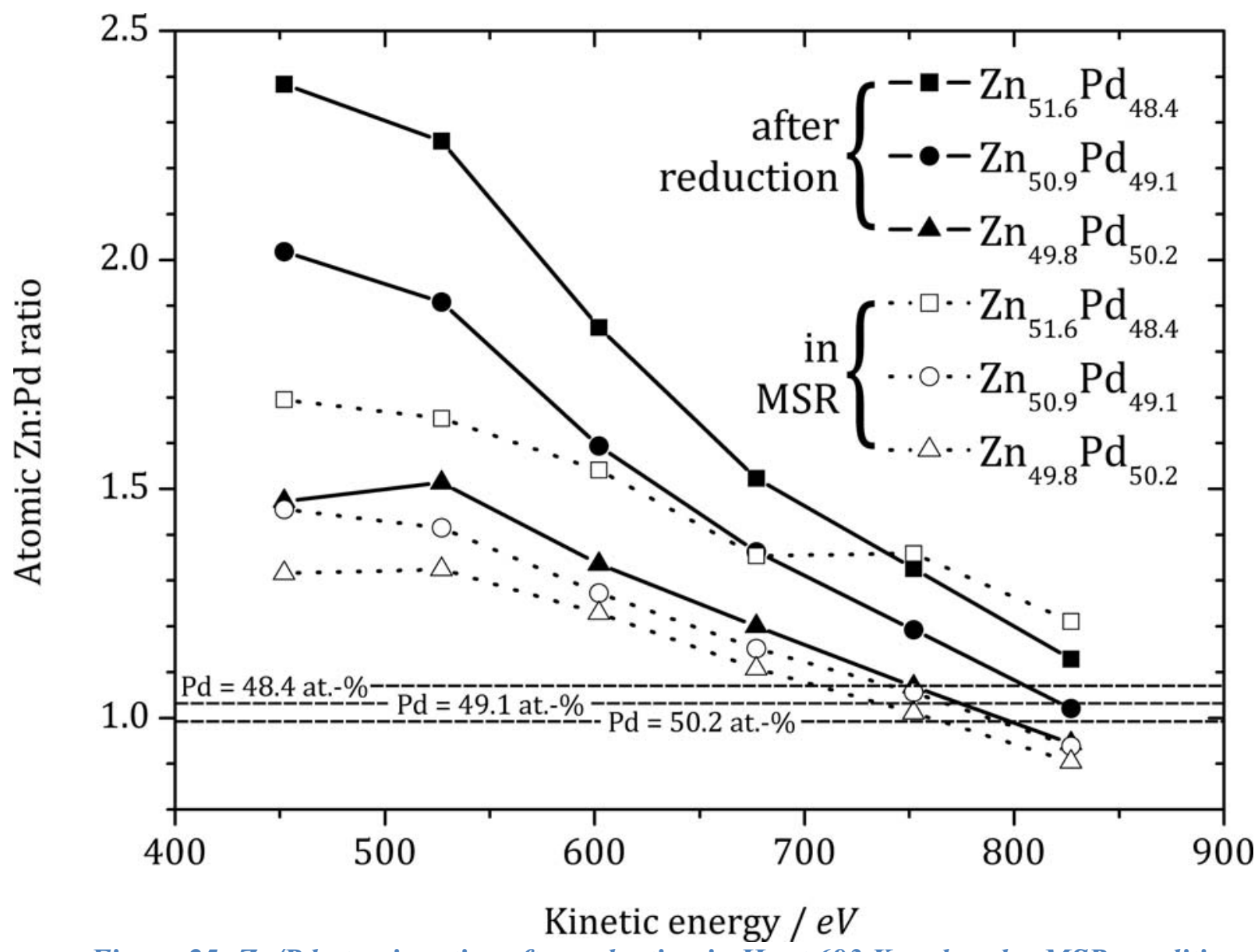

Figure 25: $\mathrm{Zn} / \mathrm{Pd}$ atomic ratios after reduction in $\mathrm{H}_{2}$ at $693 \mathrm{~K}$ and under MSR conditions (633 $\left.\mathrm{K}, \mathrm{H}_{2} \mathrm{O}: \mathrm{MeOH}=2: 1\right)$. Taken from ref. ${ }^{[62]}$.

Halevi et al. ${ }^{[65]}$ investigated $\mathrm{ZnPd}$ powders derived from aerosols, representing a novel form of model catalyst, also utilizing in situ XPS. The XPS measurements revealed the presence of the intermetallic compound $\mathrm{ZnPd}$ and of oxidized zinc coexisting at the surface upon reduction of the powders at $523 \mathrm{~K}$. Based on depth profiling data it was suggested that the outer surface was mostly composed of $\mathrm{ZnO}$. The authors concluded that the short reduction time (30 $\mathrm{min})$ and the low $\mathrm{H}_{2}$ pressure $(0.25 \mathrm{mbar})$ at the reduction temperature of $523 \mathrm{~K}$ are mainly responsible for the incomplete reduction of the $\mathrm{ZnO}$. But still formation of the intermetallic compound occurred under these conditions.

\section{6.b) Supported state}

Most commonly, palladium precursors supported on $\mathrm{ZnO}$ are used as starting materials to synthesize supported $\mathrm{ZnPd}$ particles. The active and selective $\mathrm{ZnPd}$ phase for the MSR reaction is 
then formed upon exposure of $\mathrm{Pd} / \mathrm{ZnO}$ to a reducing atmosphere at higher temperatures, typically $>523 \mathrm{~K}$, either by activation of the catalyst via reduction in hydrogen or directly in the reaction atmosphere (see section 3.b)).

A major issue for potential application of ZnPd in MSR is the stability in reactive atmosphere. Many groups reported stable catalytic properties of $\mathrm{ZnPd}$-based catalysts under reaction atmosphere in contrast to $\mathrm{Cu}$ catalysts. Fig. 26 compares the long-term stability over $60 \mathrm{~h}$ for a commercial $\mathrm{Cu} / \mathrm{ZnO} / \mathrm{Al}_{2} \mathrm{O}_{3}$ catalyst (BASF F13456) and for $\mathrm{Pd} / \mathrm{ZnO} / \mathrm{Al}_{2} \mathrm{O}_{3}{ }^{[82]}$. The $\mathrm{Cu} / \mathrm{ZnO}$ based catalyst suffers from fast initial deactivation, followed by a continuous long-term deactivation, while the ZnPd-based catalyst exhibits stable activity after an initial deactivation period. In contrast to $\mathrm{Cu}$, the initial activity of the $\mathrm{Pd} / \mathrm{ZnO} / \mathrm{Al}_{2} \mathrm{O}_{3}$ can be fully recovered by an oxidation treatment followed by re-exposure to reaction atmosphere. FTIR spectroscopy of CO adsorption confirmed that an identical state of the surface was obtained after this treatment. This was corroborated by Lebarbier et al. ${ }^{[146]}$ who used FTIR spectroscopy of CO adsorption and found that the exposure of $\mathrm{ZnPd} / \mathrm{ZnO} / \mathrm{Al}_{2} \mathrm{O}_{3}$ catalyst to a mixture of methanol and water, simulating MSR conditions, did not change the surface composition.
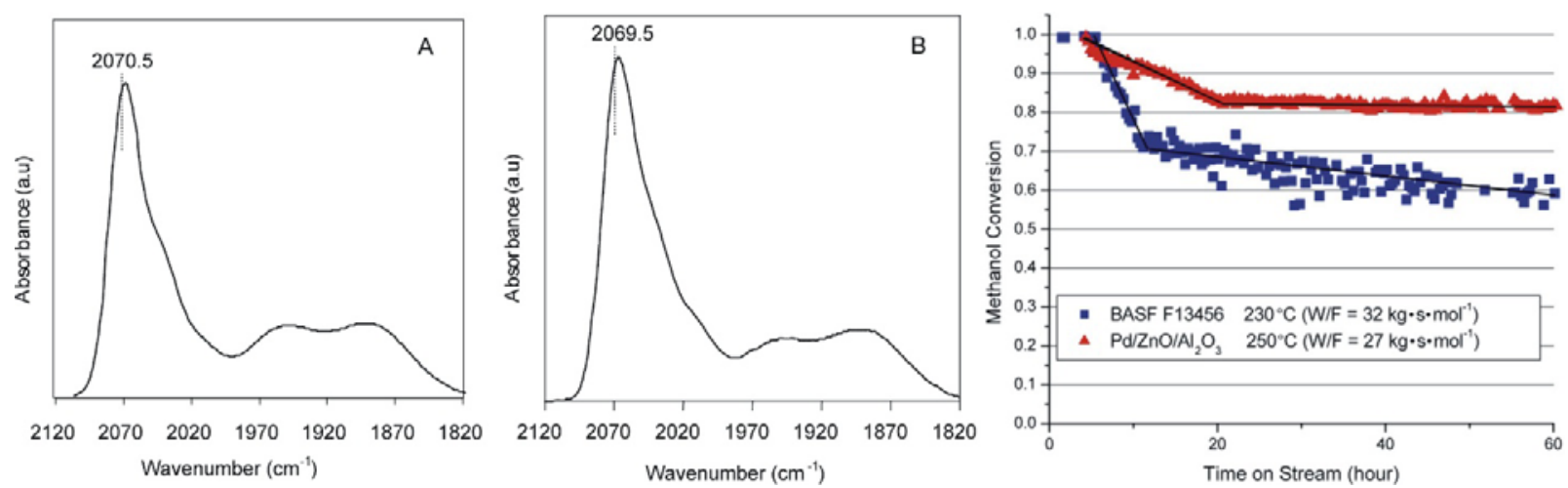

Figure 26: IR spectra of adsorbed $\mathrm{CO}$ on $\mathrm{Pd} / \mathrm{ZnO} / \mathrm{Al}_{2} \mathrm{O}_{3}(\mathrm{~A})$ after reduction at $523 \mathrm{~K}$ before being tested for MSR at $523 \mathrm{~K}$ while catalyst (B) underwent no pretreatment prior to the MSR reaction. Right panel: Activity over 60 h: comparison between a commercial Cu-based catalyst (BASF F13456) and $\mathrm{Pd} / \mathrm{ZnO} / \mathrm{Al}_{2} \mathrm{O}_{3}$. The reaction temperature was $523 \mathrm{~K}$ for the $\mathrm{Pd}$ based catalyst and $503 \mathrm{~K}$ for the Cu-based catalyst. Taken from ${ }^{[82]}$.

Liu et al. ${ }^{[186]}$ investigated the long-term catalytic performance of $\mathrm{Pd} / \mathrm{ZnO}$ for MSR, oxidative steam reforming of methanol (OSR) and partial oxidation of methanol (POM) in comparison to $\mathrm{Cu} / \mathrm{ZnO}$. Whereas $\mathrm{Cu} / \mathrm{ZnO}$ lost its activity with stable $\mathrm{CO}$ selectivity, $\mathrm{Pd} / \mathrm{ZnO}$ exhibited a more 
stable activity. However, an increasing CO production was observed with time on stream. Based on characterization by XPS and XRD, two routes were supposed for the deactivation of $\mathrm{Pd} / \mathrm{ZnO}$ catalyst: carbon deposition and surface oxidation of the intermetallic compound $\mathrm{ZnPd}$ resulting in elemental palladium on $\mathrm{ZnO}^{[186]}$.

Zhang et al. ${ }^{[177]}$ studied the long-term stability in MSR at high reaction temperatures $(673 \mathrm{~K})$ on $\mathrm{ZnPd} / \mathrm{CeO}_{2}$. Beside some $\mathrm{Pd}$ sintering, the most important cause of deactivation was formation of carbonaceous deposits. In contrast to Liu et al. ${ }^{[186]}$ the decrease in conversion was accompanied by an increase in $\mathrm{CO}_{2}$ selectivity in the work of Zhang. Upon $600 \mathrm{~h}$ continuous operation $\mathrm{CO}_{2}$ selectivity increased from 70 to $90 \%$ due to an increasing extent of $\mathrm{ZnPd}$ formation with time on stream. The carbonaceous deposits could effectively be removed by oxidation treatment at $673-873 \mathrm{~K}$. Two different types of carbon deposits were found at the catalyst surface decorating both $\mathrm{Pd}$ and $\mathrm{ZnPd}$, which could be removed at 473-673 K and 673$973 \mathrm{~K}$, respectively. Treatment of the catalyst with $\mathrm{CO}$ and $\mathrm{CO}_{2}$ at $673 \mathrm{~K}$ resulted in a drop in MSR activity, which could be reversed by oxidative regeneration. Another deactivation process potentially occurring under MSR conditions was reported by Suwa et al. ${ }^{[175]}$. In this work, it was observed that $\mathrm{Zn}-\mathrm{Pd} / \mathrm{C}$ exhibited higher stability than $\mathrm{Pd} / \mathrm{ZnO}$ in MSR. This was explained by the formation of zinc carbonate hydroxide, which was observed on $\mathrm{Pd} / \mathrm{ZnO}$ by means of $\mathrm{XRD}$. The deactivation was suggested to be due to the decoration of the active $\mathrm{ZnPd}$ particles by zinc carbonate hydroxides. Although this phenomenon also occurred on $\mathrm{Zn}-\mathrm{Pd} / \mathrm{C}$, the deactivation rate was much lower than for $\mathrm{Pd} / \mathrm{ZnO}$ because of the higher amount of $\mathrm{ZnO}$.

In a very recent TEM study, Friedrich et al. ${ }^{[188]}$ revealed strong changes of freshly reduced $\mathrm{ZnPd} / \mathrm{ZnO}$ under MSR conditions. TEM directly after reduction showed strongly structurally as well as chemically disordered $\mathrm{ZnPd}$ particles on the $\mathrm{ZnO}$, going hand in hand with a $\mathrm{CO}_{2}$ selectivity in MSR of only $40 \%$. Within the first two hours time-on-stream, the selectivity steeply increases to a stable $97 \%$. According to TEM, the material changes in two ways; i) the $\mathrm{ZnPd}$ particles become much more homogeneous concerning their composition and show much higher structural order and ii) the $\mathrm{ZnPd}$ particles are now decorated with very small $\mathrm{ZnO}$ patches. The first change reduces the number of different adsorption sites for the reactants, thus leading to an increased selectivity. Since it has been shown on unsupported $\mathrm{ZnPd}$ that the presence of $\mathrm{ZnO}$ is necessary to achieve high $\mathrm{CO}_{2}$ selectivity ${ }^{[62]}$, the decoration of the $\mathrm{ZnPd}$ particles with $\mathrm{ZnO}$ and the resulting strong increase of the presence of the $\mathrm{ZnPd}-\mathrm{ZnO}$ interface can be held responsible 
for the remarkable selectivity change, thus giving further evidence for a teamwork of $\mathrm{ZnPd}$ and $\mathrm{ZnO}$ in the reaction.

When taking a close look at FTIR spectra of CO adsorption on oxide supported ZnPd catalysts (e.g. Fig. 26) one can notice that multiply bonded $\mathrm{CO}$ is typically not completely absent in most of the reported spectra ${ }^{[28 ; 82-84 ; 146]}$. According to UHV-based model studies multiple bonding adsorption sites should be absent at CO saturation coverage (see section 4.e)). Possible explanations include an effect of the higher $\mathrm{CO}$ pressures applied when studying supported powder materials, an indication of domains of metallic palladium, or reconstruction/geometric arrangement effects. To get more insights into the origin of the bridge and hollow bonded $\mathrm{CO}$ the stability of the ZnPd surface in CO was studied by Föttinger ${ }^{[189]}$. Following room temperature $\mathrm{CO}$ adsorption with time by FTIR spectroscopy, exposure to CO led to a partial degradation of the intermetallic $\mathrm{ZnPd}$ surface. The spectra exhibited an increasing fraction of $\mathrm{CO}$ on bridge and hollow adsorption sites with exposure time, resembling that of $\mathrm{CO}$ on metallic Pd. A limited stability of the ZnPd surface was also observed in methanol/water by in situ FTIR spectroscopy during MSR, likely due to the CO formed as a byproduct. Therefore, it was concluded that the surface under reaction conditions consists of domains of metallic palladium or a Pd-rich $\mathrm{ZnPd}$ in addition to the intermetallic surface. This effect was more critical at lower temperatures in MSR, which was suggested due to a faster in situ regeneration of the intermetallic surface by the produced hydrogen at higher temperatures $(>500 \mathrm{~K})$.

Another issue concerns the stability of the intermetallic compound $\mathrm{ZnPd}$ in the presence of oxygen, e.g. during oxidation, OSR or POM. It was found in several studies that $\mathrm{ZnPd}$ is degraded by an oxidative treatment. Agrell et al. ${ }^{[31]}$ studied partial oxidation of methanol over $\mathrm{Pd} / \mathrm{ZnO}$. Using XRD, they detected elemental palladium, ZnPd and $\mathrm{PdO}$ on the spent catalyst. This was explained by either considering that not all palladium reacts to $\mathrm{ZnPd}$ or that the intermetallic compound obtained by $\mathrm{H}_{2}$ reduction decomposes partially during reaction in the presence of $\mathrm{O}_{2}$ (reaction temperature 500-573 K). In contrast, Iwasa et al. ${ }^{[190]}$ carried out OSR and found that $\mathrm{ZnPd}$ remains unchanged in the absence or presence of $\mathrm{O}_{2}$ (reaction temperature 433-623 K). Conant et al. ${ }^{[82]}$ observed formation of $\mathrm{PdO}$ and $\mathrm{ZnO}$ after oxidative treatment of ZnPd at $773 \mathrm{~K}$. However, during MSR they observed identical catalytic properties after a certain reaction time independent of the applied pretreatment. They attributed this behavior to the establishment of a certain equilibrium state of the surface during the reaction, which depends on the reaction conditions and not on the pre-treatment. They proposed a "self-healing nature of the 
catalyst". Such a self-healing effect of the catalyst surface was also proposed by Lebarbier et al. [146].

This clearly demonstrates the importance and necessity of in situ techniques to obtain information on the working catalyst's properties. Determination of the structure and surface properties after a certain treatment is not sufficient for explaining catalytic performance if the catalyst surface adapts to a certain equilibrium state, depending on the reaction conditions and not on the pre-treatment, as described above. In this line, Föttinger et al. ${ }^{[83]}$ applied in situ XAS and FTIR spectroscopy of $\mathrm{CO}$ adsorption for studying the effect of $\mathrm{O}_{2}$ on the $\mathrm{ZnPd}$ phase. $\mathrm{ZnPd}$ supported on $\mathrm{ZnO}$ was exposed to $\mathrm{O}_{2}$ at $573 \mathrm{~K}$, which led to the partial decomposition of the $\mathrm{ZnPd}$, as observed in situ by XAS (Fig. 27), where the spectral features changed back towards elemental palladium. No oxidation of the palladium was observed as long as intermetallic zinc is present, indicating preferential oxidation of the zinc under these conditions. FTIR spectroscopy revealed a partial decoration of the palladium with $\mathrm{ZnO}$ islands (see Fig. 27). Spectra after $\mathrm{ZnPd}$ exposure to oxygen showed characteristic bands of $\mathrm{CO}$ on metallic Pd. However, the intensity was strongly reduced indicating partial blocking of the palladium surface, most likely by $\mathrm{ZnO}$ islands. This is summarized in the scheme in Fig. 27. Upon reduction in $\mathrm{H}_{2}$ or methanol/water, formation of $\mathrm{ZnPd}$ was found to be reversible, in agreement with ${ }^{[82]}$.
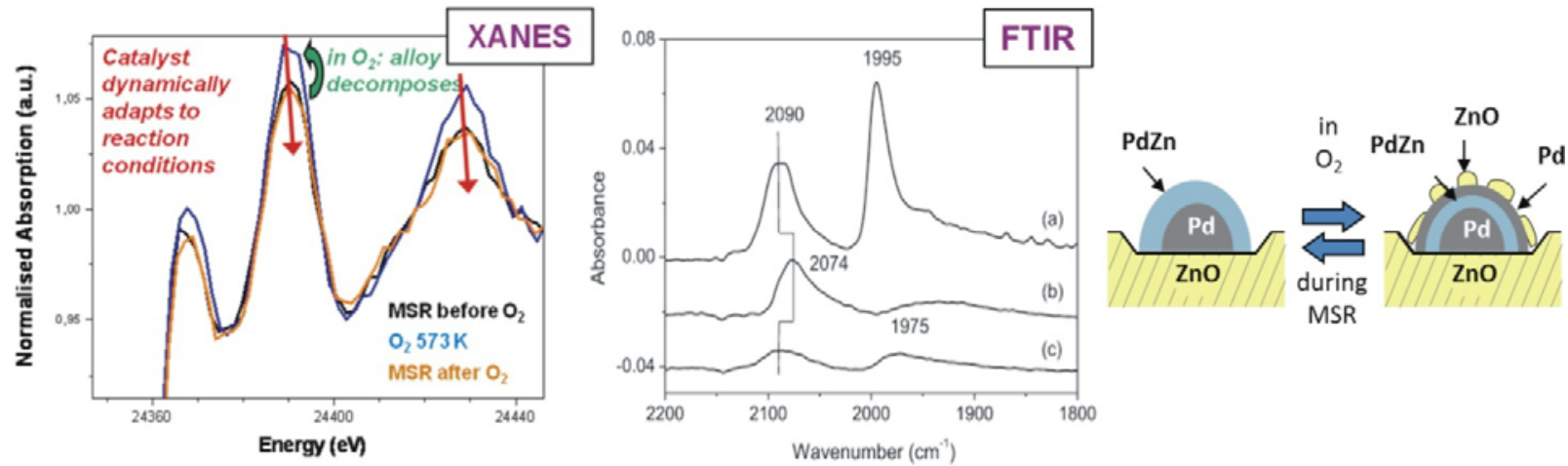

Figure 27: Effect of oxygen exposure on ZnPd/ZnO: In situ PdK-edge XANES spectra of $\mathrm{Pd} / \mathrm{ZnO}$ under MSR at $623 \mathrm{~K}$ before $\mathrm{O}_{2}$ treatment, after 30 min under $\mathrm{O}_{2} / \mathrm{He}$ at $573 \mathrm{~K}$, and after exposure to MSR for 30 min at $623 \mathrm{~K}$ following the $\mathrm{O}_{2}$ treatment (left). FTIR spectra of CO adsorption (303 K, 5 mbar CO) on $\mathrm{Pd} / \mathrm{ZnO}$ after (a) reduction at $303 \mathrm{~K}$; (b) after reduction at $623 \mathrm{~K}$; and (c) after oxidation at $573 \mathrm{~K}$ and re-reduction at $303 \mathrm{~K}$ following (b) (middle). Illustration of the suggested structural changes of $\mathrm{Pd} / \mathrm{ZnO}$ in various environments (right). Taken from Ref. ${ }^{[83]}$. 
Similarly, Uemura et al. followed reduction and oxidation of Pd supported on $\mathrm{ZnO}$ by quick XAFS and dispersive XAFS ${ }^{[191]}$. In agreement with the work of Föttinger et al. ${ }^{[83]} \mathrm{ZnPd}$ formed upon reduction was decomposed in oxygen leading to formation of oxidized zinc and $\mathrm{Pd}$ nanoparticles. They determined reduction and oxidation rate constants at $673 \mathrm{~K}$ for the following sequential processes: in $20 \mathrm{kPa} \mathrm{H}_{2}$ reduction of $\mathrm{PdO}$ to $\mathrm{Pd}$ occurred with a rate constant of $2.1 \mathrm{~s}^{-1}$, followed by $\mathrm{ZnPd}$ formation from $\mathrm{Pd} / \mathrm{ZnO}$ with a rate constant $2.7 \times 10^{-3} \mathrm{~s}^{-1}$, while in $\mathrm{O}_{2}$ at $673 \mathrm{~K}$ $\mathrm{Zn}$ migrated out of the intermetallic particles, was oxidized and Pd particles formed at $0.14 \mathrm{~s}^{-1}$. Further oxidation of Pd to PdO occurred very slowly with a rate constant of $8.3 \times 10^{-4} \mathrm{~s}^{-1}$.

\section{6.c) Surface alloys}

The last class of materials that will be discussed are surface alloys or NSIPs prepared by evaporating zinc onto palladium single crystals followed by thermal annealing. In this section we will take a closer look at the surface behavior of these alloys in reactive atmospheres by in situ XPS. Rameshan et al. ${ }^{[114 ; 119]}$ compared the properties and reactivity of SA-1 and SA-2 $\mathrm{ZnPd} / \mathrm{Pd}(111)$ NSIPs. These NSIPs show considerable differences in the structure (different corrugation), reaction selectivity ( $\mathrm{CO}$ vs. $\mathrm{CO}_{2}$ ) and electronic properties (valence band spectra), as described in sections 3.c), 4.a) and 5.c). Beside these intrinsic differences due to the different subsurface chemistry also a different behavior in the reactive atmosphere of methanol and water was detected by XPS. From the Zn3d spectra acquired under MSR reaction conditions (Fig. 23) it was found that SA-1 activates water by forming $\mathrm{ZnOH}$ species (resulting in a shoulder at 10.25 $\mathrm{eV}$ ), while this species was not observed on SA-2 under the same conditions. It was concluded that the monolayer alloy SA-2 does not activate water, which is necessary to convert intermediate formaldehyde to $\mathrm{CO}_{2}$. Thus, a dehydrogenation to $\mathrm{CO}$ is more likely to occur on the unselective SA-2. This result was supported by the corresponding $\mathrm{C} 1 s$ spectra ${ }^{[119]}$, where signals of $\mathrm{CH}_{2} \mathrm{O}$ or related oxygenates were observed on the multilayer NSIP SA-1. Above around $570 \mathrm{~K}$ the $\mathrm{CH}_{2} \mathrm{O}$ was replaced by $\mathrm{CO}$, indicating the transformation of multilayer to monolayer alloy by diffusion of the zinc into the bulk.

Recently, Weilach et al. ${ }^{[154]}$ showed that CO has a strong influence on the surface structure of $\mathrm{ZnPd} / \mathrm{Pd}(111)$. This has to be taken into account when applying $\mathrm{CO}$ as a probe molecule to characterize adsorption sites on the intermetallic surfaces, and has to be considered as well under reaction conditions due to the typical presence of CO as a byproduct in MSR. In ref. ${ }^{[154]}$ TPD and PM-IRAS experiments of CO adsorption, as described in section 4.e), were combined with 
DFT calculations of the stability of different surface geometric arrangements (Fig. 28). While the "row structure" consisting of alternating rows of $\mathrm{Pd}$ and $\mathrm{Zn}$ (corresponding to the bulk termination of a (111) $\mathrm{ZnPd}$ surface) is the most stable geometric arrangement in vacuum, CO was calculated to induce a geometric rearrangement to a "zigzag"-like structure without changing the stoichiometric composition. The relative stabilities of the proposed structures are illustrated in Figure 28. Experimental evidence for such a CO-induced rearrangement was provided by TPD and PM-IRAS of adsorbed CO. While bridge sites are more stable on the row structure, on-top sites should be favored on the zigzag structure. The absence of stable bridge $\mathrm{CO}$ adsorption sites on the $\mathrm{ZnPd}$ surface detected by PM-IRAS clearly supports the zigzag structure. Additional proof was derived from CO TPD experiments. Both the experimentally determined saturation coverage of $0.5 \mathrm{ML}$ and the desorption energies obtained are in excellent agreement with the predicted values for the zigzag-like structure for the NSIP.

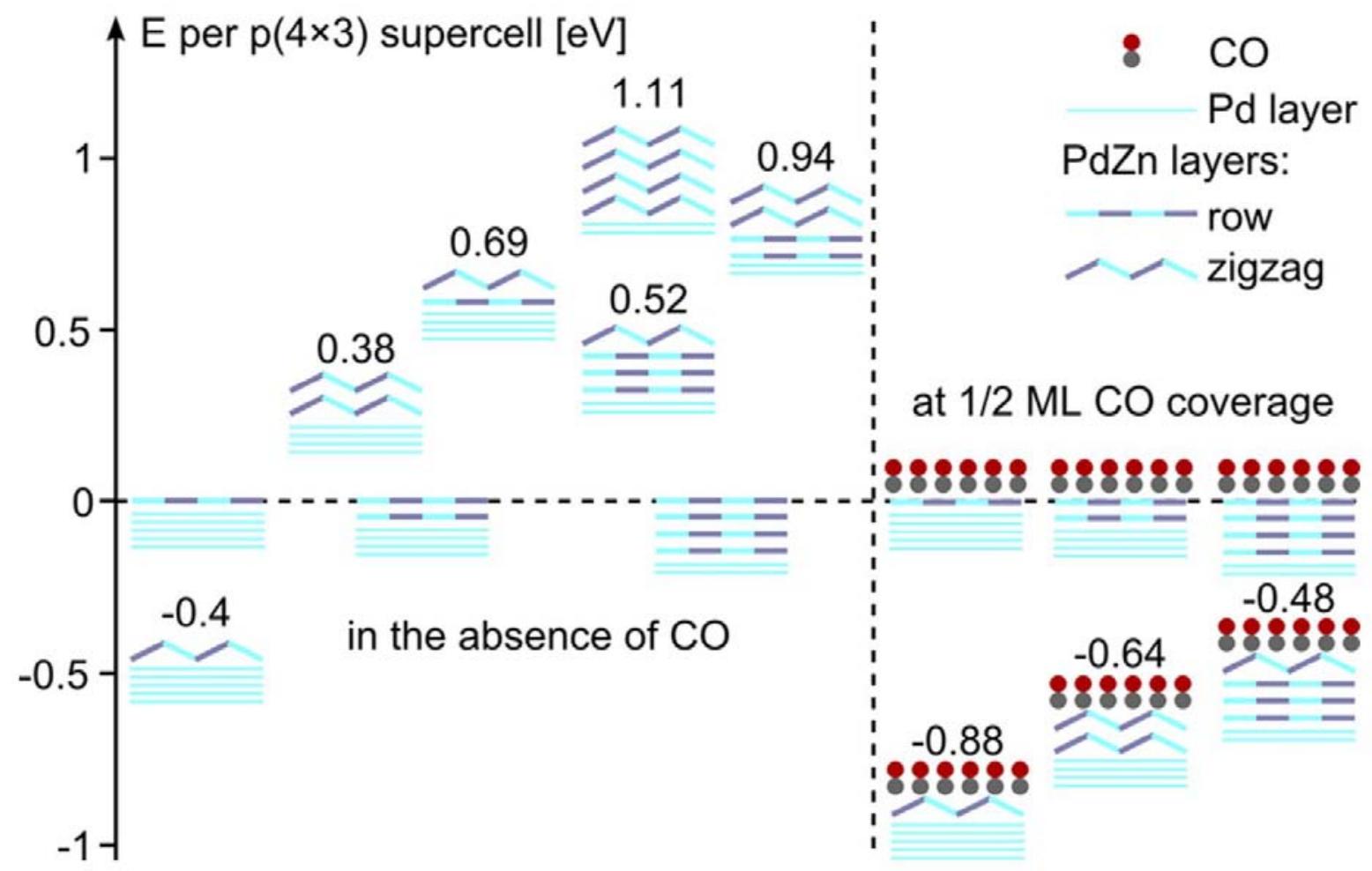

Figure 28: Calculated relative stability of various structures of ZnPd/Pd(111) surface alloys with respect to the conventional structure (all layers arranged in rows), depending on the number of layers arranged in zigzags and on the CO coverage. Values are given per $p(4 \times 3)$ supercell, which has 12 metal atoms in each layer. From ${ }^{[154]}$. 
The large number of investigations on different materials provides an insight on the ongoing processes at elevated temperatures under reactive atmospheres containing hydrogen, oxygen or the methanol steam reforming feed. While unsupported $\mathrm{ZnPd}$ shows only small changes between reductive and MSR conditions, small $\mathrm{ZnPd}$ particles supported on $\mathrm{ZnO}$ are a fast adapting system, which is stable under MSR conditions. Exposure to CO leads to decomposition of the intermetallic surface with time. In contrast, the intermetallic bulk particles are surprisingly stable in oxygen-containing atmospheres: temperatures above $573 \mathrm{~K}$ are needed to oxidize the compound to $\mathrm{PdO}$ and $\mathrm{ZnO}$. Only a few studies have addressed the changes of the material leading to deactivation. Two possible scenarios are suggested: i) deactivation is caused by carbonaceous deposits ${ }^{[177]}$ and ii) loss of activity and selectivity is attributed to the partial oxidation of $\mathrm{ZnPd}$ to elemental palladium and zinc carbonate hydroxide formation ${ }^{[175]}$.

Investigations on the thermodynamically unstable surface alloys revealed a large difference in reactivity of bilayer SA-1 and monolayer SA-2. While SA-1 is able to activate water, SA-2 is not, explaining their very different catalytic behavior in MSR. In addition, the surface of the NSIPs is strongly influenced by the presence of $\mathrm{CO}$, leading to a restructuring of the row structure to a zigzag structure, thus showing the flexibility of the surface under reaction conditions, where $\mathrm{CO}$ is usually present in the $1000 \mathrm{ppm}$ regime. 


\section{Conclusions}

Detailed and interdisciplinary review of the literature on the intermetallic compound $\mathrm{ZnPd}$ is performed to obtain a comprehensive knowledge of the compound. The chemical bonding, especially the covalent Pd-Pd interactions, is responsible for the tetragonal distortion of the crystal structure. In consequence, a strongly altered band structure results compared to the constituting elements, turning $\mathrm{ZnPd}$ - as each other intermetallic compound - into a "new element" concerning its adsorption and thus its catalytic properties.

The material can be synthesized in an unsupported state from the elements in a microcrystalline form or by reduction of palladium and zinc precursors as nanoparticles. In addition, supported ZnPd-based catalysts can be synthesized by a large variety of approaches including impregnation, electroless plating and careful decomposition of precursor materials. The rich surface alloy - or near-surface intermetallic phase (NSIP) - chemistry also allows studying materials mimicking bulk $\mathrm{ZnPd}$ in ultra-high vacuum using the large number of surface science methods. Comparison of literature on these variety of materials shows, that they behave quite differently. Bulk compounds withstand oxidizing conditions better than supported nanoparticles and according to the numerous quantum chemical studies the NSIPs differ in their adsorption properties from the bulk compounds. Nevertheless, when keeping these differences in mind, each material and each experimental as well as theoretical study contributes to the understanding of the ongoing processes during methanol steam reforming. In addition, the possibility to study the different forms of $\mathrm{ZnPd}$ is a huge step forward to narrow the materials gap.

The rich literature on adsorption and catalytic properties covers not only experimental studies but also a large number of quantum chemical calculations concerning the possible reaction paths and adsorption properties. The experimental studies involve all four classes of materials, revealing large differences of the catalytic properties with the $\mathrm{Zn}: \mathrm{Pd}$ ratio or the thickness of the NSIPs. Besides these basic studies, they show the possibility to implement ZnPd-based catalysts in microstructured reactors, thus easing application of these materials. From the quantum chemical studies, a most likely reaction path for MSR on $\mathrm{ZnPd}$ has been derived involving $\mathrm{CH}_{2} \mathrm{O}$ as hub between $\mathrm{CO}$ - and $\mathrm{CO}_{2}$-selective catalysts. This enables future experimental studies to address not only the suggested path experimentally, but also to focus on a synergetic effect 
between $\mathrm{ZnO}$ and $\mathrm{ZnPd}$, which is likely due to experimental evidence as well as quantum chemical calculations.

Numerous studies are concerned with the behavior of the different materials in reactive atmosphere. They reveal the highly dynamic nature of $\mathrm{ZnPd}$ which adapts to the different atmospheres. In consequence, the bulk compound - depending on its composition which determines its reduction potential - has an oxidic zinc species at the surface or not. Supported nanoparticles on $\mathrm{ZnO}$ have been shown to decompose upon the exposure of $\mathrm{CO}$ or under oxidizing conditions. In addition, the oxidation is fully reversible by heating the materials in hydrogen. Thus, the surface of the intermetallic compound is prone to change with changing chemical reducing or oxidizing potential of the atmosphere, necessitating monitoring the surface under reaction conditions. The changes of the surface depend strongly on the composition of the bulk material, the latter providing a stable backbone for the adopting surface.

Based on the extensive knowledge about the different materials, revealing the synergistic effect between $\mathrm{ZnPd}$ and $\mathrm{ZnO}$ in MSR by experimental as well as quantum chemical studies is possible and will most likely form the central point of future investigations. Especially answering the question whether the mechanism involves exchange by spillover of reactants from the materials or if the reaction takes predominantly place at the $\mathrm{ZnPd}-\mathrm{ZnO}$ interface remain future tasks. The very interesting and - besides $\mathrm{ZnPd}$ and a handful other intermetallic compounds mostly unknown chemical properties make intermetallic compounds a class of materials with a high potential in heterogeneous catalysis worthwhile to be explored further.

\section{Acknowledgement}

The authors are members of the Think Tank of Young Researchers of the COST Action CM0904 "Intermetallic Compounds as Catalysts for Methanol Steam Reforming", which is acknowledged for financial support of the creative meetings nurturing this publication. M.A. and M.F. thank the DFG for financial support (AR617/3-1). S.K.M. thanks the SBF for financial support (C11.0034). 


\section{Reference List}

[1.] U. Eberle, M. Felderhoff, F. Schüth, Angew. Chem. Int. Ed. 2009, 48 6608-6630.

[2.] G. A. Olah, G. K. S. Prakash, A. Goeppert, J. Am. Chem. Soc. 2011, 133 12881-12898.

[3.] X. Cheng, Z. Shi, N. Glass, L. Zhang, J. Zhang, D. Song, Z.-S. Liu, H. Wang, J. Shen, J. Power Sources 2007, 165 739-756.

[4.] K. Narusawa, M. Hayashida, Y. Kamiya, H. Roppongi, D. Kurashima, K. Wakabayashi, JSAE Rev. 2003, 24 41-46.

[5.] S. Sá, H. Silva, L. Brandão, J. M. Sousa, A. Mendes, Appl. Catal. B 2010, 99 43-57.

[6.] J. D. Holladay, Y. Wang, E. Jones, Chem. Rev. (Washington, DC, U.S.) 2004, 104 47674790 .

[7.] H. Purnama, F. Girgsdies, T. Ressler, J. H. Schattka, R. A. Caruso, R. Schomäcker, R. Schlögl, Catal. Lett. 2004, 94 61-68.

[8.] J.-P. Shen, C. Song, Catal. Today 2002, 77 89-98.

[9.] M. Behrens, M. Armbrüster, in Catalysis for Alternative Energy Generation (Eds.: L. Guczi, A. Erdôhelyi), Springer, Berlin, New York 2012, pp. 175-235.

[10.] N. Iwasa, S. Kudo, H. Takahashi, S. Masuda, N. Takezawa, Catal. Lett. 1993, 19211 216.

[11.] C.-T. Hong, C.-T. Yeh, F.-H. Yu, Appl. Catal. 1989, 48 385-396.

[12.] D. V. Sokolskii, L. M. Kurashvili, K. Sergazieva, K. K. Kuzembaev, React. Kinet. Catal. Lett. 1985, 28 373-377.

[13.] R. C. Castellano, Y. Liu, A. Moini, G. S. Koermer, R. J. Farrauto, US7,569,511, 2009.

[14.] J. Hu, Y. Wang, D. VanderWiel, C. Chin, D. Palo, R. Rozmiarek, R. Dagle, J. Cao, J. Holladay, E. Baker, Chem. Eng. J. 2003, 93 55-60.

[15.] F. Ammari, PhD Thesis, L'Université Louis Pasteur, Strasbourg, 2002.

[16.] J. Araña, N. Homs, J. Sales, J.-L. G. Fierro, P. R. de la Piscina, Catal. Lett. 2001, 72 183189.

[17.] N. Iwasa, M. Takizawa, M. Arai, Appl. Catal. A 2005, 283 255-263.

[18.] N. Iwasa, M. Yoshikawa, M. Arai, Phys. Chem. Chem. Phys. 2002, 4 5414-5420. 
[19.] L. M. Kurashvili, K. Sergazieva, A. F. Burcev, A. S. Kunashev, L. R. Krylova, A. V. Korolev, C. L. Smirnov, K. K. Kuzenbaev, N. A. Kuanyshev, 7 Vsesoyuznaya Konferentsiya Kataliticheskie Reaktsii v Zhidkoi Faze 1988, part 2, 49.

[20.] A. Sarkany, Z. Zsoldos, B. Furlong, J. W. Hightower, L. Guczi, J. Catal. 1993, 141 566582.

[21.] N. Semagina, M. Grasemann, N. Xanthopoulos, A. Renken, L. Kiwi-Minsker, J. Catal. 2007, 251 213-222.

[22.] D. V. Sokolskii, L. M. Anisimova, L. N. Edygenova, Russ. J. Phys. Chem. 1986, 60 16391641 .

[23.] M. W. Tew, H. Emerich, J. A. van Bokhoven, J. Phys. Chem. C 2011, 115 8457-8465.

[24.] A. Kirilin, P. Mäki-Arvela, K. Kordas, A.-R. Leino, A. Shchukarev, D. Boström, J.-P. Mikkola, L. M. Kustov, T. O. Salmi, D. Yu. Murzin, Kinet. Catal. 2011, 52 72-76.

[25.] A. Kirilin, P. Mäki-Arvela, K. Kordas, A.-R. Leino, A. Shchukarev, D. Boström, J.-P. Mikkola, L. M. Kustov, T. O. Salmi, D. Yu. Murzin, Kinet. Catal. 2011, 52 77-81.

[26.] M. Lenarda, M. Casagrande, E. Moretti, L. Storaro, R. Frattini, S. Polizzi, Catal. Lett. 2007, 114 79-84.

[27.] X.-L. Liang, X. Dong, G.-D. Lin, H.-B. Zhang, Appl. Catal. B 2009, 88 315-322.

[28.] L. Bollmann, J. L. Ratts, A. M. Joshi, W. D. Williams, J. Pazmino, Y. V. Joshi, J. T. Miller, A. J. Kropf, W. N. Delgass, F. H. Ribeiro, J. Catal. 2008, 257 43-54.

[29.] V. Lebarbier, R. Dagle, A. Datye, Y. Wang, Appl. Catal. A 2010, 379 3-6.

[30.] H. Wei, C. Gomez, R. J. Meyer, Top. Catal. 2012, 55 313-321.

[31.] J. Agrell, G. Germani, S. G. Järås, M. Boutonnet, Appl.Catal.A 2003, 242 233-245.

[32.] M. L. Cubeiro, J. L. G. Fierro, Appl. Catal. A 1998, 168 307-322.

[33.] M. L. Cubeiro, J. L. G. Fierro, J. Catal. 1998, 179 150-162.

[34.] A. Casanovas, J. Llorca, N. Homs, J. L. G. Fierro, P. R. de la Piscina, J. Molec. Catal. A 2006, 250 44-49.

[35.] T. Komatsu, K. Inaba, T. Uezono, A. Onda, T. Yashima, Appl. Catal. A 2003, $251315-$ 326.

[36.] A. B. Sánchez, N. Homs, J. L. G. Fierro, P. R. de la Piscina, Catal. Today 2005, 107-108 431-435.

[37.] C. Paparizos, W. G. Shaw, J. L. Callahan, US4877898, 1989. 
[38.] V. Engels, A. Rachamim, S. H. Dalal, S. M. L. Pfaendler, J. Geng, A. Berenguer-Murcia, A. J. Flewitt, A. E. H. Wheatley, Nanoscale Res. Lett. 2010, 5 904-907.

[39.] M. Armbrüster, in Encyclopedia of Catalysis (Ed.: I. T. Horvath), Wiley, 2011, DOI: $10.1002 / 0471227617$.

[40.] M. Friedrich, A. Ormeci, Y. Grin, M. Armbrüster, Z. Anorg. Allg. Chem. 2010, 636 17351739.

[41.] C. Stampfl, M. V. Ganduglia-Pirovano, K. Reuter, M. Scheffler, Surf. Sci. 2002, 500 368394.

[42.] M. Armbrüster, K. Kovnir, M. Behrens, D. Teschner, Yu. Grin, R. Schlögl, J. Am. Chem. Soc. 2010, 132 14745-14747.

[43.] M. Armbrüster, K. Kovnir, M. Friedrich, D. Teschner, G. Wowsnick, M. Hahne, P. Gille, L. Szentmiklósi, M. Feuerbacher, M. Heggen, F. Girgsdies, D. Rosenthal, R. Schlögl, Yu. Grin, Nat. Mater. 2012, 11 690-693.

[44.] H. Nowotny, H. Bittner, Monatsh. Chem. 1950, 81 679-680.

[45.] H. Nowotny, E. Bauer, A. Stempfl, Monatsh. Chem. 1951, 82 1086-1093.

[46.] M. Armbrüster, Diploma Thesis, Philipps University Marburg, 2001.

[47.] O. Gourdon, Z. Izaola, L. Elcoro, V. Petricek, G. J. Miller, Philos. Mag. 2006, 86 419425.

[48.] O. Gourdon, G. J. Miller, Chem. Mater. 2006, 18 1848-1856.

[49.] O. Gourdon, Z. Izaola, L. Elcoro, V. Petricek, G. J. Miller, Inorg. Chem. 2009, 48 97159722.

[50.] T. Chiang, H. Ipser, Y. A. Chang, Z. Metallkd. 1977, 68509.

[51.] T. Chiang, H. Ipser, Y. A. Chang, Z. Metallkd. 1977, 68 141-147.

[52.] M. Friedrich, Phd Thesis, Technical University Dresden, 2013.

[53.] T. B. Massalski, in Binary Alloy Phase Diagrams (Ed.: T. B. Massalski), ASM International, Materials Park 1990, pp. 3068-3070.

[54.] W. Köster, U. Zwicker, in Festschrift 100 Jahre W.C. Heräus, Hanau 1951, pp. 76-90.

[55.] K. M. Alasafi, T. Chattopadhyay, K. Schubert, J. Less-Common Met. 1978, 59 P41-P50.

[56.] S. Kou, Y. A. Chang, Acta Metall. 1975, 23 1185-1190.

[57.] S. Kou, Y. A. Chang, Acta Metall. 1976, 24881. 
[58.] J. P. Neumann, H. Ipser, Y. A. Chang, J. Less-Common Met. 1978, 57 P29-P37.

[59.] M. Hansen, K. Anderko, Constitution of Binary Alloys (Eds.: R. F. Mehl, M. B. Bever), McGraw-Hill Book Company, New York, Toronto, London 1958.

[60.] W. Heike, J. Schramm, O. Vaupel, Metallwirtsch. 1936, 15 655-662.

[61.] Z.-X. Chen, K. M. Neyman, A. B. Gordienko, N. Rösch, Phys. Rev. B 2003, 68 075417-1075417-8.

[62.] M. Friedrich, D. Teschner, A. Knop-Gericke, M. Armbrüster, J. Catal. 2012, 285 41-47.

[63.] R. E. Cable, R. E. Schaak, Chem. Mater. 2007, 19 4098-4104.

[64.] L. M. Bronstein, D. M. Chernyshov, I. O. Volkov, M. G. Ezernitskaya, P. M. Valetsky, V. G. Matveeva, E. M. Sulman, J. Catal. 2000, 196 302-314.

[65.] B. Halevi, E. J. Peterson, A. DeLaRiva, E. Jeroro, V. M. Lebarbier, Y. Wang, J. M. Vohs, B. Kiefer, E. Kunkes, M. Hävecker, M. Behrens, R. Schlögl, A. K. Datye, J. Phys. Chem. 2010, 114 17181-17190.

[66.] E. J. Peterson, B. Halevi, B. Kiefer, M. N. Spilde, A. K. Datye, J. Peterson, L. Daemen, A. Llobet, H. Nakotte, J. Alloys Compd. 2011, 509 1463-1470.

[67.] A. V. Zadesenets, E. Yu. Filatov, K. V. Yusenko, Yu. V. Shubin, S. V. Korenev, I. A. Baidina, Inorg. Chim. Acta 2008, 361 199-207.

[68.] R. A. Dagle, Y.-H. Chin, Y. Wang, Top. Catal. 2007, 46 358-362.

[69.] A. Karim, T. Conant, A. Datye, J. Catal. 2006, 243 420-427.

[70.] Y. Luo, Y. Sun, U. Schwarz, M. Armbrüster, Chem. Mater. 2012, 24 3094-3100.

[71.] S. Kameoka, T. Kimura, A. P. Tsai, Catal. Lett. 2009, 131 219-224.

[72.] M. Armbrüster, G. Wowsnick, M. Friedrich, M. Heggen, R. Cardoso-Gil, J. Am. Chem. Soc. 2011, 133 9112-9118.

[73.] Y. Wang, J. Zhang, H. Xu, Chin. J. Catal. 2006, 27 217-222.

[74.] Y. Wang, J. Zhang, H. Xu, X. Bai, Chin. J. Catal. 2007, 28 234-238.

[75.] N. Iwasa, T. Mayanagi, W. Nomura, M. Arai, N. Takezawa, Appl. Catal. A 2003, 248 153-160.

[76.] L. L. Jewell, B. H. Davis, Appl. Catal. A 2006, 310 1-15.

[77.] A. M. Karim, T. Conant, A. K. Datye, Phys. Chem. Chem. Phys. 2008, 10 5584-5590. 
[78.] E. Marceau, X. Carrier, M. Che, O. Clause, C. Marcilly, in Handbook of Heterogeneous Catalysis, Wiley VCH, 2008.

[79.] E. Marceau, X. Carrier, M. Che, in Synthesis of Solid Catalysts, Wiley VCH 2009.

[80.] J. R. Regalbuto, in Synthesis of Solid Catalysts, Wiley VCH, 2009.

[81.] Y. H. Chin, Y. Wang, R. A. Dagle, X. S. Li, Fuel Process. Technol. 2003, 83 193-201.

[82.] T. Conant, A. M. Karim, V. Lebarbier, Y. Wang, F. Girgsdies, R. Schlögl, A. Datye, J. Catal. 2008, 257 64-70.

[83.] K. Föttinger, J. A. van Bokhoven, M. Nachtegaal, G. Rupprechter, J. Phys. Chem. Lett. 2011, 2 428-433.

[84.] A. Ota, E. L. Kunkes, I. Kasatkin, E. Groppo, D. Ferri, B. Poceiro, R. M. N. Yerga, M. Behrens, J. Catal. 2012, 293 27-38.

[85.] J. A. Eastman, L. J. Thompson, B. J. Kestel, Phys. Rev. B 1993, 48 84-92.

[86.] M. W. Tew, J. T. Miller, J. A. van Bokhoven, J. Phys. Chem. C 2009, 113 15140-15147.

[87.] M. Yamauchi, R. Ikeda, H. Kitagawa, M. Takata, J. Phys. Chem. C 2008, 112 3294-3299.

[88.] N. Iwasa, N. Takezawa, Top. Catal. 2003, 22 215-224.

[89.] S. Bernal, J. J. Calvino, M. A. Cauqui, J. M. Gatica, C. L. Cartes, J. A. P. Omil, J. M. Pintado, Catal. Today 2003, 77 385-406.

[90.] S. J. Tauster, S. C. Fung, R. L. Garten, J. Am. Chem. Soc. 1978, 100 170-175.

[91.] A. J. Simoens, R. T. K. Baker, D. J. Dwyer, C. R. F. Lund, R. J. Madon, J. Catal. 1984, $86359-372$.

[92.] S. J. Tauster, Acc. Chem. Res. 1987, 20 389-394.

[93.] J. Liu, ChemCatChem 2011, 3 934-948.

[94.] N. Iwasa, S. Masuda, N. Ogawa, N. Takezawa, Appl. Catal. A 1995, 125 145-157.

[95.] Z. Zsoldos, A. Sarkany, L. Guczi, J. Catal. 1994, 145 235-238.

[96.] N. Iwasa, T. Akazawa, S. Ohyama, K. Fujikawa, N. Takezawa, React. Kinet. Catal. Lett. 1995, 55 245-250.

[97.] S. Penner, B. Jenewein, H. Gabasch, B. Klötzer, D. Wang, A. Knop-Gericke, R. Schlögl, K. Hayek, J. Catal. 2006, 241 14-19. 
[98.] M. Lenarda, E. Moretti, L. Storaro, L. Patrono, L. Pinzari, E. Rodríguez-Castellón, A. Jiménez-Lopéz, G. Busca, E. Finocchio, T. Montanari, R. Frattini, Appl. Catal. A 2006, 312 220-228.

[99.] C. Fukuhara, Y. Kamata, A. Igarashi, Appl. Catal. A 2007, 330 108-116.

[100.] C. Rameshan, W. Stadlmayr, S. Penner, H. Lorenz, L. Mayr, M. Hävecker, R. Blume, T. Rocha, D. Teschner, A. Knop-Gericke, R. Schlögl, D. Zemlyanov, N. Memmel, B. Klötzer, J. Catal. 2012, 290 126-137.

[101.] A. Bayer, K. Flechtner, R. Denecke, H.-P. Steinrück, K. M. Neyman, N. Rösch, Surf. Sci. 2006, 600 78-94.

[102.] W. Stadlmayr, C. Rameshan, C. Weilach, H. Lorenz, M. Hävecker, R. Blume, T. Rocha, D. Teschner, A. Knop-Gericke, D. Zemlyanov, S. Penner, R. Schlögl, G. Rupprechter, B. Klötzer, N. Memmel, J. Phys. Chem. C 2010, 114 10850-10856.

[103.] J. A. Rodriguez, J. Phys. Chem. 1994, 98 5758-5764.

[104.] A. Fasana, I. Abbati, L. Braicovich, Phys. Rev. B 1982, 26 4749-4751.

[105.] I. Kovács, J. Kiss, F. Solymosi, Vacuum 2008, 82 182-185.

[106.] M. P. Hyman, V. M. Lebarbier, Y. Wang, A. K. Datye, J. M. Vohs, J. Phys. Chem. C 2009, 113 7251-7259.

[107.] W. Stadlmayr, S. Penner, B. Klötzer, N. Memmel, Surf. Sci. 2009, 603 251-255.

[108.] G. Weirum, M. Kratzer, H. P. Koch, A. Tamtögl, J. Killmann, I. Bako, A. Winkler, S. Surnev, F. P. Netzer, R. Schennach, J. Phys. Chem. C 2009, 113 9788-9796.

[109.] H. P. Koch, I. Bako, G. Weirum, M. Kratzer, R. Schennach, Surf. Sci. 2010, 604 926-931.

[110.] H. Gabasch, A. Knop-Gericke, R. Schlögl, S. Penner, B. Jenewein, K. Hayek, B. Klötzer, J. Phys. Chem. B 2006, 110 11391-11398.

[111.] E. Jeroro, V. Lebarbier, A. Datye, Y. Wang, J. M. Vohs, Surf. Sci. 2007, 601 5546-5554.

[112.] A. Tamtögl, M. Kratzer, J. A. Killman, A. Winkler, J. Chem. Phys. 2008, 129224706.

[113.] M. Kratzer, A. Tamtögl, J. Killmann, R. Schennach, A. Winkler, Appl. Surf. Sci. 2009, 255 5755-5759.

[114.] C. Rameshan, C. Weilach, W. Stadlmayr, S. Penner, H. Lorenz, M. Hävecker, R. Blume, T. Rocha, D. Teschner, A. Knop-Gericke, R. Schlögl, D. Zemlyanov, N. Memmel, G. Rupprechter, B. Klötzer, J. Catal. 2010, 276 101-113.

[115.] X. He, Y. Huang, Z.-X. Chen, Phys. Chem. Chem. Phys. 2011, 13 107-109. 
[116.] W. Stadlmayr, B. Klötzer, S. Penner, N. Memmel, J. Phys. Chem. C 2012, 1163635 3644.

[117.] Z.-X. Chen, K. M. Neyman, N. Rösch, Surf. Sci. 2004, 548 291-300.

[118.] L. Vitos, A. V. Ruban, H. L. Skriver, J. Kollár, Surf. Sci. 1998, 411 186-202.

[119.] C. Rameshan, W. Stadlmayr, C. Weilach, S. Penner, H. Lorenz, M. Hävecker, R. Blume, T. Rocha, D. Teschner, A. Knop-Gericke, R. Schlögl, N. Memmel, D. Zemlyanov, G. Rupprechter, B. Klötzer, Angew. Chem. Int. Ed. 2010, 49 3224-3227.

[120.] M. Klanjšek, A. Gradišek, A. Kocjan, M. Bobnar, P. Jeglič, M. Wencka, Z. Jagličic, P. Popčevic, J. Ivkov, A. Smontara, P. Gille, M. Armbrüster, J. Dolinšek, J. Phys.: Condens. Matter 2012, 24085703.

[121.] V. Ponec, G. C. Bond, Stud. Surf. Sci. Catal. 1995, 95.

[122.] J. H. Sinfelt, Bimetallic Catalysts, Wiley, New York 1983.

[123.] A. P. Tsai, S. Kameoka, Y. Ishii, J. Phys. Soc. Japan 2004, 73 3270-3273.

[124.] J. C. Vickerman, I. S. Gilmore, Surface Analysis - The Principal Techniques, Wiley, Chichester 2009.

[125.] K. Nozawa, N. Endo, S. Kameoka, A. P. Tsai, K. Ishii, J. Phys. Soc. Japan 2011, 80 064801-1-064801-13.

[126.] S. Hüfner, G. K. Wertheim, J. H. Wernick, Solid State Commun. 1975, 17 417-422.

[127.] V. Engels, D. A. Jefferson, F. Benaskar, P. C. Thüne, A. Berenguer-Murcia, B. F. G. Johnson, A. E. H. Wheatley, Nanotechnology 2011, 22205701.

[128.] P. S. Wehner, G. C. Tustin, B. Gustafson, J. Catal. 1984, 88 246-248.

[129.] N. Takezawa, N. Iwasa, Catal. Today 1997, 36 45-56.

[130.] D. R. Lide, CRC Handbook of Chemistry and Physics: A ready-reference book of chemical and physical data, 92th ed., CRC Taylor \& Francis, Boca Raton 2011.

[131.] C. H. Johansson, J. O. Linde, Ann. Phys. 1925, 383 439-460.

[132.] K. Schubert, Z. Metallkd. 1955, 46 43-51.

[133.] W. K. Wang, H. Iwasaki, J. Phys. Chem. Solids 1987, 48 559-561.

[134.] U. Dehlinger, Z. Phys. 1937, 105588.

[135.] J. Braun, M. Ellner, B. Predel, Z. Metallkd. 1995, 86 870-876.

[136.] Z. W. Lu, A. Zunger, A. G. Fox, Acta Metall. Mater. 1994, 42 3929-3943. 
[137.] H. Iwasaki, Acta Crystallogr., Sect. A: Found. Crystallogr. 1980, 36 299-303.

[138.] G. E. Ewing, J. Chem. Phys. 1962, 37 2250-2256.

[139.] G. Blyholder, J. Phys. Chem. 1964, 68 2772-2777.

[140.] C. Lamberti, A. Zecchina, E. Groppo, S. Bordiga, Chem. Soc. Rev. 2010, 39 4951-5001.

[141.] L. E. Orgel, Inorg. Chem. 1962, 1 25-29.

[142.] R. P. Eischens, S. A. Francis, W. A. Pliskin, J. Phys. Chem. 1956, 60 194-201.

[143.] S. Bertarione, D. Scarano, A. Zecchina, V. Johánek, J. Hoffmann, S. Schauermann, M. M. Frank, J. Libuda, G. Rupprechter, H.-J. Freund, J. Phys. Chem. B 2004, 108 3603-3613.

[144.] K. A. Clarke, G. Farren, H. E. Rubalcava, J. Phys. Chem. 1967, 71 2376-2377.

[145.] T. Lear, R. Marshall, J. A. Lopez-Sanchez, S. D. Jackson, T. M. Klapötke, M. Bäumer, G. Rupprechter, H. J. Freund, D. Lennon, J. Chem. Phys. 2005, 123 174706-1-174706-13.

[146.] V. Lebarbier, R. Dagle, T. Conant, J. M. Vohs, A. K. Datye, Y. Wang, Catal. Lett. 2008, 122 223-227.

[147.] A. B. Sanchez, N. Homs, S. Miachon, J. A. Dalmon, J. L. G. Fierro, P. R. de la Piscina, Green Chem. 2011, 13 2569-2575.

[148.] N. Iwasa, T. Mayanagi, S. Masuda, N. Takezawa, React. Kinet. Catal. Lett. 2000, $69355-$ 360.

[149.] I. Bako, R. Schennach, G. Palinkas, J. Phys. Conf. Ser. 2008, 100052067.

[150.] K. M. Neyman, K. H. Lim, Z.-X. Chen, L. V. Moskaleva, A. Bayer, A. Reindl, D. Borgmann, R. Denecke, H.-P. Steinrück, N. Rösch, Phys. Chem. Chem. Phys. 2007, 9 3470-3482.

[151.] E. Groppo, S. Bertarione, F. Rotunno, G. Agostini, D. Scarano, R. Pellegrini, G. Leofanti, A. Zecchina, C. Lamberti, J. Phys. Chem. C 2007, 111 7021-7028.

[152.] E. Ozensoy, D. W. Goodman, Phys. Chem. Chem. Phys. 2004, 6 3765-3778.

[153.] K. Wolter, O. Seiferth, H. Kuhlenbeck, M. Bäumer, H.-J. Freund, Surf. Sci. 1998, 399 190-198.

[154.] C. Weilach, S. M. Kozlov, H. Holzapfel, K. Föttinger, K. Neyman, G. Rupprechter, J. Phys. Chem. C 2012, 116 18768-18778.

[155.] M. F. Hoffmann, Surf. Sci. Rep. 1983, 3 109-192.

[156.] G. Rupprechter, H. Unterhalt, M. Morkel, P. Galletto, L. Hu, H. J. Freund, Surf. Sci. 2002, 502-503 109-122. 
[157.] H. Unterhalt, G. Rupprechter, H.-J. Freund, J. Phys. Chem. B 2002, 106 356-367.

[158.] E. Jeroro, M. P. Hyman, J. M. Vohs, Phys. Chem. Chem. Phys. 2009, 11 10457-10465.

[159.] A. S. Kuanyshev, L. M. Kurashvili, K. Sergazieva, L. B. Babenkova, I. N. Naidina, G. L. Padyukova, Russ. J. Phys. Chem. 1993, 67 936-939.

[160.] Z.-X. Chen, K. M. Neyman, K. H. Lim, N. Rösch, Langmuir 2004, 20 8068-8077.

[161.] G. K. Smith, S. Lin, W. Lai, A. Datye, D. Xie, H. Guo, Surf. Sci. 2011, 605 750-759.

[162.] Z.-X. Chen, K. H. Lim, K. M. Neyman, N. Rösch, Phys. Chem. Chem. Phys. 2004, 6 4499-4504.

[163.] K. H. Lim, Z.-X. Chen, K. M. Neyman, N. Rösch, J. Phys. Chem. B 2006, 11014890 14897.

[164.] Z.-X. Chen, K. H. Lim, K. M. Neyman, N. Rösch, J. Phys. Chem. B 2005, $1094568-$ 4574.

[165.] Y. Huang, W. Ding, Z.-X. Chen, J. Chem. Phys. 2010, 133214702.

[166.] H. P. Koch, I. Bako, R. Schennach, Surf. Sci. 2010, 604 596-608.

[167.] Y. Huang, Z.-X. Chen, J. Phys. Chem. C 2011, 115 18752-18760.

[168.] S. Lin, D. Xie, H. Guo, J. Phys. Chem. C 2011, 115 20583-20589.

[169.] S. Lin, D. Xie, H. Guo, J. Molec. Catal. A 2012, 356 165-170.

[170.] Y. Huang, Z.-X. Chen, Langmuir 2010, 26 10796-10802.

[171.] M. Mavrikakis, B. Hammer, J. K. Nørskov, Phys. Rev. Lett. 1998, 81 2819-2822.

[172.] K. H. Lim, L. V. Moskaleva, N. Rösch, ChemPhysChem 2006, 7 1802-1812.

[173.] Y.-H. Chin, R. Dagle, J. Hu, A. C. Dohnalkova, Y. Wang, Catal. Today 2002, 77 79-88.

[174.] E. S. Ranganathan, S. K. Bej, L. T. Thompson, Appl. Catal. A 2005, 289 153-162.

[175.] Y. Suwa, S.-I. Ito, S. Kameoka, K. Tomishige, K. Kunimori, Appl. Catal. A 2004, 267 916.

[176.] G. Xia, J. D. Holladay, R. A. Dagle, E. O. Jones, Y. Wang, Chem. Eng. Technol. 2005, 28 515-519.

[177.] Q. Zhang, R. J. Farrauto, Appl. Catal. A 2011, 395 64-70.

[178.] C. Cao, G. Xia, J. Holladay, E. Jones, Y. Wang, Appl. Catal. A 2004, 262 19-29. 
[179.] P. Pfeifer, K. Schubert, M. A. Liauw, G. Emig, Appl. Catal. A 2004, 270 165-175.

[180.] P. Pfeifer, A. Kölbl, K. Schubert, Catal. Today 2005, 110 76-85.

[181.] O. Ilinich, Y. Liu, C. Castellano, G. Koermer, A. Moini, R. Farrauto, Platinum Met. Rev. 2008, 52 134-143.

[182.] H. Lorenz, M. Friedrich, M. Armbrüster, S. Penner, J. Catal. 2013, 297 151-154.

[183.] S. Liu, K. Takahashi, K. Uematsu, M. Ayabe, Appl. Catal. A 2005, 283 125-135.

[184.] S. Liu, K. Takahashi, H. Eguchi, K. Uematsu, Catal. Today 2007, 129 287-292.

[185.] S. Liu, K. Takahashi, M. Ayabe, Catal. Today 2003, 87 247-253.

[186.] S. Liu, K. Takajashi, K. Fuchigami, K. Uematsu, Appl. Catal. A 2006, 299 58-65.

[187.] S. Liu, K. Takahashi, K. Uematsu, M. Ayabe, Appl. Catal. A 2004, 277 265-270.

[188.] M. Friedrich, S. Penner, M. Heggen, M. Armbrüster, Angew. Chem. Int. Ed. 2013, DOI: 10.1002/anie.201209587.

[189.] K. Föttinger, Catal. Today 2013, DOI: 10.1016/j.cattod.2012.12.004 .

[190.] N. Iwasa, M. Yoshikawa, W. Nomura, M. Arai, Appl. Catal. A 2005, 292 215-222.

[191.] Y. Uemura, Y. Inada, Y. Niwa, M. Kimura, K. K. Bando, A. Yagishita, Y. Iwasawa, M. Nomura, Phys. Chem. Chem. Phys. 2012, 14 2152-2158. 